\title{
Progresses in conductive polyaniline-based nanocomposites for biomedical applications: A review
}

Ehsan Nazarzadeh Zare ${ }^{1 *}$, Pooyan Makvandi ${ }^{2,3^{*}}$, Behnaz Ashtari ${ }^{3}$, Filippo Rossi ${ }^{4}$, Ahmad Motahari ${ }^{5}$, Giuseppe Perale $6,7,8$

${ }^{1}$ School of Chemistry, Damghan University, Damghan 36719-41167, Iran

${ }^{2}$ Institute for Polymers, Composites and Biomaterials (IPCB), National Research Council (CNR), Naples 80125, Italy

${ }^{3}$ Department of Medical Nanotechnology, Faculty of Advanced Technology in Medicine, Iran University of Medical Sciences, Tehran 14496 -14535, Iran

${ }^{4}$ Department of Chemistry, Materials and Chemical Engineering, Politecnico di Milano Technical University, Milano 32, 20133, Italy

${ }^{5}$ Young Researchers and Elite Club, Jahrom Branch, Islamic Azad University, Jahrom 74147-85318, Iran ${ }^{6}$ Biomaterials Laboratory, Institute for Mechanical Engineering and Materials Technology, University of Applied Sciences and Arts of Southern Switzerland, Manno 2, 6928, Switzerland

${ }^{7}$ Department of Surgical Sciences, Faculty of Medical Sciences, Orthopaedic Clinic-IRCCS A.O.U. San Martino, Genova 10, 16132, Italy

${ }^{8}$ Ludwig Boltzmann Institute for Experimental and Clinical Traumatology, Donaueschingenstrasse 13, 1200 Vienna, Austria 


\begin{abstract}
Inherently conducting polymers (ICPs) are a specific category of synthetic polymers with distinctive electro-optic properties, which involve conjugated chains with alternating single and double bonds. Polyaniline (PANI), as one of the most well-known ICPs, has outstanding potential applications in biomedicine because of its high electrical conductivity and biocompatibility caused by its hydrophilic nature, low-toxicity, good environmental stability and nanostructured morphology. Some of the limitations in the use of PANI, such as its low processability and degradability, can be overcome by the preparation of its blends and nanocomposites with various (bio)polymers and nanomaterials, respectively. This review describes the state-ofthe-art of biological activities and applications of conductive PANI-based nanocomposites in the biomedical fields, such as antimicrobial therapy, drug delivery, biosensors, nerve regeneration and tissue engineering. The latest progresses in the biomedical applications of PANI-based nanocomposites are reviewed to provide a background for future research.
\end{abstract}

Keywords: Conductive polyaniline nanocomposites, biological activities, biosensor, drug delivery, tissue engineering, antimicrobial activity, antioxidant activity. 


\section{Introduction}

Most polymers are insulators since they are made by covalent bonds without free moveable electrons or ions; some polymers can nevertheless form a conductive path under an electrical stress. These polymers have different tendencies to form a conductive path under various conditions. Some properties such as resistivity, arc resistance, dielectric constant, and dissipation factor are used to express the electrical properties of polymers ${ }^{1}$.

Inherently conducting polymers (ICPS) are a specific category of synthetic polymers with distinctive electro-optic properties. These polymers have conjugated chains with alternating single and double bonds ${ }^{2}$. The $\pi$-electrons in the ICPs, which are highly delocalized and simply polarizable, show an imperative role in the electro-optic properties of ICPs. Furthermore, the physiochemical properties of ICPs, such as structural, electrical, and optical properties are affected by the nature of the inherent quasi-one-dimensional and the level of both intra- and inter-chain delocalization of $\pi$-electrons ${ }^{3}$.

The first conducting polymer, iodine-doped polyacetylene, was discovered by Alan Heeger, Alan MacDiarmid, and Hideki Shirakawai in 1977. They were awarded the Nobel prize in chemistry for this discovery in $2000^{2}$. Polyacetylene (PAs), polypyrrole (PPy), polythiophene (PTh), polyfuran (PFu) and polyaniline (PANI) are examples of 
ICPs ${ }^{4}$. These ICPs are extensively used in the biomedical fields including tissue engineering and biosensors because of their smart response to the electrical fields ${ }^{5}$.

Among ICPs, polyaniline has received considerable attention in various industrial and biomedical fields due to their facile preparation, low cost, high electrical conductivity, biocompatibility, low toxicity, and environmental stability ${ }^{3}$. However, PANI has some disadvantages, such as low solubility or insolubility in the most common solvents, infusibility, and weak processability. Also, its electrical conductivity decreases over a long cycle time ${ }^{6}$. A number of approaches, such as re-doping with the functionalized organic acids, copolymerization with PANI derivatives or other polymers, and the preparation of the blends and nanocomposites with various materials have been developed to diminish the aforementioned disadvantages ${ }^{7}$.

Polyaniline nanocomposites are one of the most promising ICPs nanocomposites showing an electrical conductivity by combining the PANI matrix with the conducting or insulating nanofillers. These nanocomposites with improved properties are extensively used in the biomedical fields, such as tissue regeneration and antimicrobial therapy. Also, they have been applied in the industrial sectors (e.g. in electronics and water purification) ${ }^{8}$.

The current review describes a state-of-the-art update on the biological activities (i.e., biocompatibility, cytotoxicity, antioxidant and antimicrobial activities) and biomedical 
applications (i.e., antimicrobial therapy, drug delivery, bone regeneration, nerve regeneration, wound healing, and biosensor) of conductive PANI-based nanocomposites to provide a background for future research.

\section{Synthesis}

Polyaniline, or more specifically "aniline black", is one of the oldest ICPs which was discovered in the mid-nineteenth century ${ }^{9}$. The molecular structure of PANI may possess either benzenoid or quinonoid units or both types at different proportions ${ }^{3,10}$.

The PANIs are synthesized using both chemical and electrochemical oxidative polymerization in an acidic medium (Fig. 1). The most widely used initiators for the chemical polymerization of aniline are ammonium persulfate (APS) and potassium persulfate (KPS) ${ }^{3,10}$. Usually, the electrochemical method is used for the small scale synthesis, whereas the chemical method allows large-scale preparation of the polymer and/or the corresponding nanocomposites ${ }^{11}$. The electrochemical methods include the electrode coating and co-deposition approaches. In the electrode coating method, reference, working, and counter electrodes are used in a onecompartment cell containing the electrolyte and the monomer solution ${ }^{12}$. In the co-deposition method, an insulating polymer host is dissolved in an electrolyte solution comprising the monomer of the conductive polymer ${ }^{12}$. 
(A)
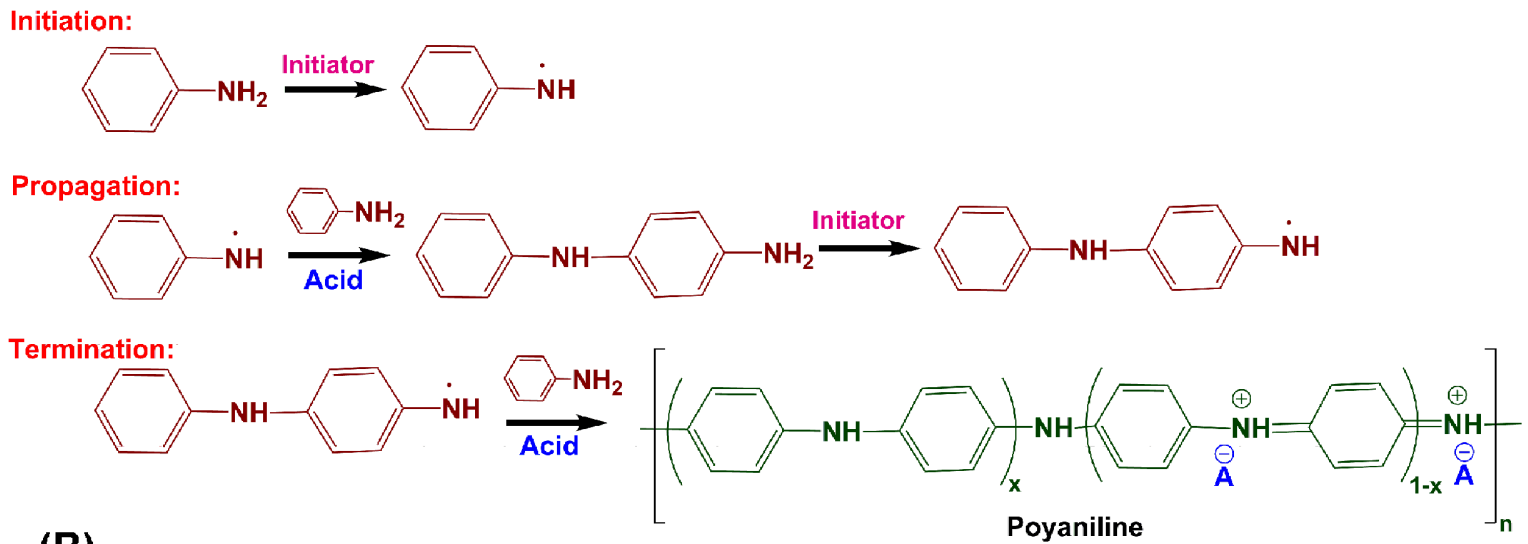

(B)

Poyaniline

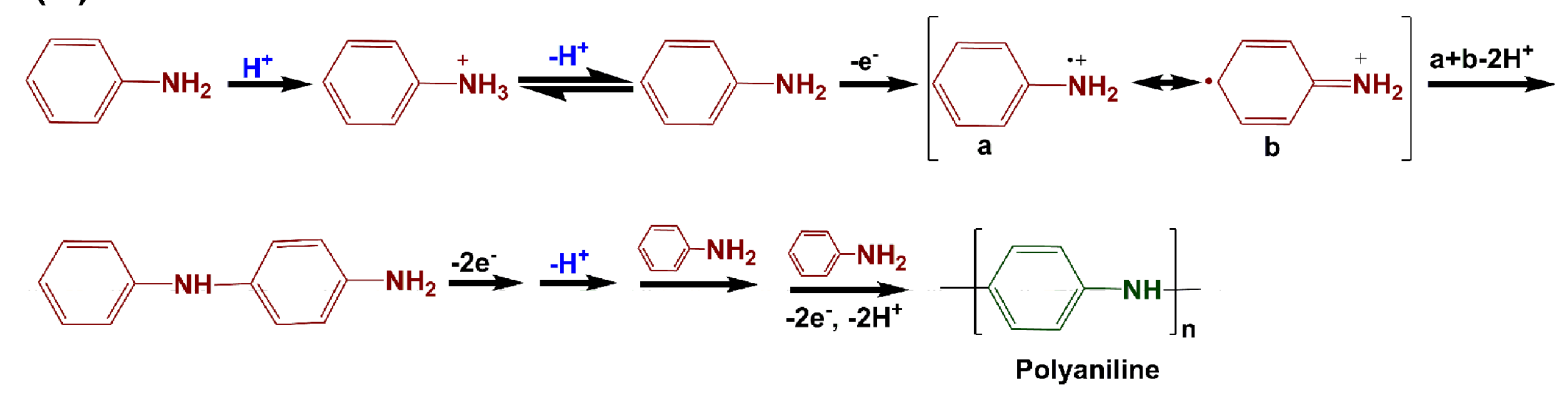

Fig. 1 Chemical (A) and electrochemical (B) polymerization mechanisms of polyaniline. Chemical polymerization of polyaniline is carried out in acidic medium by using a common initiator such as ammonium persulfate and potassium persulfate, while the electro-polymerization of polyaniline is carried out in the electrolyte solution of aniline and acid through applying a potential difference between the working and counter electrode.

Polyanilines containing various nanostructures with different properties have been reported by many research groups. Different nanoarchitectures show additional advantages because of their high surface-to-volume ratio, which leads to the improvement of the properties of their nanocomposites ${ }^{13}$. Therefore, the optimization of the synthesis conditions of PANI with specific morphologies and sizes for high-performance applications is very important.

Several procedures such as solution, self-assembling, heterophase interfacial, and electrochemical polymerizations have been used for the design and synthesis of PANI nanostructures, such as nanospheres, nanogranules, nanorods, nanoflowers, nanofibers, and nanotubes ${ }^{7,13-19}$. In addition, many parameters and processes including the initiator or oxidant, 
$\mathrm{pH}$, temperature, solvent, chemical additives (oligoaniline and $\pi$ bonding compounds), chemical oxidation process (interfacial reaction), template (hard or soft), electrochemistry, radiochemistry and sonochemistry for the design of unique PANI nanostructures should be taken into consideration ${ }^{14}$. Fig. 2 shows the scanning electron micrographs of various PANI nanostructures synthesized in various conditions.

As mentioned before, a number of researches have been devoted to the preparation of PANI nanocomposites to overcome some weaknesses of the pristine PANI. There are three main procedures for the fabrication of ICPs nanocomposites including:

1. Solvent casting: It is one of the very first and simplest processing methods for the fabrication of the polymer composites. In this technique, a polymer is dissolved in a proper solvent and a desired nanofiller is then added to the solution under stirring ${ }^{20}$. In fact, the main advantage of the solvent casting method is its simplicity of manufacturing without the need of specific apparatus. There are numerous factors that can affect the solvent casting method, including the polymer molecular weight, polymer structure, stoichiometric amount, composition, filler, solvent type, and processing conditions (temperature, rate of drying, agitation rate, and frequency of stirring) 21. 
2. In-situ polymerization in the presence of nanofillers: In this method, a nanofiller surface is modified and then the monomer and initiator are added to form a polymer nanocomposite. Some polymer properties are improved in this method because of the strong interactions between the polymer matrix and the nanofiller ${ }^{22}$.

3. In situ nanoparticle formation in the presence of polymers: In this approach, an appropriate solvent is used to dissolve polyaniline and then a nanofiller precursor is added, followed by thermal or electrochemical treatment to form the polymer nanocomposite. The formed nanostructures in this method are uniform in various morphologies within the polymer matrix ${ }^{23}$.

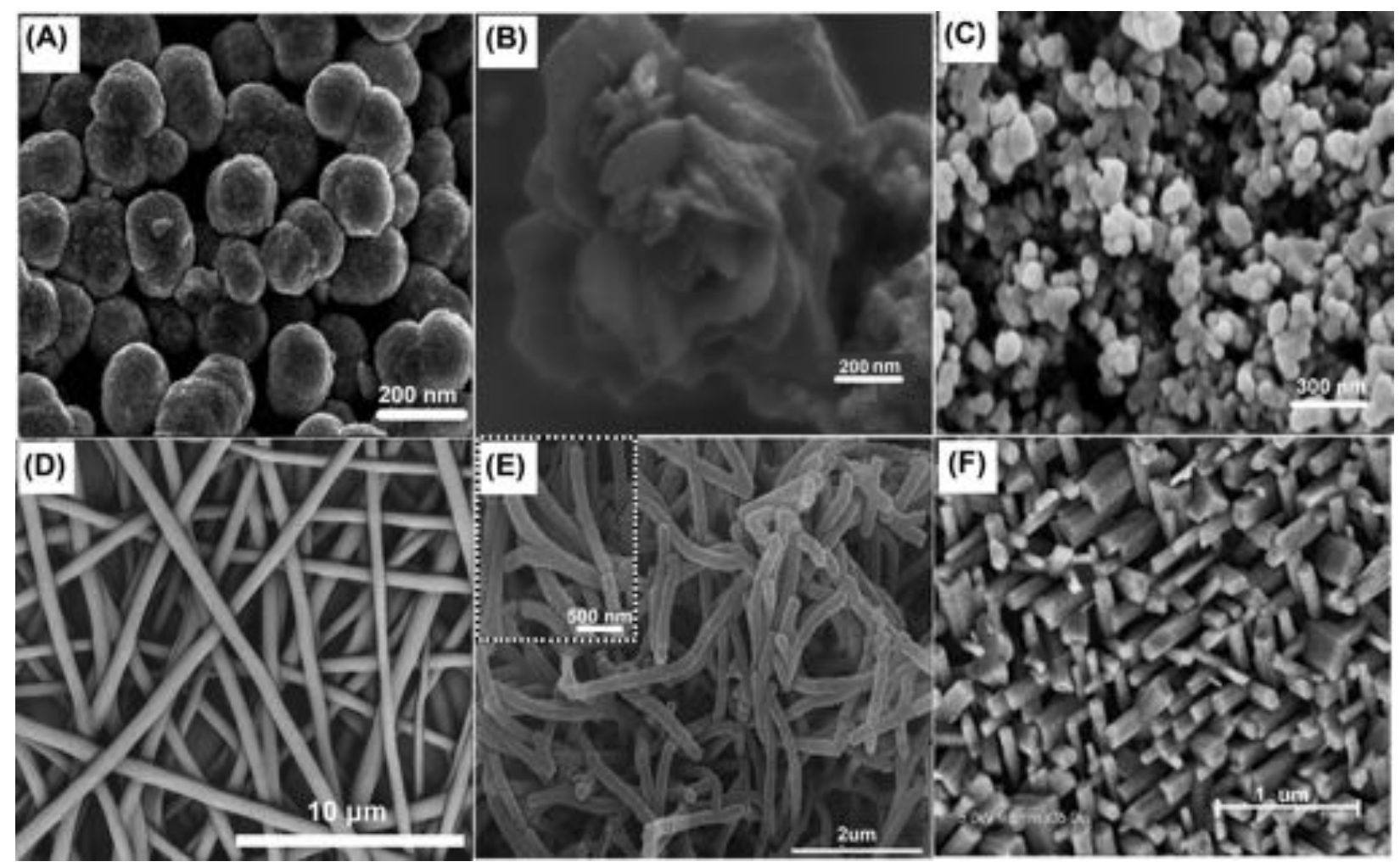


Fig. 2 Scanning electron microscopy images of different shapes of polyaniline nanostructures; (A) polyaniline nanospheres synthesized in the acidic sodium carboxymethyl cellulose (CMC) solution. Reprinted with permission from ref ${ }^{15}$. Copyright 2015 Royal Chemical Society. (B) polyaniline nanoflowers synthesized by the interfacial polymerization in toluene solvent. Reprinted with permission from ref ${ }^{13}$. Copyright 2018 Elsevier. (C) polyaniline nanogranules synthesized by the sonochemistry method in the acidic aqueous solution. (D) polyaniline nanofiber synthesized by the oxidation polymerization of aniline monomer at $0{ }^{\circ} \mathrm{C}$ in the acidic aqueous solution followed by the electrospinning in $50 \mathrm{ml}$ of $\mathrm{CHCl}_{3}$. Reprinted with permission from ref ${ }^{24}$. Copyright 2017 Hindawi (E) polyaniline nanotubes synthesized by the micelle soft-template procedure in the oxalic acid solution as a dopant. Reprinted with permission from ref ${ }^{18}$. Copyright 2015 Royal Chemical Society. (F) polyaniline nanorods synthesized by the ultrasonication. Reprinted with permission from ref ${ }^{16}$. Copyright 2014 Royal Chemical Society.

\section{Structure and properties}

\subsection{Structure}

Polyaniline structure consists of reduced (x) and oxidized (1-x) blocks $(0 \leq \mathrm{x} \leq 1){ }^{10}$ (Fig. 3A). According to the redox state of the polymer structure, PANI can be observed in one of three oxidation forms, i.e., leucoemeraldine (LE, yellow, for $\mathrm{x}=1$, Fig. 3B), pernigraniline (PG, purple, for $x=0$, Fig. 3C) and emeraldine (EM, dark green and blue, for $x=0.5$, Fig. 3D and E). The emeraldine form of PANI can be found in the emeraldine-salt (EM-S, dark green) and emeraldinebase (EM-B, blue) forms depending on the acidic and basic conditions, respectively ${ }^{25}$. The oxidation forms of PANI have different colors, conductivities and stabilities. The EM-S is the conducting form of PANI. The electrical conductivity of PANI is related to several conditions, such as the redox state, protonation degree, temperature and dopant type ${ }^{3,10}$.

The electrical conductivity of PANI enhances with the doping of the EM-B (insulator form, $\sigma \leq 10^{-10} \mathrm{~S} / \mathrm{cm}$ ) and formation of the EM-S (conductive form, $\sigma \geq 1 \mathrm{~S} / \mathrm{cm}$ ) ${ }^{2}$. Inorganic acids, such as $\mathrm{HCl}, \mathrm{H}_{2} \mathrm{SO}_{4}, \mathrm{HClO}_{4}$ and $\mathrm{H}_{3} \mathrm{PO}_{4}$, and organic acids, such as camphorsulfonic acid, para-toluene sulfonic acid and dodecyl benzenesulfonic acid are used for the doping process of PANI, while the 
ammonium hydroxide base is responsible for the undoping process of PANI ${ }^{10,26,27}$. In addition, it is well known that the electrical properties of PANI-based polymers depend on the microscopic (i.e., level of doping, conjugation, length of polymer chain) and macroscopic (i.e., materials compactness and molecular orientation) properties ${ }^{28}$.

(A)

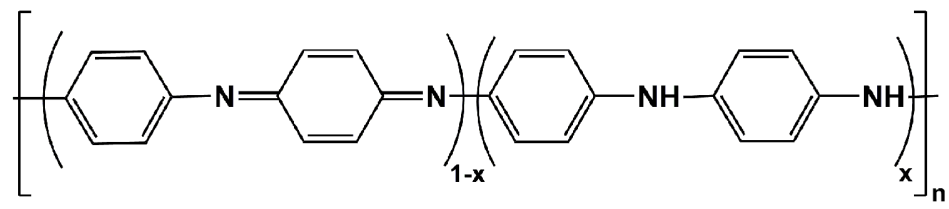

Polyaniline

(B)

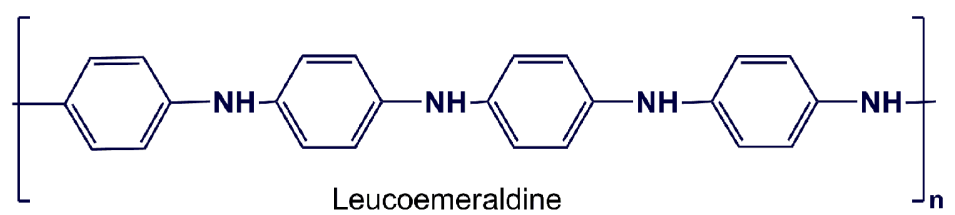

(C)

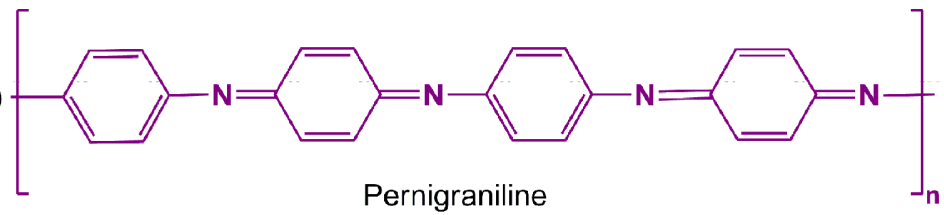

(D)

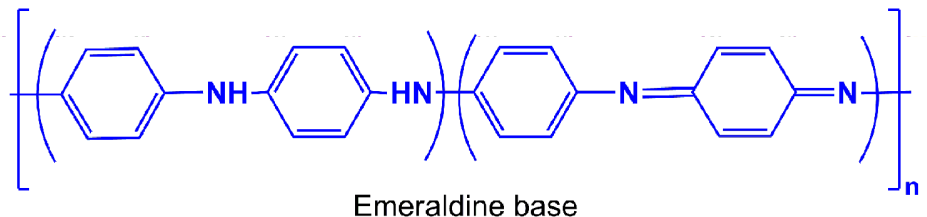

(E)

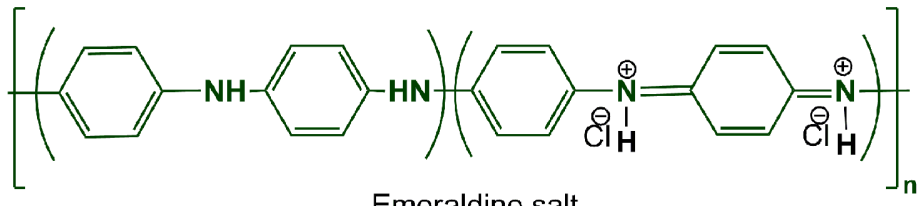

Fig. 3 Structure of polyaniline (A), leucoemeraldine (B), pernigraniline (C), emeraldine base (D) and emeraldine salt (E).

\subsection{Physiochemical and mechanical properties}

Polyaniline is chemically stable and demonstrates high chemical and structural resistance in acidic and alkaline solutions without undergoing any chemical reaction or degradation ${ }^{10}$. Depending on the redox states, PANI has different solubility in the common organic solvents. In general, PANI in the doped form (PANI-EM-S) is insoluble in the common organic solvents 
including dimethyl sulfoxide (DMSO), $N$-methyl-2-pyrrolidone (NMP), dimethylformamide (DMF) and tetrahydrofuran (THF), whereas in the undoped form, PANI-EM-B is soluble in the aforementioned organic solvents ${ }^{10,28}$.

Polyaniline pellet shows a good mechanical strength due to good compactness of the PANI powders. Moreover, a significant improvement in the physical and mechanical properties, such as Young's modulus and heat resistance, has been seen in the PANI nanocomposites ${ }^{29}$. Polyaniline in blends and nanocomposite forms prepared using polyurethane, natural rubber, chitosan, carbon nanotubes, and montmorillonite operates as a conducting component in a proper matrix to provide the needed mechanical properties. Indeed, the increased toughness and decreased elongation at break can be achieved in blends and/or nanocomposites by enhancing the amount of polyaniline ratio.

The rheological properties of PANI and its composites are very important for their processing in industrial and medicinal applications. For instance, the rheological parameters of the injectable PANI nanocomposites should be evaluated before being injected to animal and human organs. Indeed, the rheological properties provide information about viscosity, modulus, and gelation temperature of the injectable PANI-based nanocomposites. The size, shape, and distribution of nanomaterials have considerable effects on the rheological parameters of the PANIbased composites

As earlier mentioned, one of the main problems of PANI is its insolubility in common organic solvents. This problem has been solved successfully by developing various approaches for the synthesis of soluble PANI, such as the synthesis of PANI by the micro-emulsion polymerization or in the presence of oleic acid ${ }^{30-32}$. On the other hand, combination of PANI with various polymers/nanomaterials to form blends or composites can be a facile method for the 
improvement of its mechanical properties ${ }^{30,33}$. For example, Bilal et al. studied the rheological properties of polyaniline-poly (ethylene oxide) (PANI-PEO) and their composites with $\mathrm{KNO}_{3}$ and $\mathrm{NaNO}_{3}$. They reported that pyridine is the best solvent for the rheological measurements. Their results showed that the nitrate salts of $\mathrm{Na}$ and $\mathrm{K}$ added to the PEO-based composite tend to decrease the hydrodynamic volume of the polymer molecule, which results in the decreasing the intrinsic viscosity of the composites. In addition, when the inorganic salts such as $\mathrm{KNO}_{3}$ and $\mathrm{NaNO}_{3}$ were added, the composites showed somewhat higher values of viscosity. The temperature change has a profound effect on the viscosity as well. For instance, at low temperatures, e.g. 10 ${ }^{\circ} \mathrm{C}$, the pure PANI-PEO has a lower viscosity than the PANI-PEO- $\mathrm{KNO}_{3}$ composite, and the viscosities of both composites drop by increasing the temperature to $20^{\circ} \mathrm{C}^{30}$.

Apart from organic solutions, the rheological properties of the aqueous PANI blends, e.g. polyaniline-poly(vinyl pyrrolidone) (PVP) dispersion have also been investigated. The PANI-PVP dispersion is stable enough showing no precipitates gelation. It was shown that the rheological behavior of this system are not governed by any of the polymeric materials. In fact, the hydrogen bonding between the PVP and PANI is the key for determination of the viscoelastic properties of this suspended blend ${ }^{31}$.

Polyaniline has also been used in the thermoresponsive injectable hydrogels. In-situ injectable hydrogels can be easily administrated and match any shape of damaged tissue. These hydrogels can reduce the suffering of patients as a minimally invasive method, and therefore, their easy handling is an optimal choice for the clinicians. Thermosensitive hydrogels containing conductive PANI has drawn much attention due to their conductivity, antioxidant and antimicrobial activity. For instance, quaternary ammonium chitosan-g-PANI shows antibacterial activity and conductivity along with biodegradability due to the presence of chitosan. These in situ forming 
gels undergo a sol-gel transition upon the injection into the human body. In fact, in the ambient condition or low temperature, such hydrogels act as liquid (elastic modulus $<$ viscous modulus) and can be easily injected. In contrast, at the body temperature, their rheological properties change and they become gels (elastic modulus $>$ viscous modulus). This alteration of temperature also enhances the viscosity properties of the thermoresponsive hydrogels ${ }^{34-36}$. Apart from temperaturesensitive materials, polyaniline and its composite particles, due to the conductivity features, can be used in electrorheological (ER) fluids. The ER fluid is a sort of smart electro-responsive system showing transition characteristics from a liquid-like to a solid-like state in the presence of an external electric field. For instance, PANI has been used as a coating for $\mathrm{SiO}_{2}$ nanoparticles to impart electrorheological properties ${ }^{37,38}$. The summary of the physicochemical properties of PANI are listed in Table 1.

Table 1: Physicochemical properties of polyaniline.

\begin{tabular}{|c|c|}
\hline $\begin{array}{l}\text { Redox state } \\
\text { structure }\end{array}$ & $\begin{array}{l}\text { Leucoemeraldine (yellow), pernigraniline (purple) and } \\
\text { emeraldine (dark green and blue) }{ }^{25}\end{array}$ \\
\hline Electrical conductivity & $\begin{array}{l}\text { Leucoemeraldine (insulator), pernigraniline (insulator) and } \\
\text { emeraldine salt }\left(10^{-2}-10^{\circ} \mathrm{S} / \mathrm{cm}\right)^{2,9}\end{array}$ \\
\hline Common dopants & $\begin{array}{l}\text { Inorganic acids }\left(\mathrm{HCl}, \mathrm{H}_{2} \mathrm{SO}_{4}, \mathrm{HClO}_{4} \text { and } \mathrm{H}_{3} \mathrm{PO}_{4} \text { ) and organic }\right. \\
\text { acids (camphorsulfonic acid, para toluene sulfonic acid and } \\
\text { dodecyl benzenesulfonic acid) }{ }^{10,26}\end{array}$ \\
\hline Solubility & $\begin{array}{l}\text { Emeraldine salt (insoluble in the common organic solvents), } \\
\text { emeraldine base soluble in NMP, DMSO, DMF and THF }{ }^{10,28}\end{array}$ \\
\hline Mechanical property & $\begin{array}{c}\text { Young's modulus } 1.91 \mathrm{Gpa} ; \text { strength at breakpoint } 89.5 \mathrm{Mpa} ; \\
\text { Elongation } 5.88 \%^{29}\end{array}$ \\
\hline Stability & $\begin{array}{l}\text { High chemical and structural resistance in the acidic and } \\
\text { alkaline solutions } 10\end{array}$ \\
\hline Crystallinity & $\begin{array}{l}\text { Depending on the synthesis conditions and dopants can be semi- } \\
\text { crystalline or amorphous }\end{array}$ \\
\hline Morphology & $\begin{array}{l}\text { Depending on the synthesis conditions can be nanosphere }{ }^{15} \text {, } \\
\text { nanoflower }^{13} \text {, nanogranule }{ }^{7} \text { __nanofiber }{ }^{24} \text {, nanotube }{ }^{18} \text {, and } \\
\text { nanorod }^{16}\end{array}$ \\
\hline
\end{tabular}




\subsection{Degradability}

Non-biodegradability of some scaffolds still poses a limitation in biomedicine. Therefore, degradable PANI, as an electrically conductive polymer, is preferred for the biomedical applications. In recent years, the carbohydrate biopolymers (i.e., chitosan, gelatin, heparin, and collagen) and biodegradable aliphatic polyesters (i.e., polylactide, polycaprolactone, polyglycolide and their copolymers) have been employed for the fabrication of PANI blends/composites to prepare degradable scaffolds for tissue engineering ${ }^{40,41}$. As discussed earlier, one of the methods to overcome the drawbacks such as the non-degradability of PANI is the preparation of blends and composites based on PANI and degradable naturally occurring polymers including carbohydrates such as dextrin (Fig. 4A), starch, and gelatin ${ }^{22,39,40}$. Consequently, the final composites/blends can be degraded by microorganisms in environmental conditions. For instance, Zare et al. evaluated the soil biodegradability of PANI/dextrin nanocomposites at various weight ratios and reported that the maximum degradation $\sim 74.5 \%$ after two months was seen for the nanocomposite with the weight ratio $1 / 3$ of $\mathrm{PANI} /$ dextrin. Moreover, the biodegradability of the PANI/dextrin nanocomposites improved considerably with the content of dextrin natural polymer ${ }^{22}$.

Recently, a research conducted by Xia et al. revealed an excellent in vitro and in vivo biodegradability and biocompatibility of a PANI-porous silicon hybrid nanocomposite (PANI-PSi NPs). They found that the presence of the biocompatible and biodegradable PSi NPs resulted in higher biocompatibility and biodegradability of the nanocomposites as compared with the pristine PANI $^{42}$. The biodegradable blends of PANI with poly(ethylene glycol) (PEG) and polycaprolactone (PCL) for the tissue regeneration applications have been also reported ${ }^{43,44}$. The 
applications of the degradable PANI blends and composites in tissue engineering will be discussed in Section 6.3.

\section{Biocompatibility and cytotoxicity}

Polyaniline and its nanocomposites are quickly developing as promising materials for the biomedical applications. Therefore, the health risks related to PANI and PANI nanocomposites are of great importance. The biocompatibility is the ability of the materials to coexist with living things and tissues without damaging them ${ }^{45}$. On the other hand, the cytotoxicity depends on the chemical composition, size and shape of the nanomaterials in the nanocomposites 46. For instance, the cytotoxicity of the globular polymers is different from that of the polymer nanoparticles. Thus, the structures of PANI and its nanocomposites can affect the biocompatibility and cytotoxicity.

It is well-known that the deprotonation-reprotonation sequences undertaken on PANI result in the decrease of cytotoxicity. However, PANI can hardly be toxic since it is fully insoluble and stable in an aqueous solution. Hence, the cytotoxicity reported on the biological entities is related to the low-molecular-weight compounds. Two types of these low-molecular-weight compounds are available; (I) reaction of by-products with oligomers of aniline ${ }^{47,48}$ and (II) the acids that form the PANI salts. As a result, the modification of PANI with regard to the aforementioned materials is of significance ${ }^{49}$.

According to the ISO 10993 standards, PANI shows biocompatibility properties in terms of dermal irritation and sensitization. It was reported that both PANI-EM-S and PANI-EM-B have outstanding biocompatibility properties in the duration of dermal irritation. Moreover, the cytotoxicity of the PANI-EM-S is lower than that of the PANI-EM-B due to the reprotonationdeprotonation cycle and the presence of the low-molecular-weight impurities ${ }^{45}$. The cell 
biocompatibility of the PANI film prepared through electroless surface polymerization with PC12 cells was also reported. The results showed that the PANI film enhances the cell proliferation, revealing promising potentials of this compound as a surface coating to cultivate neuronal cells which can be used in tissue regeneration ${ }^{50}$.

In a study, Humpolicek et al. used different cell lines, such as mouse embryonic fibroblast $(\mathrm{NIH} / 3 \mathrm{~T} 3)$ cell lines and embryonic stem cells to evaluate the biocompatibility of PANI. In contrast to their previous findings, it was found that the correlation of the cytotoxicity with the impurity contents is not always strictly linear. They reported that the cytotoxicity of PANI-salts and PANI-based compounds are similar (Fig. 4B) ${ }^{46}$.

The biocompatibility of the macroporous PANI cryogel prepared in the frozen poly(vinyl alcohol) solution was investigated by the examination of its cytotoxicity on the mouse embryonic fibroblasts as well as by the examination of the embryo-toxicity based on the production of beating foci inside spontaneous differentiating embryonic stem cells. It was reported that the PANI cryogel with the low contents of low-molecular-weight impurities has a good biocompatibility ${ }^{51}$.

The cytotoxicity of the colloidal PANI on the human keratinocyte (HaCaT) and mouse embryonic fibroblast (NIH/3T3) cell lines through 3-(4,5-dimethylthiazol-2-yl)-2,5diphenyltetrazolium bromide (MTT) assay was investigated and the results showed that the cytotoxicity of the colloidal PANI is low ${ }^{52}$. In another research, the cytotoxicity of PANI salt in the globular and nanotubular morphologies decreased after reprecipitation from NMP compared to the primary polymer. Also, no cytotoxicity on the NIH/3T3 cells was seen at 5 and $10 \%$ of the extract concentration in the case of globular and nanotubular polymers, respectively ${ }^{49}$.

The cytotoxicity evaluation of the PANI nanofibers on the rat celiac macrophages (at the concentrations $\leq 1 \mathrm{mg} / \mathrm{ml}$ ) showed that the PANI nanofibers did not have a considerable impact on 
the level of cellular ROS and the loss of mitochondrial membrane potential (MMP) of the macrophages; while a higher amount of PANI nanofibers (at the concentrations $\geq 10 \mathrm{mg} / \mathrm{ml}$ ) caused cell death, alterations of ROS level and MMP. It was found that the cytotoxicity of PANI nanofibers was originated by the production of the oxidative stress and change of the intracellular MMP 53.

In other researches, the teratogenic and eco-toxicity impacts of PANI nanoparticles and nanofibers in Rhinella arenarum larvae and embryos were reported (Fig. 4C). The results revealed that there is a low-risk potential after exposing $R$. arenarum to both PANI nanofibers and nanoparticles ${ }^{54,55}$.

The difference in the biocompatibility of the PANI composites is because of the various factors such as, chemical composition, size and shape of the nanomaterials in the nanocomposites, dopants and preparation methods ${ }^{56}$. The biocompatibility of the PANI biocomposites such as starch/PANI increases with the increase of the naturally occurring polymer content ${ }^{57}$. It was proposed that the starch/PANI biocomposite be used in the tissue engineering. Surprisingly, in another research, the polyaniline-coated cotton fabric showed high cytotoxicity on the NIH/3T3 cell ${ }^{58}$, which is because of the existence of the low-molecular-weight toxic impurities in the PANI. These entrapped impurities in the PANI cotton structure are released during the extraction of the coated cotton prior to the cytotoxicity tests ${ }^{58}$. The aquatic toxicology of PANI and $\mathrm{CuO} / \mathrm{PANI}$ nanocomposites through acute (ISO 6341) and chronic toxicity (ISO 10706) tests with microcrustaceans Daphnia magna and Vibrio fischeri, a marine bacterium, were evaluated by Rossetto et al. According to their report, the PANI had no acute toxicity to D. magna (EC50,48 h, $99.21 \mathrm{mg} / \mathrm{L}$ ), while the $\mathrm{CuO} / \mathrm{PANI}$ nanocomposite had the EC50 value of $0.48 \mathrm{mg} / \mathrm{L}^{56}$. 
Regarding carbon-based nanocomposites of PANI, the in vitro cellular toxicity of the nanodiamonds-PANI (NDs/PANI) composite on the human embryonic kidney (HEK) cells showed that at low concentrations $(0.1$ to $1 \mu \mathrm{g} / \mathrm{ml})$ the NDs/PANI composite can be applied for the biomedical applications without a negative effect on the cells life activities ${ }^{59}$. It was reported that its application in bioscience depends on the determination of the proper concentration under the in-vivo condition. The cellular biocompatibility of the poly( $N$-isopropylacrylamide)-carbon nanotube (CNT)-PANI nanocomposite for tissue engineering applications using the mouse L929 fibroblast cells showed very good cells growth and viability along with the cells detachment function ${ }^{60}$. This nanocomposite was first fabricated via the combination of coupling and electrospinning and then applied for the woven microfabric scaffolds construction. 


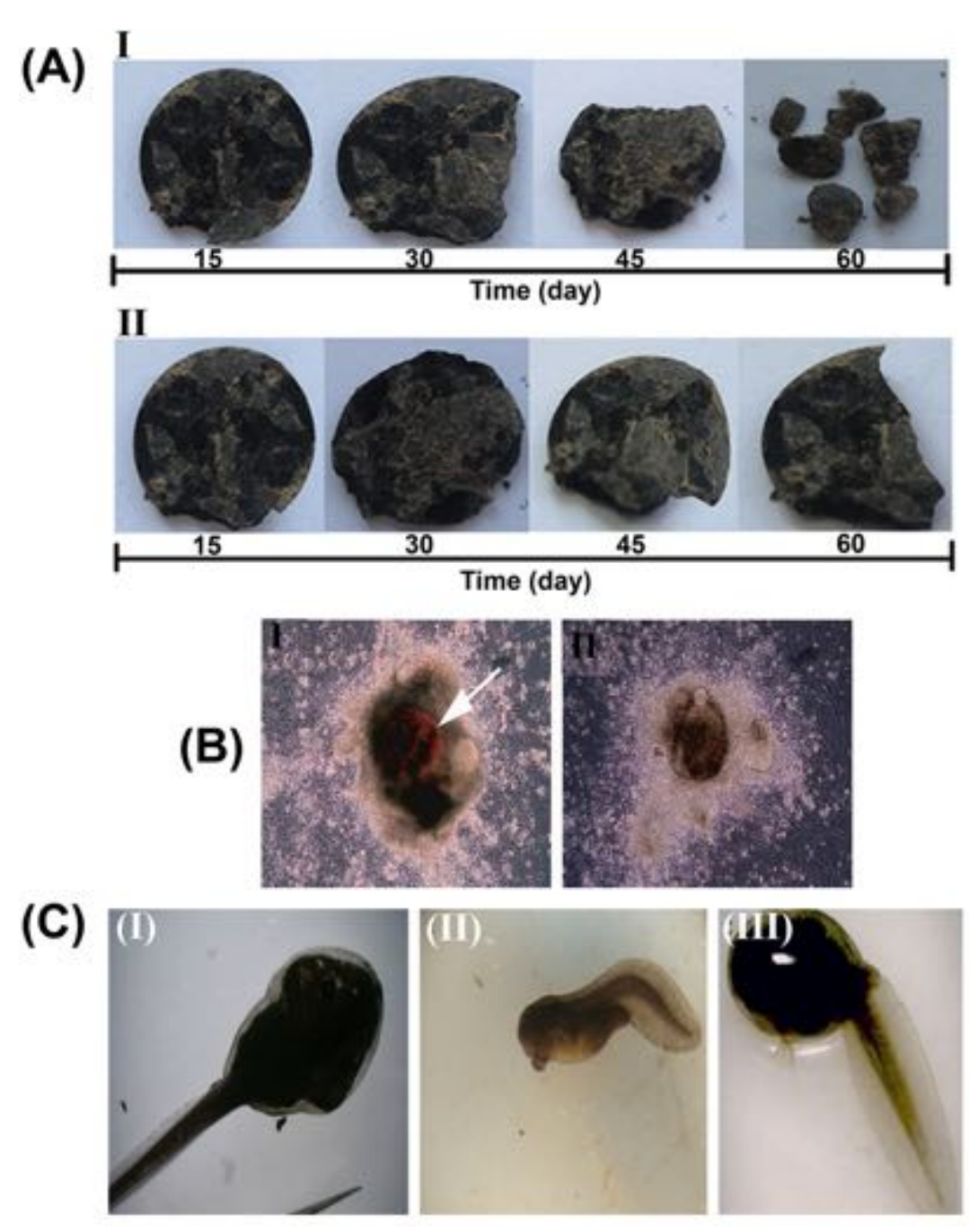

Fig. 4 (A) The soil degradability of polyaniline/dextrin nanocomposite tablets with the diameter of $14 \mathrm{~mm}$ for I [polyaniline:dextrin (1:3)] and II [polyaniline:dextrin (2:1)] buried in soil (pH:7.5) in the relative humidity of $60-70 \%$ at $28-30{ }^{\circ} \mathrm{C}$ for 60 days. Reprinted with permission from ref 22. Copyright 2014 Springer. (B) The formation of the erythroid clusters (the red clusters marked with an arrow) within the embryoid body. (I) positive reference and (II) absence of the red erythroid clusters after cultivation in the presence of $25 \%$ extracts of PANI-salt Reprinted with permission from ref ${ }^{46}$. Copyright 2018 Elsevier. Photographic recording of malformations detected in the embryos treated with $400 \mathrm{mg} / \mathrm{L}$ polyaniline nanofibers, (I) the control test without any treatment, (II) embryo with incurvated body axis and (III) embryo with underdeveloped gills. Reprinted with permission from ref ${ }^{55}$. Copyright 2012 Elsevier.

\section{Biological activity}




\subsection{Antimicrobial activity}

The infection caused by microbes affects the human life severely. Hence, a number of studies have been devoted to prepare new antimicrobial agents to fight pathogens. The advent of new compounds containing antimicrobial properties continues unabated. Polymers with antibacterial and antifungal activities are widely used in the biomedical applications since the pathogens become resistant to the existing drugs. Conducting polymers, such as PANIs, are appealing in biomedicine because of their high cellular response ${ }^{61}$. In this regard, the PANI-based compounds have been synthesized to control the microbial contaminations ${ }^{62}$. The antimicrobial activity of PANI towards the Gram-negative and Gram-positive bacteria have been reported ${ }^{63,64}$. However, a number of various nanomaterials, polymers and other compounds have been added to PANI to enhance the antimicrobial activity, conductivity, and photocatalytic activity ${ }^{65,66}$. Hence, the PANI-based nanocomposites consist of different nano-architectures such as rods, spherical particles, tubes and sheets have been exploited for the biomedical applications. For instance, the PANI/zinc-aluminum layered double hydroxide nanocomposite prepared by the free radical emulsion polymerization has been reported to show antibacterial activity ${ }^{67}$. Other architectures, such as PANI decorated Au nanorods, have also shown high antibacterial properties toward Escherichia coli and Staphylococcus aureus ${ }^{68}$. Nanofibers of PANI/silver NPs showed antibacterial properties against $E$. coli and B. subtilis strains, while neat PANI did not show any antibacterial activity ${ }^{69}$. The application of PANI/silver nanocomposites is not limited to antimicrobial purposes. For instance, the use of Ag functionalized PANI-based biosensor has been reported for the determination of anticancer drugs ${ }^{70}$.

The PANI nanocomposites containing microbicidal nanomaterials, such as zinc oxide and Ag nanocompounds, have shown synergistic antimicrobial effects ${ }^{64}$. Silver NPs and carbon nanotubes 
incorporated PANI showed higher antibacterial activity than PANI-carbon nanotubes and PANIAg nanocomposites because of the synergistic effect of the fillers ${ }^{71}$. In another study, the antibacterial effect of the $\mathrm{ZrO}_{2}$ NPs-PANI nanocomposite against E. coli and $S$. aureus was determined to be higher than that of the pure PANI ${ }^{72}$.

The polymers containing quaternary ammonium compounds have high antibacterial and antifungal activity ${ }^{73,74}$. Therefore, copolymers of PANI with the biopolymers containing quaternary ammonium salts, such as chitosan, have been employed to improve the antibacterial activity with enhancing the biocompatibility of PANI ${ }^{75}$. With this in mind, quaternized chitosangraft-PANI injectable hydrogels have been used as the biocompatible scaffolds for tissue regeneration (Fig. 5). The in situ forming biodegradable conductive hydrogels have in vitro and in vivo antibacterial properties and can improve the proliferation of the $\mathrm{C} 2 \mathrm{C} 12$ myoblasts in comparison with the quaternized chitosan hydrogel ${ }^{35}$. The microcapsules of poly(lactic-coglycolic acid) have been applied as a carrier for the delivery of ginseng/PANI for the implant restoration. The presence of PANI enhanced the antibacterial efficacy up to $88 \%{ }^{76}$. Apart from releasing antimicrobial agents, non-leaching antibacterial and antifungal compounds, which have a chemical linkage to the polymer matrix is another option to form an antimicrobial surface. For instance, poly(3-aminobenzoic acid) and PANI have been applied to form an antibacterial surface 77.

The antimicrobial mechanism of PANI includes the production of $\mathrm{H}_{2} \mathrm{O}_{2}$ that causes the oxidative stress characterized by the perturbation of iron homeostasis (Fenton reaction). In fact, free iron can propagate $\mathrm{H}_{2} \mathrm{O}_{2}$ stress by participating in Fenton reaction which accelerates the formation of hydroxyl radicals leading to the microorganism destruction and, subsequently, cell death. Polyaniline is more active against Gram-negative bacteria, such as E. coli, in aerobic 
conditions compared with the anaerobic environments. Higher antibacterial property in aerobic conditions supports the role of reactive oxygen species ${ }^{78}$.
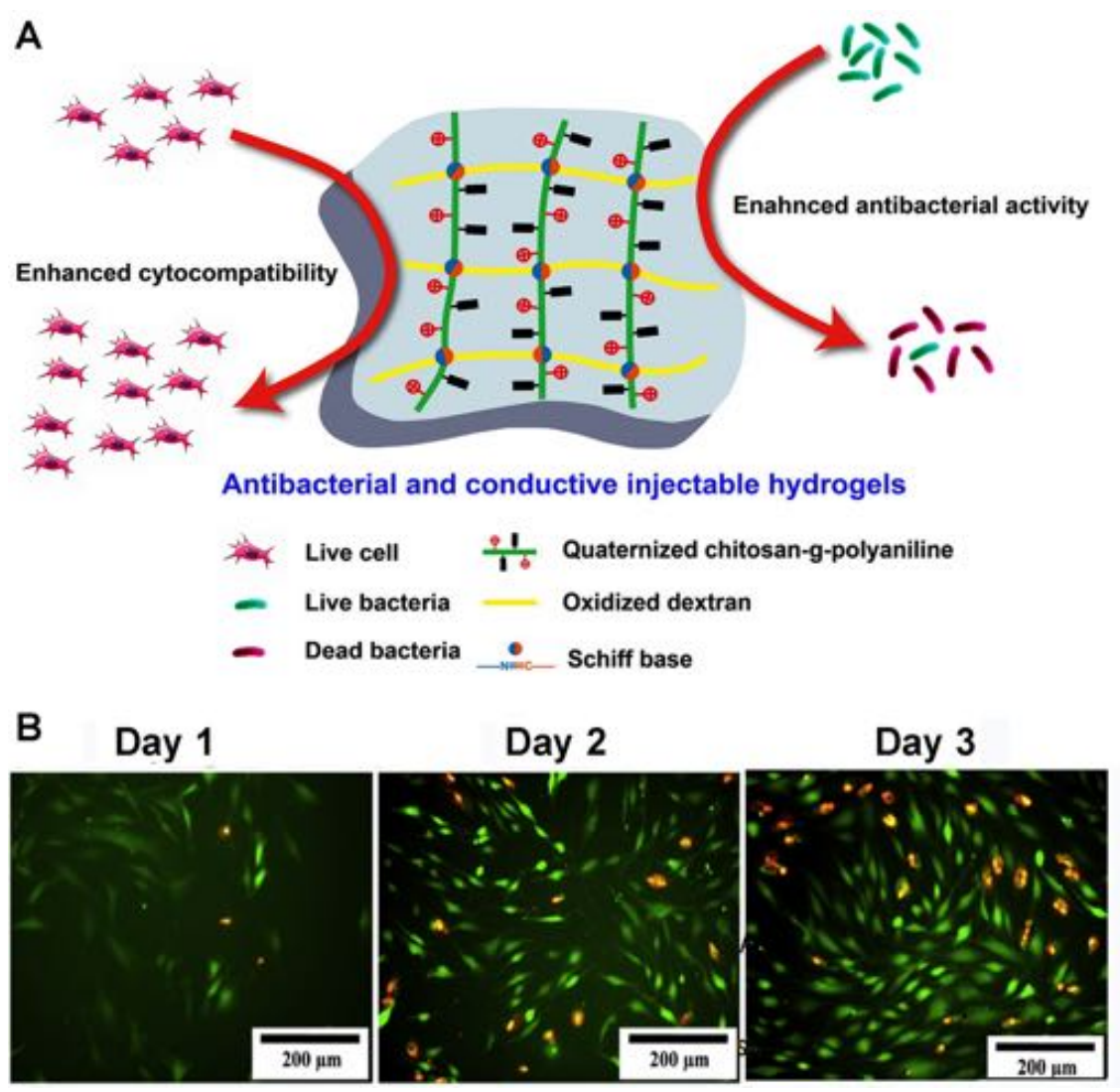

Fig. 5. (A) Schematic presentation for the antibacterial activity of injectable conducting hydrogels. (B) Live/dead staining of adipose-derived mesenchymal stem cells at successive culture periods for the quaternized chitosan-graft-PANI crosslinked by oxidized dextran using the Alamar Blue and Live/Dead Viability/Cytotoxicity assay. Scale bar: $200 \mu \mathrm{m}$. Reprinted with permission from ref ${ }^{35}$. Copyright 2015 Elsevier.

\subsection{Antioxidant activity}

Free radical intermediates lead to the tissue damage and diseases progression such as inflammation, heart disease, cancer and premature aging ${ }^{79}$. Antioxidant materials are compounds that prevent the oxidation of other materials. They play an 
important role in foods and tissues as a health protective factor and decrease the risk of the chronic diseases ${ }^{79}$. The antioxidant activity of ICPS has important consequences for their applications in the biomedicine. It is particularly useful in the tissues suffering from the oxidative stress, where the capability to lower excessive stages of the reactive radical species (RRS) is appropriate ${ }^{80}$. The ICPs, such as PPy and PANI, have shown good antioxidant activities in the presence of 1,1-diphenyl-2picrylhydrazyl (DPPH) free radical scavenger ${ }^{80}$. The swift heavy ion irradiation of PANI and the nature of the dopant acids have shown a significant role in the antioxidant activity of the PANI nanostructures ${ }^{81}$. The HCl-doped PANI nanofibers induced by the swift heavy ion irradiation showed the best antioxidant activity compared to other undoped PANI structures ${ }^{82}$. It was reported that the observed antioxidant activity of the PANI nanofibers is related to the decrease of the size of PANI nanofibers after the swift heavy ion irradiation, which points the access of more reaction sites for DPPH scavenging ${ }^{82}$. On the other hand, the antioxidant activity of the materials depends on their capability to donate hydrogen to reduce DPPH, and therefore, the chemical structure of the materials are important for their antioxidant activity ${ }^{22}$.

There are a few studies on the antioxidant activity of PANI nanocomposites to be developed in the biomedical applications. The antioxidant activity of PANI/starch biocomposites was improved upon increasing the PANI ratio. This can be related to the fact that the PANI, because of its redox active nature, is effective as a DPPH free radical scavenger ${ }^{57}$. The antioxidant activity of other polysaccharides/PANI composites, such as PANI/dextrin nanocomposite, prepared by in-situ polymerization of aniline and dextrin biopolymer, increased up to $72 \%$ with the aniline content. 
This antioxidant activity of PANI can have substantial effect on the tissues and organs suffering from the oxidative stress ${ }^{22}$.

Regarding polyaniline containing metal nanomaterials, the maximum antioxidant activity of the PANI/polyxanthonetriazole $/ \mathrm{Fe}_{3} \mathrm{O}_{4}$ nanocomposite fabricated via an insitu emulsion polymerization was evaluated to be PANI 58\% at an interval of $10-120$ min. This amount of antioxidant activity is because of the presence of a higher number of electrons and hydrogen atoms ${ }^{79}$.

The effect of the supporting electrolytes, such as para-toluene sulfonic acid ( $p$-TSA) and $\mathrm{KCl}$ with different molar ratios on the antioxidant activity of PANI/reduced graphene oxide ( $r$-GO) has also been investigated. Accordingly, the antioxidant activity of the PANI/r-GO nanocomposite in the $p$-TSA supporting electrolyte increased with the $p$-TSA molar ratio. It was also found that the protonation of the PANI/r-GO nanocomposite by $p$-TSA donates hydrogen to reduce DPPH as an antioxidant ${ }^{83}$.

As mentioned earlier, the antioxidant activity of ICPs, which comes from their capability to decrease the levels of RRS, is possibly helpful for the suffered tissues from the oxidative stress. Thus, the antioxidant activity of polyaniline may be important, especially for the diseases that cause excessive levels of RRS. Furthermore, the PANI composites, such as the PANI/starch, may have the capability to decrease the oxidant produced via the chemotherapeutic drugs which can assist in neutralizing or at least decreasing the side effects of the chemotherapeutic cancer therapy. According to the literatures on this subject, a schematic illustration for the proposed mechanism 
of antioxidant activity of PANI in the presence of the DPPH radical scavenger is shown in Fig.

6.

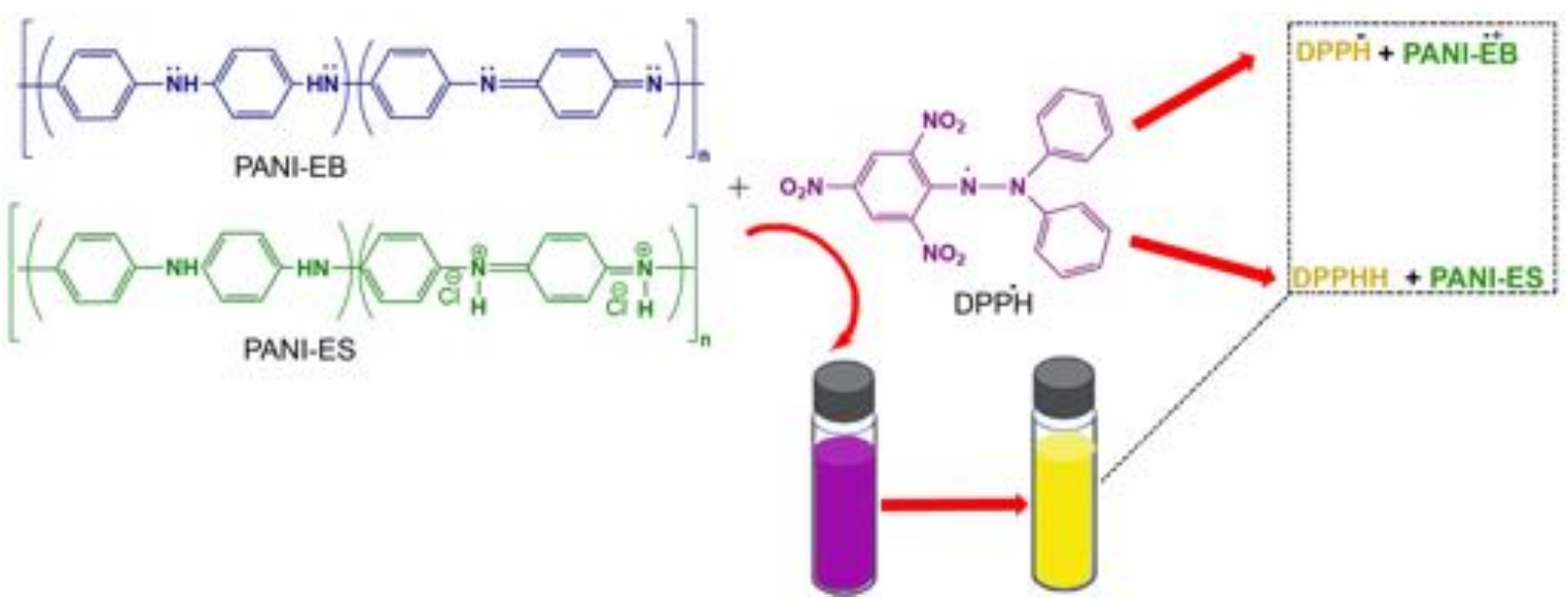

Fig. 6. The proposed mechanism for the antioxidant activity of polyaniline in the presence of DPPH radical scavenger.

\section{Biomedical applications}

Among ICPs, the PANI has outstanding potential applications in different fields such as super-capacitor, gas sensor, water treatment, anti-corrosion coating, drug delivery, biosensor and tissue engineering ${ }^{84-86}$.

In the following sections, the applications of PANI nanocomposites in the biomedical and clinical fields are addressed. It should be noted that according to our knowledge, based on ClinicalTrials.gov international database, PANI-based medical devices has not yet reached the clinical stage, and consequently has not gained the certifications to enter the market. PANI is indeed extremely promising and interesting, but they have not yet reached a sufficient stage of maturity to allow a safe translation 
from bench to bedside. In addition, the regulatory framework has not yet well defined the borders for the applications containing nanocomponents.

\subsection{Antimicrobial therapy}

Antimicrobial conducting PANI has been applied in biomedicine including electrotherapy, antimicrobial clothing, and electromagnetic devices for monitoring health ${ }^{87}$. Infections in the treatment of diseases are still challenging; for instance, during or post scaffold transplantation which reduces the efficacy of bone healing. PANI nanocomposites have been developed in combination with various antimicrobial agents including silver $\mathrm{NPs}, \mathrm{TiO}_{2}$, releasable drugs and biomolecules, and the non-leachable compounds, such as quaternary ammonium salts, to prepare a number of antimicrobial devices ${ }^{42,62,69,88}$.

PANI nanofibers combined with mupirocin, a topical microbicidal compound, have been prepared via a self-assembly approach for their potential applications as a wound healing dress ${ }^{89}$. It was shown by the agar diffusion method that the antibacterial activity of the PANI-mupirocin was higher than that of the neat PANI due to the release of mupirocin ${ }^{90}$. Fiber-highly porous scaffolds based on poly- $\varepsilon$-caprolactone-PANI were fabricated by electrospinning approach for their potential applications in electrically stimulated cell growths and cytoprotection of cells against oxy-radials. The nanostructured bioactive scaffolds revealed both antibacterial and antioxidant activities (free radical-scavenging capability) with no cytotoxicity against L929 cells on the scaffolds ${ }^{91}$.

Colloidal aqueous dispersions of PANI showed low bactericidal effects $\left(3500 \mathrm{~g} \mathrm{~mL}^{-1}\right)$ against B. cereus and E. coli. Although the PANI dispersion has low cytotoxicity, the toxicity effect depends on the cell line and PANI dose; for example, the human keratinocyte cells were less 
sensitive than the mouse embryonic fibroblast cells. In addition, the neutrophil oxidative burst assay revealed that $150 \mathrm{~g} \mathrm{~mL}^{-1}$ is the critical concentration of the PANI colloid dispersions for the biologically safe applications ${ }^{52}$.

Thermosensitive gels possessing electrical conductivity and self-healing capability are of great interest as cell carriers for tissue engineering ${ }^{92,93}$. In a study conducted by Dong et al., an injectable and biodegradable hydrogel with antibacterial activity was synthesized by mixing dibenzaldehyde-terminated poly(ethylene glycol) (PEG-DA) and chitosan-graft-aniline tetramer (CS-g-AT) to be used for the repair of the damaged cardiac tissue. The electroactive and antibacterial hydrogels showed good viability and proliferation with rapid self-healing capability because of the cross-linking network made through the Schiff-base reaction of aniline (Fig. 7) ${ }^{92}$. The cell growth and proliferation was also reported for hard tissue regeneration using $\mathrm{TiO}_{2}$ nanotubes-PANI nanocomposites ${ }^{94}$.

The PANI-polyurethane foam (PANI/PUF) was employed as an antibacterial dress for the wound healing applications. The PANI/PUF film was fabricated by using in-situ radical polymerization of aniline monomer in the presence of usnic acid (UA, as a dopant) and PUF. The UA improved the bactericidal property of PANI toward E.coli and S.aureus strains ${ }^{95}$. Other bandage dressings, such as antimicrobial membrane composed of aniline tetramer/siloxane terminated polyurethane (AT/STPU), have also been suggested. The AT/STPU membranes were fabricated via the sol-gel method using the STPU prepolymer and AT. The presence of polysiloxane-linked PU chains improved the dimensional stability even at the high hydrated condition. It was also reported that the AT led to the improvement of the cells viability and antimicrobial activity for both bacteria and fungal strains ${ }^{96}$. 

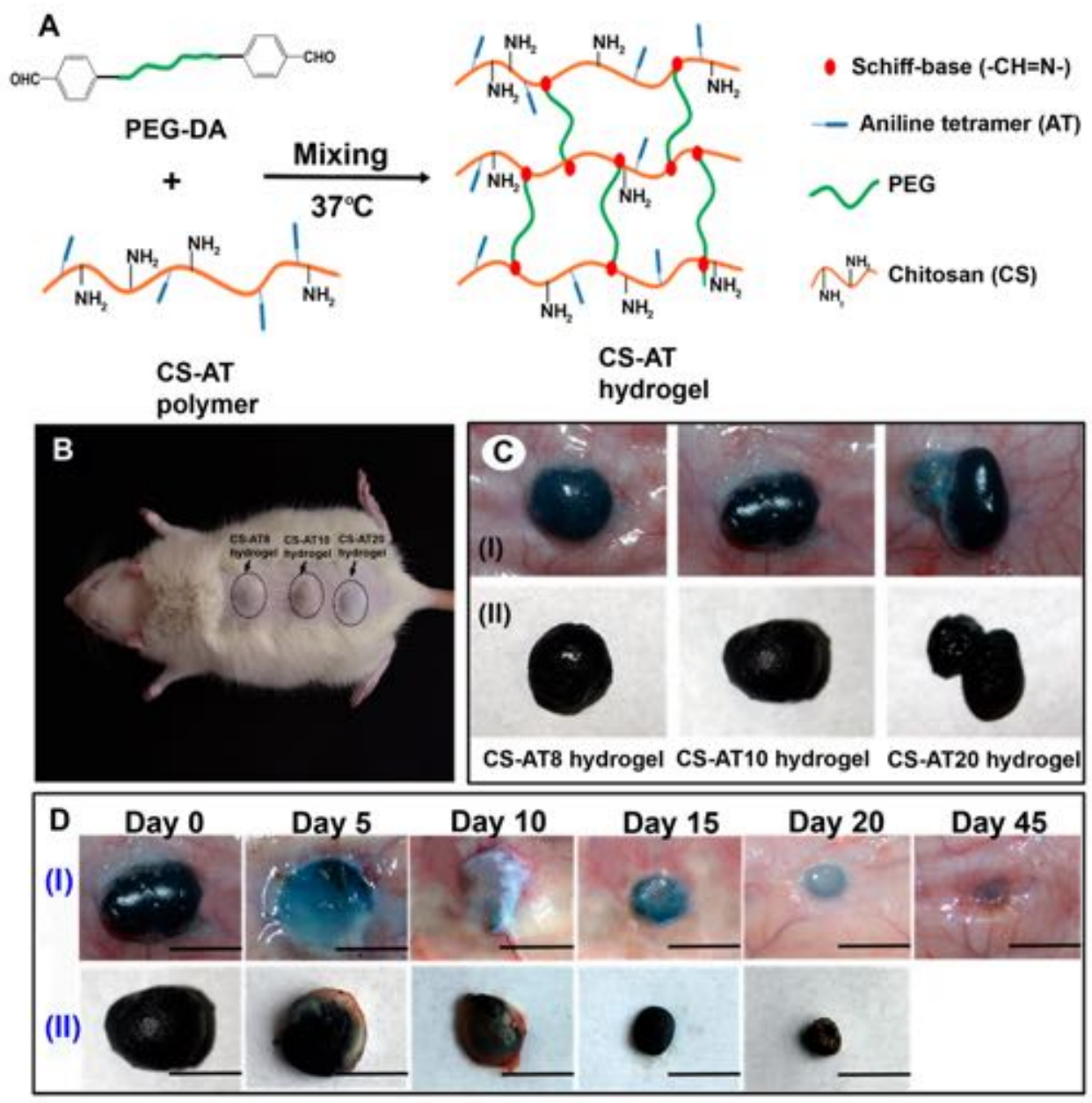

Fig. 7 ((A) Schematic procedure for the synthesis of thermosensitive chitosan-graft-aniline tetramer (CS-g-AT) hydrogel. (B) CS- $g$-AT hydrogels after subcutaneous injection. (C) CS- $g$-AT hydrogels wrapped in the rat's skin (row I) and the hydrogels peeled from the rat's skin (row II). The hydrogels with different aniline tetramer (AT) contents, including CS-AT8, CS-AT10 and CS-AT20, were prepared. (D) Degradation properties of the hydrogels in vivo. Row I shows the hydrogel under the skin and row II displays the hydrogel that peeled from the skin. CS: chitosan, AT: aniline tetramer. Reprinted from ref ${ }^{92}$. Copyright 2016 American Chemical Society.

PANI and its composites not only target the human body for the antimicrobial therapy but also are suggested to be used in places (e.g. hospitals) and devices (e.g. medical devices) that are prone to the microbial growth. For instance, Robertson et al. evaluated the antimicrobial activities of PANI and poly(3-aminobenzoic acid) (P3ABA) as the effective agents to fabricate bacteria- 
resistant surfaces. The antimicrobial activities of PANI and P3ABA against E.coli and S.aureus were seen in both absorbent and non-absorbent surfaces. It was proposed that these surfaces could be applied as the wall coating in hospitals ${ }^{77}$. PANI coated modified polypropylene (MPP) has been prepared by using dip-coating technique as an anti bioaerosol filter. The PANI NPs were synthesized by micro-emulation polymerization and then coated onto the polypropylene filter. The antibioaerosol property of the PANI/MPP was investigated against S. aureus, E. coli, and B. subtilis bioaerosols. It was shown that the water absorption property, stability and antibacterial efficiency of the PANI/MPP were meaningfully improved as compared to the unmodified PP filter 97.

Metal nanomaterials embedded PANI nanocomposites have also been applied to improve the antibacterial and antifungal activity of the nanocomposites. For instance, the conductive polyaniline containing silver showed higher antibacterial activity than the neat PANI ${ }^{88,98}$. Though the mechanism of antimicrobial activity of nanomaterials against different microorganisms varies for the types of metals, ions and, species, the dissolution of nanomaterials into ions is often the first step and a common reason for the toxicity of metallic nanostructures (Fig. 8). For instance, the metal ions can produce hydroperoxide radicals, whereas zinc oxide can form hydroxyl radicals 99. 


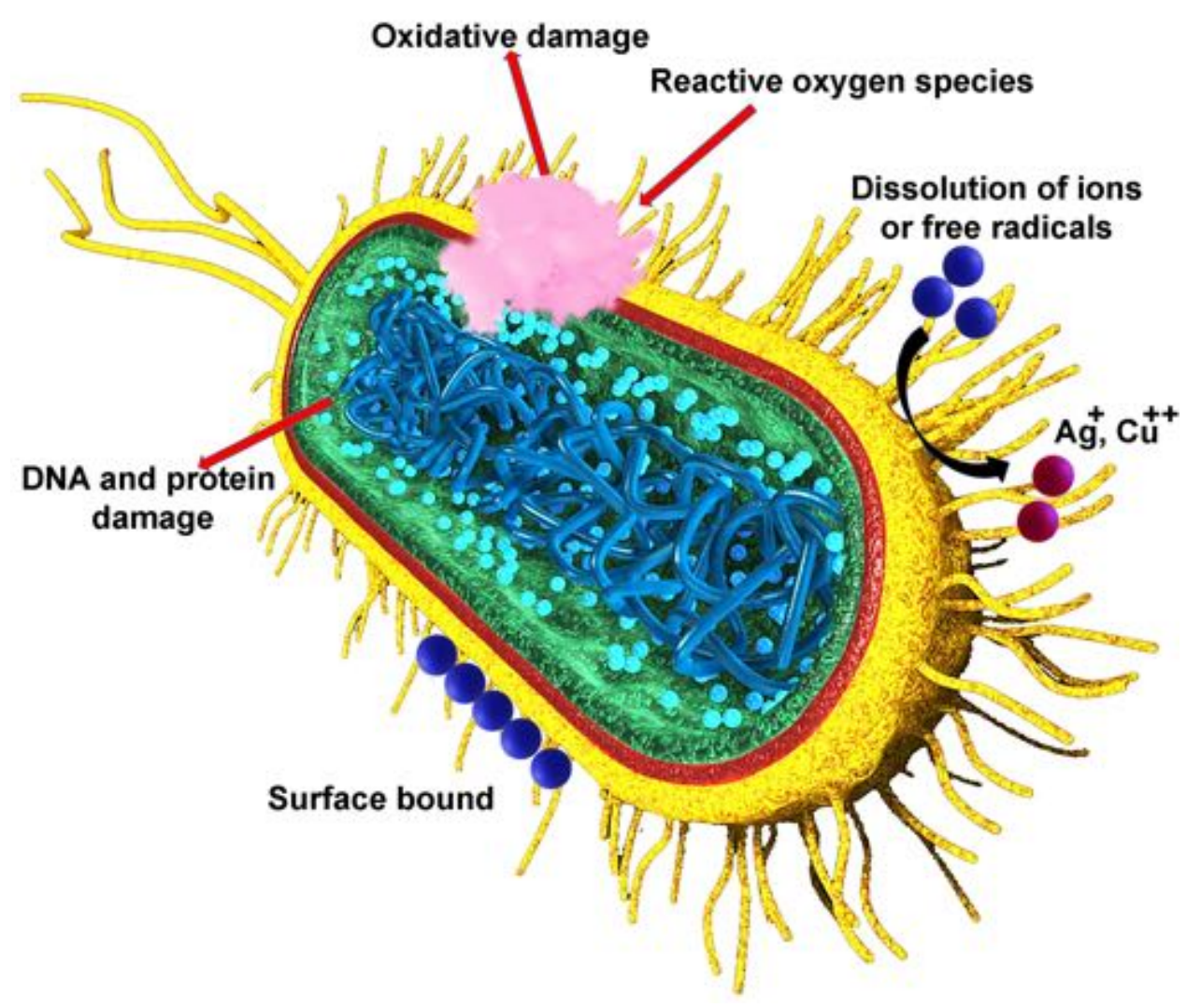

Fig. 8 Illustration of potential interactions and modes of toxicity when engineered nanoparticles targeted at different parts of a generic bacterium: capsule, cell wall, cell membrane, and cytoplasmic contents. Numerous nanoparticle shapes may reduce the bactericidal toxicity by one or some of these mechanisms. These mechanisms include the cell membrane disruption, disruption of electron transport chains, ROS production, and damage of proton efflux pumps.

\subsection{Drug delivery}

It is widely accepted that the kinetics by which a drug is released presents a high impact on its efficacy ${ }^{100}$. Traditional approaches for delivering a drug or biomolecule through oral or injection lead to the accumulation of drugs/biomolecules(concentration peak) in the human body. ${ }^{101}$ Accordingly, to reach the therapeutic levels, the initial concentration of the biomolecules must be more than the threshold level which causes the biomolecule accumulation; however, this concentration peak is gradually reduced to an ineffective level over time. Thus, the most important objective behind the sustained and controlled drug delivery systems is to offer an optimal drug 
delivery adjusting drug level to avoid under- and overdosing and preserve the released amount within a certain period. This approach leads to the reduction of the number of drugs administration per day ${ }^{102}$. These strategies often called smart drug delivery systems or devices (SDDS), are based on multidisciplinary approaches that combine pharmaceutics, materials science, and molecular biology together with the engineering skills ${ }^{103}$. The main aim is to release a certain amount of a drug, loaded within carriers, to a specific target site for a prolonged period of time with a sustained kinetics. The drug delivery device can be either inert (and so the device works only as a drug carrier) or an active part of the therapy. Following the second strategy, due to the intrinsic conductivity of PANI, PANI derivatives can be used as the drug carriers with the electric-driven release ${ }^{104}$. A common issue of those devices is their very low mechanical strength ${ }^{105}$. A good strategy to improve the mechanical properties is represented by using supramolecular nanofibers self-assembled from the sorbitol derivatives ${ }^{106}$. PANI is also a good candidate to be a photothermal converting material for the theranostic applications. Therefore, it can be used for diagnosis and simultaneously delivering a drug. In this regard, the biocompatible graphene and Au NP core PANI shell nanocomposites have successfully been fabricated. These nanocomposites showed high biocompatibility, good stability, strong near-infrared (NIR) absorbance, and suitable drug loading efficiency. This light-sensitive system has NIR/pH-responsive drug-releasing capability, which promotes the practical applications in the chemo-photothermal therapy ${ }^{107}$.

Chemo-phototherapy is the incorporation of a therapeutic agent within a material that is responsive to NIR irradiation inducing anticancer activity. Of organic NIR-responsive materials, PANI emerged as an extremely promising material ${ }^{42,108-111}$. This strategy has attracted great attention in recent years in view of its enhanced drug accumulation and controlled release, while the side effects were relatively decreased ${ }^{112}$. For instance, Nguyen et al. ${ }^{108}$ embedded a 
chemotherapeutic agent, methotrexate and PANI (a photosensitizer material) within hybrid polymer NPs that can target cancer cells after conjugation with lanreotide, a synthetic analog of somatostatin. The synthesis and structure of these multifunctional hybrid polymer NPs together with the mechanism of their anticancer activity are schematized in Fig. 9. In addition, the efficacy of the composite systems to kill the cancer cells could be improved using the PANI derivatives, such as the PANI impregnated with the magnetic $\left(\mathrm{Fe}_{3} \mathrm{O}_{4}\right)$ nanoparticles ${ }^{113}$.

The use of PANI nanocomposites in cancer therapy is also reported by Gao et al. ${ }^{114}$ with the development of folate-based particles functionalized with PANI. The decorated nanoparticles were able to efficiently target the cancer cells and selectively accumulate within them to achieve the NIR-triggered localized release of their content (cisplatin). It was also shown that the gold nanorods could be coated with the PANI in order to reduce the cytotoxicity and instability. After the incubation of the nanorods with HeLa cells and exposure to a NIR laser, the threshold energy to kill the cancer cells was found to be significantly lower compared with the previous studies ${ }^{115}$.

Apart from the metallic nanostructures, the PANI chains with various lengths have been attached onto the surface of the spherical particles of hollow mesoporous silica using in situ chemical oxidative polymerization. The encapsulated anti-cancer drug (doxorubicin) exhibited an acidic $\mathrm{pH}$-responsive release behavior; while indomethacin showed an alkaline release. The effect of the length of PANI chain-gate in the drug encapsulation capacity was also studied. Indeed, the long PANI chains decreased the loading capacity due to the blocked mesoporous channel ${ }^{116}$. In the field of photothermal chemotherapy, PANI was also exploited to cover inorganic ${ }^{117}$ and organic ${ }^{118}$ NPs as a functionalizing compound to improve their performance. Table 2 represents the use of polyaniline and its nanocomposites in drug delivery and bioimaging applications. 


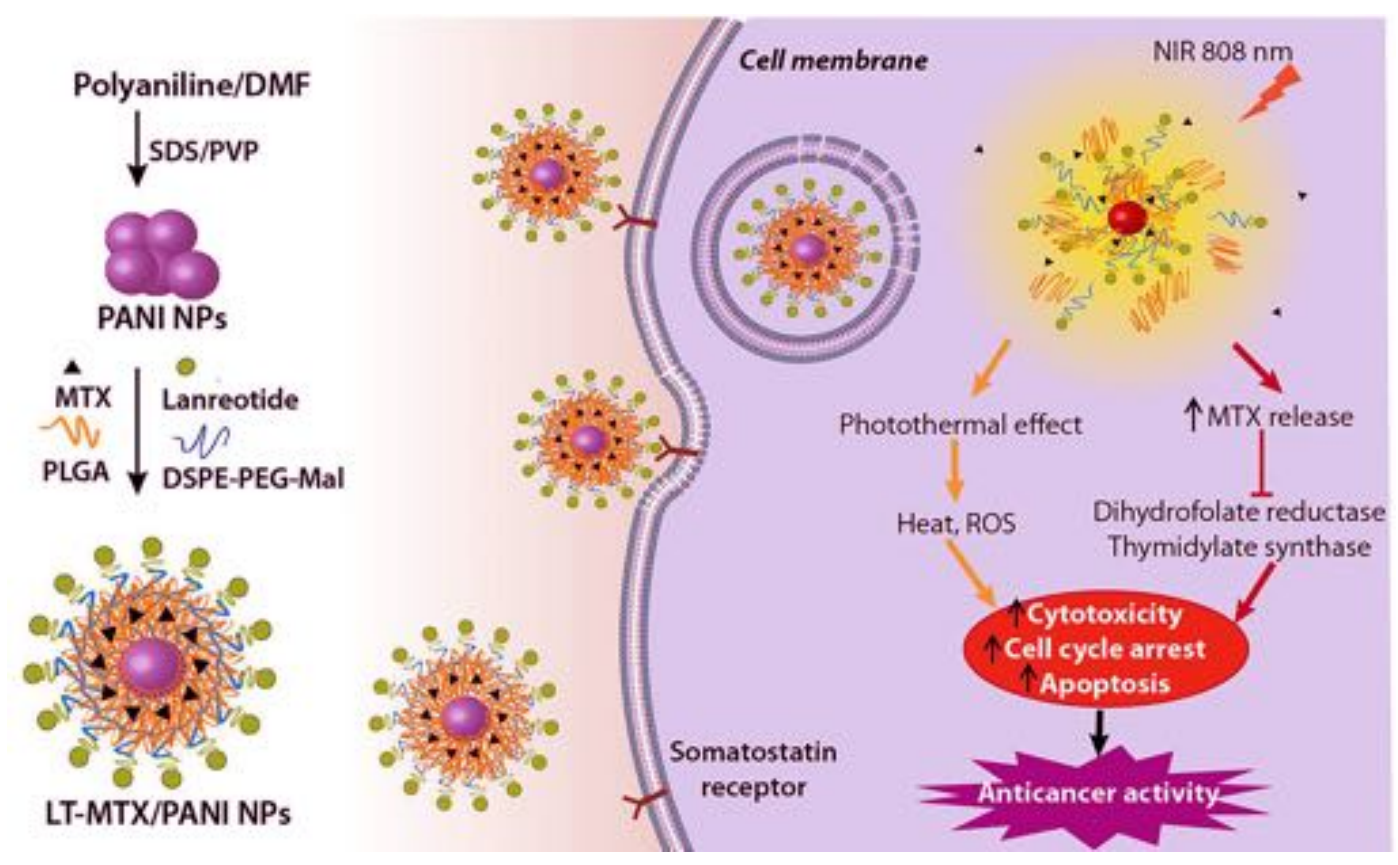

Fig. 9. Schematic illustration on the preparation of multifunctional hybrid polymer nanoparticles along with their anticancer activity mechanism. Reprinted with permission from ref 108. Copyright 2018 Elsevier. 
Table 2. Polyaniline nanocomposites used in drug delivery, photothermal therapy, and bioimaging applications.

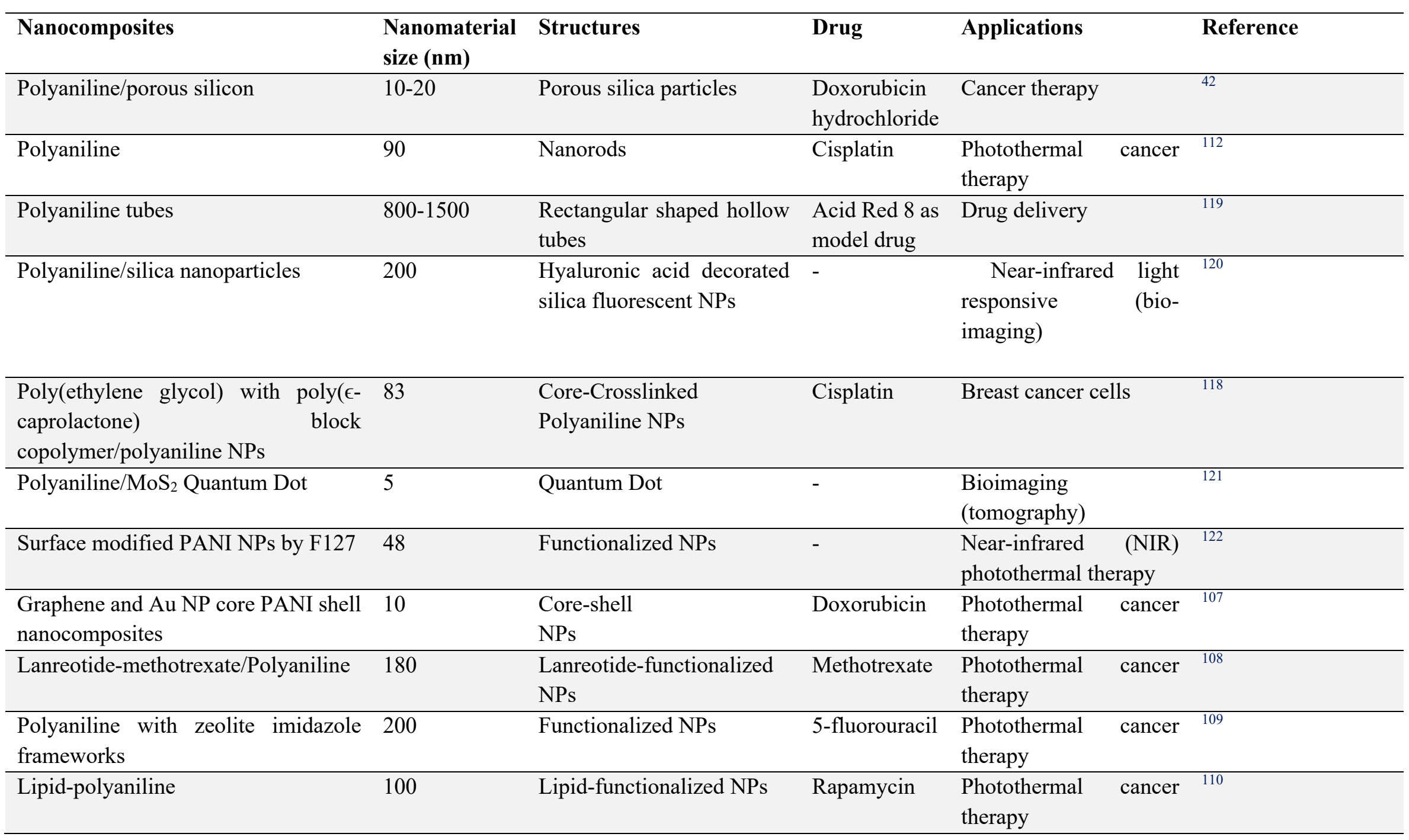




\begin{tabular}{|c|c|c|c|c|c|c|}
\hline $\mathrm{CaCO}_{3} /$ polyaniline & 1200 & $\begin{array}{l}\text { L-cysteine-functionalized } \\
\text { microparticles }\end{array}$ & - & $\begin{array}{l}\text { Photothermal } \\
\text { therapy }\end{array}$ & cancer & 111 \\
\hline Polyaniline/Pluronic F127 & $50 \mathrm{~nm}$ & Nanoparticles & - & $\begin{array}{l}\text { Photothermal } \\
\text { therapy }\end{array}$ & cancer & 122 \\
\hline $\mathrm{Fe}_{3} \mathrm{O}_{4} /$ polyaniline & $10 \mathrm{~nm}$ & $\begin{array}{l}\text { Core-shell } \\
\text { NPs }\end{array}$ & - & $\begin{array}{l}\text { Photothermal } \\
\text { therapy }\end{array}$ & cancer & 113 \\
\hline Polyaniline/polyglutamic acid & $80 \mathrm{~nm}$ & $\begin{array}{l}\text { Cysteine-functionalized } \\
\text { NPs }\end{array}$ & - & $\begin{array}{l}\text { Photothermal } \\
\text { therapy }\end{array}$ & cancer & 123 \\
\hline $\begin{array}{l}\text { Folate/poly(ethylene glycol)- } \\
\text { distearoylphosphatidylcholine }\end{array}$ & $100 \mathrm{~nm}$ & Polyaniline-loaded NPs & Cisplatin & $\begin{array}{l}\text { Photothermal } \\
\text { therapy }\end{array}$ & cancer & 114 \\
\hline Au nanorods/polyaniline & $40 \mathrm{~nm}$ & Core - shell nanorods & - & $\begin{array}{l}\text { Photothermal } \\
\text { therapy }\end{array}$ & cancer & 115 \\
\hline Polyaniline/porous silicon & $110 \mathrm{~nm}$ & Porous silica particles & Doxorubicin & $\begin{array}{l}\text { Photothermal } \\
\text { therapy }\end{array}$ & cancer & 116 \\
\hline $\begin{array}{l}\text { lanthanide-based upconversion NPs } \\
\text { /Polyaniline }\end{array}$ & $120 \mathrm{~nm}$ & Core - shell NPs & - & $\begin{array}{l}\text { Bioimaging } \\
\text { photothermal } \\
\text { therapy }\end{array}$ & $\begin{array}{r}\text { and } \\
\text { cancer }\end{array}$ & 117 \\
\hline
\end{tabular}




\subsection{Tissue engineering}

\subsubsection{Wound healing}

The possibility to transplant tissue is limited by several issues, such as immune rejection and donor shortage ${ }^{124}$. Novel research studies are looking for the combination of cells with the active molecules (drugs or biomolecules) to improve the regenerative therapeutic effects ${ }^{125}$. In this framework, in the last decades, a lot of studies were devoted to the development of proper 3D scaffolds that can work as a temporary substrate, helping to the growth of cells in an organized fashion, before transplanting them within patients ${ }^{126}$. This necessity comes from the fact that the cells injected from in vitro cultured cells can easily escape, leaving the zone of injection with an uncertain fate through the circulatory torrent. In this regard, not only scientific literature agrees with addressing this issue, but also regulatory supranational directives (e.g. EU668/2009 and 47/2007/EC) are now pointing towards the necessity to use cells in combination with suitable support structures. Consequently, great attention has been devoted to the polymers that can be applied for the production of the three-dimensional scaffolds and developing the injectable devices for tissue regeneration. In this field, PANI can improve the scaffold physical properties ${ }^{62,127}$. This improvement in the elasticity and mechanical performances allows the scaffolds to better mimic the native tissue properties ${ }^{127,128}$. For instance, the composites based on PANI could reach a high conductivity range and low tensile strain with the consequent high fibroblast and myoblasts adhesion ${ }^{129}$.

Electrical stimulation of the fibroblasts loaded within the PANI composite scaffolds presented low cell death and improved metabolic rate. Sharma et al. ${ }^{130}$ developed a composite system based on PANI-carbon nanotubes, the nanofibers of poly( $N$-isopropyl acrylamide-co-methacrylic acid) (PNIPAm-co-MAA), and PC/PNIPAm-co-MAA by electrospinning. The seen excellent growth of cells on the surface of the composite can be due to the higher conductivity and mechanical strength 
of polyaniline and carbon nanotubes. PANI-based NPs were also used to improve the performances of the graphene papers ${ }^{131}$. The combination of flexibility, biocompatibility, and electrochemical properties, coming from nanostructured PANI and graphene, makes them to be good candidates for hybrid devices for the biomedical sectors, such as flexible biosensors, batteries, and bioelectrodes along with the ability to culture the electrically excitable cells. Indeed, the conductivity given by PANI in hydrogels is also used in cellulose nanofibers ${ }^{132}$, resulting in better degradability and biocompatibility. The amelioration of the composite systems in the applications of tissue engineering was shown in the regeneration of cardiac cells ${ }^{132}$.

PANI has also been mixed with gelatin, and the co-electrospun nanofibers were utilized to support the cell growth ${ }^{133}$. The experimental results revealed that all the PANI/gelatin nanofibers support the $\mathrm{H} 9 \mathrm{c} 2$ cell attachment and proliferation and can control the tissue culture-treated plastic and smooth glass substrates. The use of PANI nanocomposites in cardiac tissue engineering is very promising ${ }^{134}$. For instance, PANI associated with caprolactone producing patches was able to better guarantee the high viability of human mesenchymal stem cells than the neat polycaprolactone $(\mathrm{PCL})^{134}$.

Hsiao et al. ${ }^{135}$ developed a mesh (Fig. 10) including aligned composite nanofibers of PANI and PLGA, as an electrically conductive platform for coordinating the beatings of the cultured cardiomyocytes synchronously. The PANI/lactide composite was also applied to stimulate the neuromuscular junction ${ }^{136}$ and nerve regeneration ${ }^{137}$ because of its ability to provide electrical signals. Due to this ability, PANI was used in combination with PCL to prepare the electrically active fibers that can maintain stable electrical features in the simulated cell culture conditions for up to one week with the improved NGF-induced neurite outgrowth of PC12 cells ${ }^{138}$. 


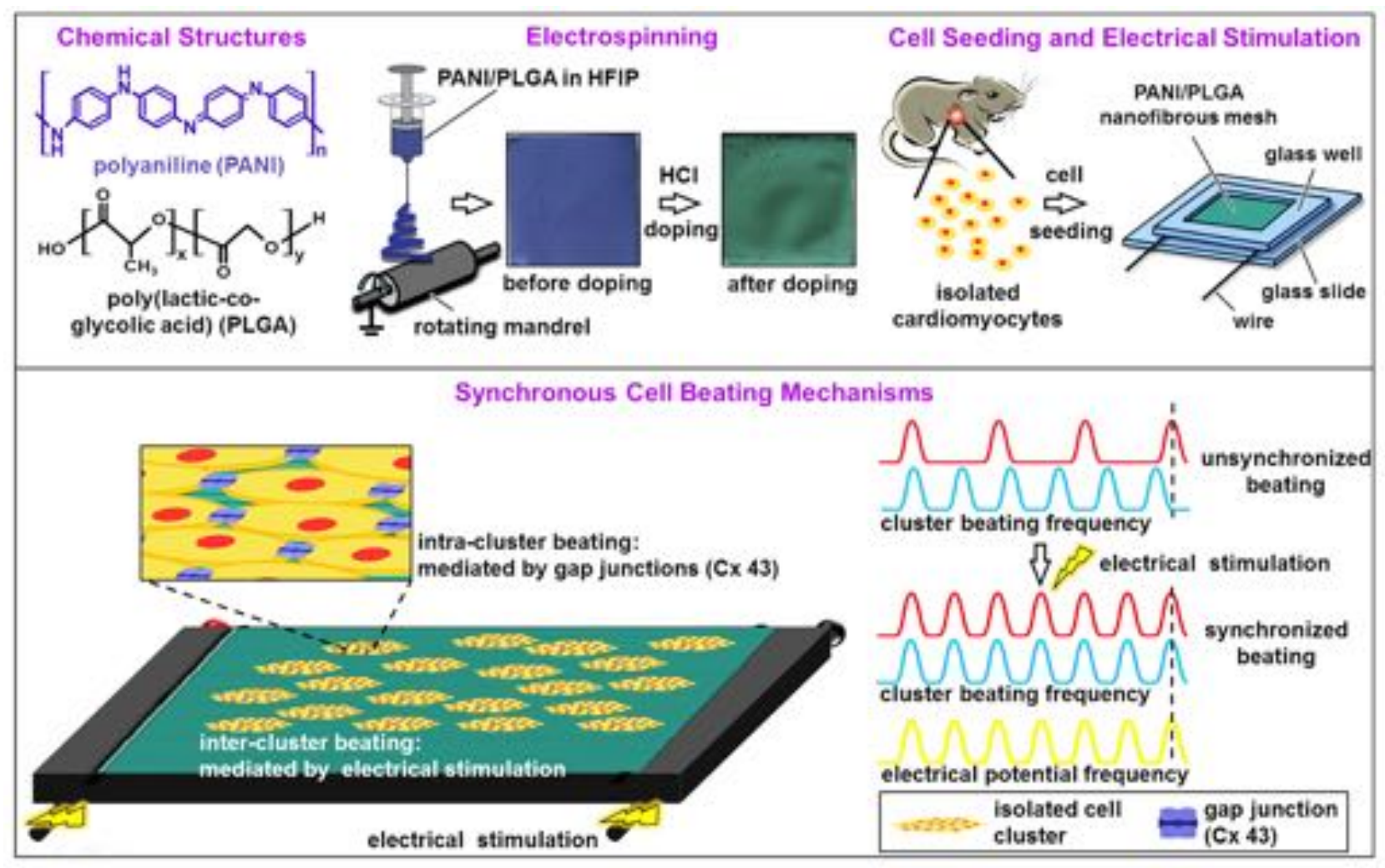

Fig. 10. Schematic diagrams on the preparation procedure of polyaniline/poly(lactic-coglycolic acid) (PANI/PLGA) nanofibrous mesh, cell sowing, electrical excitation, and synchronous cell thrashings mechanisms. Reprinted with permission from ref ${ }^{135}$. Copyright 2013 Elsevier.

PANI nanotubes are one of the most promising nanostructures for cardiac tissue regenerations because of their electroactive characteristics. Their biocompatibility and low hydrophilic characteristics can be enhanced by their functionalization with polyglycerol dendrimers ${ }^{139}$.

\subsubsection{Bone regeneration}

Evidences of clinical requests concerning the bone regeneration date back to ancient Egypt and are very important in the present age. A more rigorous scientific method has been followed since 1889 when "modern" researchers began to focus their efforts on what can be defined as the early bone tissue regeneration ${ }^{140}$. Although nowadays several hundred millions of surgical intervention per year are carried out, autograft bone still remains the current clinical gold standard for the 
treatment of critical-sized and non-union bone defects. Being advantageous for the immunocompatibility, autografts nevertheless carry a wide spectrum of risks, such as general anesthesia, complex surgical maneuvers, secondary infections, secondary fractures, pain, site morbidity, etc.; since they lead to high percentage of failure (more the 10\%) followed by important costs increases ${ }^{141-143}$. Furthermore, it is generally accepted that not all the defects can be addressed, particularly the bigger ones, as far as few healthy sites can be harvested without loss of function ${ }^{143}$. The requirement of proper bone replacements for the remodeling of native bone tissues is hence evident and sees a wide spectrum of proposed solutions related to the academia, clinics and industry ${ }^{144}$. In this framework, surgeons can choose from substitutes that can be divided into three main categories apart from autografts:

1) allografts, i.e. bone segments taken from cadavers and duly sterilized

2) xenografts, i.e. bone segments taken from animal bones (bovine, equine, porcine, etc.) duly acellularized and sterilized

3) synthetic scaffolds

Allografts derived from cadavers bone are an acceptable option. However, there are some concerns, such as diseases transmission, toxicity associated with the requirement of sterilization, immunologic rejection risks, and very high sample variability that progressively leads to other available alternatives; the challenge still remains an open scientific and clinical topic but current focus remains on autografting rather than xenografting and synthetic scaffolds ${ }^{141,142}$.

There are many different bone grafts available on the market. Bone is the second most transplanted tissue after blood. Today, no products based on PANI are currently certified for routine clinical use. Nevertheless, the use of PANI in new generation of synthetic bone scaffolds is progressively taking its way, particularly for the tissue engineering applications, i.e. where the 
use of scaffolds and stem cells is meant to provide support to restore tissue anatomy and functionality. Indeed, new highlights point towards the use of moderate content of PANI in the conductive nanofibrous scaffolds made from bioresorbable aliphatic polyesters, such as poly(lactic acid) (PLA), which significantly promotes the osteogenic differentiation of bone marrow-derived stem cells ${ }^{145}$. Similarly, osteoinductivity of polyethersulfone-based electrospun scaffolds increased by using PANI ${ }^{146}$, showing the same mechanism of action found on PLA-PANI scaffolds.

Another class of emerging resorbable biomaterials is poly-3-hydroxybutyrate (PHB). This material, doped with conductive PANI, has been tested for the preparation of the scaffolds that increase the proliferation of human mesenchymal stem cells ${ }^{147}$. The use of PANI-enhanced structure is, indeed, gaining interest in drug delivery purposes. For instance, very recently, a thin coating of PANI on lignin was developed to carry aminoglycoside gentamicin sulfate (GS) or magnetite nanoparticles loaded with GS which further deposited by the matrix-assisted pulsed laser evaporation (MAPLE) technique on titanium-based biomedical surfaces. The final purpose is to induce the multi-functional characteristics to the implantable device, e.g. the site-specific controlled delivery of the therapeutically active substance under a magnetic and/or electric field. ${ }^{148}$

\subsubsection{Nerve regeneration}

A great deal of consideration has been dedicated to the repair and regeneration approaches of the neural tissue because it straightly influences the patient's quality of life. There are several conventional and novel developed therapies to repair the damaged nerves. The development of synthetic scaffolds, which are biocompatible, 
biodegradable, conductive, immunologically inert, and infection-resistant, is necessary to support the neurite outgrowth ${ }^{149}$.

Polyaniline is applied for the preparation of the bioactive scaffolds to be used in the neural repair owing to its high electrical conductivity, good environmental stability and biocompatibility in contact with the particular cell lines containing cardiac myoblasts and rat pheochromocytoma cells (PC12) ${ }^{128,137}$. These scaffolds can electrically stimulate the cells and regulate some particular cellular activities, and therefore, affect the regeneration process of the tissues that respond to the electrical impulses.

A polyaniline/cellulose conductive composite hydrogel with a hierarchical micro/nanostructure was prepared through the interfacial polymerization technique as a scaffold material of neuron for the sciatic nerve regeneration in rats (Fig. $11 \mathrm{~A}$ to D) ${ }^{149}$. Due to the hierarchical micro/nanostructure of PANI and its electrical conductivity, the composite promoted considerably the adhesion and guided the extension of neurons, showing its high potentials for the biomedical applications.

Polyaniline/polyethyleneglycol diacrylate (PANI/PEGDA) hybrid hydrogels with a porous architecture were fabricated through in-situ precipitation of PANI in the solution of PEGDA, followed by the crosslinking via the UV irradiation. The PANI resulted in the improvement of the biological response of the human mesenchymal 
stem cells (HMSC) and PC12. It was also shown that the PANI/PEGDA hybrid materials might be utilized to design innovative devices, which are capable of a more efficient responding to an external electric field for the nerve regeneration ${ }^{150}$.

In another study, a PANI/silk fibroin nanocomposite was fabricated through electrospinning and rolling of the electrospun sheet ${ }^{151}$. The in-vitro and in-vivo biocompatibility of PANI, as well as the positive immune response or graft rejection of PANI-silk fibroin nanocomposite over a period of one year revealed the safety of scaffolds based on PANI nanocomposite. It was also shown that the outstanding electrophysiological parameters achieved after one year of implantation of nerve conduit based on PANI. Cellular recruitment and myelin thick lamellar deposition over regenerating axons inspire more in vivo investigations by the conductive polymers for developing the electrically conductive nerve conduits.

The progress of a porous scaffold by incorporating the PANI/graphene nanoparticles into a chitosan/gelatin matrix for the nerve regeneration application has also been reported. Accordingly, the electrical and mechanical properties of the PANI scaffold increased, while its porosity and water retention capacity decreased. Furthermore, the cytotoxicity test showed the largest number of attached Schwann cells on the scaffold containing 2.5 wt.\% PANI/graphene NPs ${ }^{152}$. 


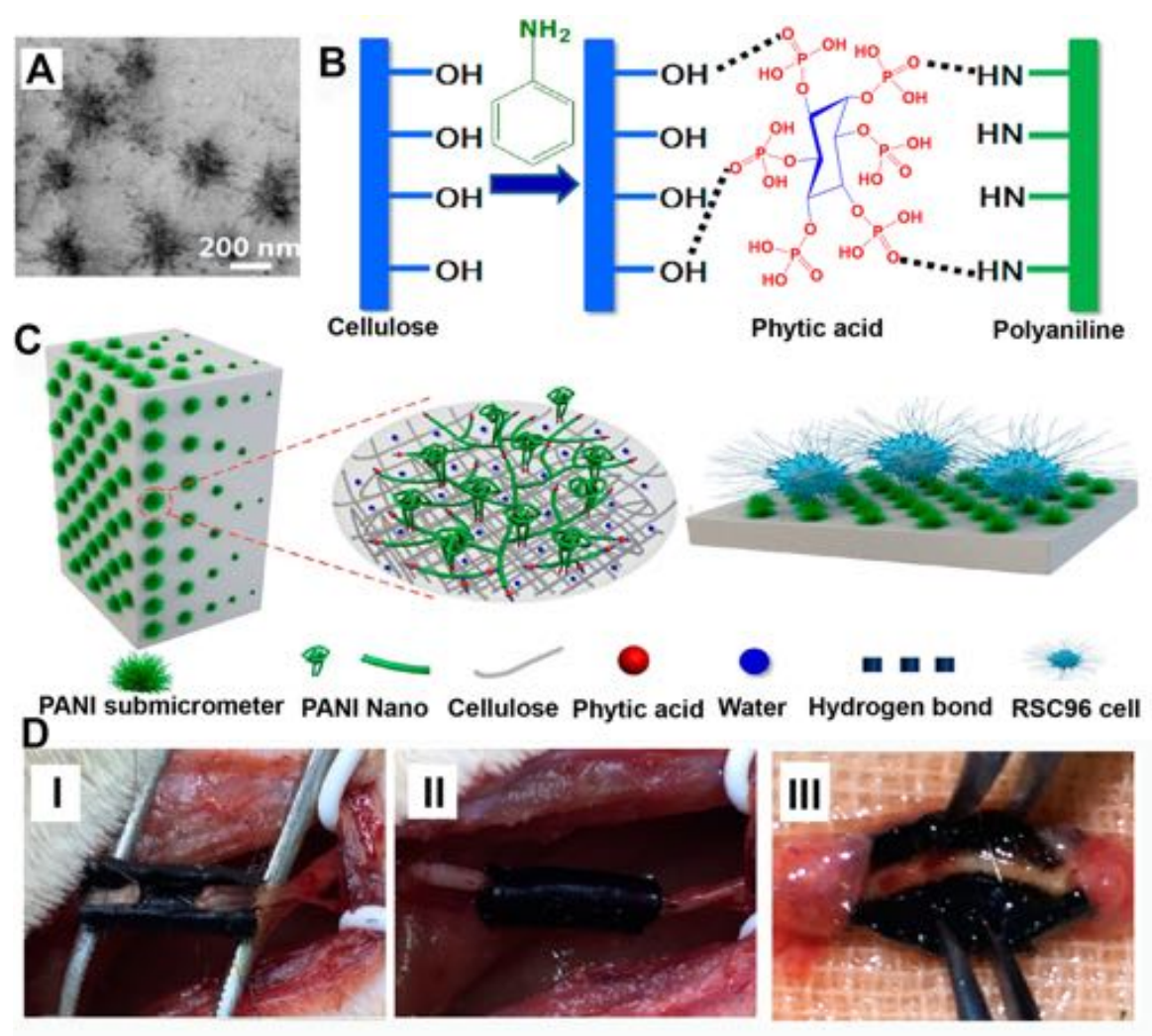

Fig. 11. (A) TEM image of the cross-section of the PANI/cellulose conductive blend. (B) Schematic illustration of the polymerization reaction of polyaniline in the presence of cellulose and phytic acid as the cross-linking agent and dopant. (C) The hierarchical micro-nano-structured polyaniline implanted in the cellulose matrix and the RSC96 cell adhesion. (D) Intraoperative image of the PANI/cellulose composite hydrogels, immediately after cutting (I), after sewing (II), and after 3 months (III). PANI/cellulose obviously speeded the injured nerve regeneration after 3 months. Reprinted from ref ${ }^{149}$. Copyright 2016 American Chemical Society.

\subsubsection{Cardiac tissue engineering}

Cardiac tissue engineering (CTE) is a developing method designed to repair and regenerate a damaged cardiac tissue by applying cellular transplantation and biomaterial 3D scaffolds ${ }^{153}$. An ideal scaffold for the CTE should be electrically conductive and biocompatible with a similar elasticity to the native myocardium ${ }^{153}$. The electroactive materials including conductive polymers, such as PANI, carbon-based nanoarchitectures, such as CNTs and graphene, and metallic nanostructures, such as Au NPs, have been developed and utilized in $\mathrm{CTE}^{153}$. 
However, chronic inflammation in the implanted tissues was reported for pure PANI. Accordingly, researchers have combined PANI with different safe polymers, e.g. from natural to synthetic ones such as gelatin, PLGA, PCL and, polyurethane, to improve its biocompatibility ${ }^{134,135,154}$. Some researchers have shown cellular interactions with PANI and its blends in CTE. For instance, nanofibrous blends of PANI and gelatin were fabricated by means of co-electrospinning, supported attachment, migration, and proliferation of cardiac myoblasts. In this regard, Hsiao et al. prepared the PANI-PLGA aligned fibers to fabricate a 3D environment for the synchronous beating of cardiomyocytes ${ }^{135}$. The cardiomyocytes formed isolated cell clusters and beat synchronously. The HCl-doped PANI improved the electrical conductivity and cell adhesion along with attracting positively charged proteins of the cell membrane. In order to achieve electrically conductive compounds, a number of studies have been conducted to introduce PANI into various materials. For instance, cardiac patches based on camphorsulfonic acid-doped conductive PANI were fabricated by solvent casting ${ }^{133}$. The patches showed high biocompatibility and led to attachment, elongation, and proliferation of $\mathrm{C} 2 \mathrm{C} 12$ myoblasts. Even after 4 days, the scaffolds conductivity was similar to the native myocardium.

Apart from the aforementioned composites and blends of PANI, the PANI containing metal/metal oxides nanostructures and carbon-based nanomaterials can be investigated for future studies. These nanofillers may be sued lonely or in combination with each other. Despite the widespread lab studies of the PANI and its blends, their use in clinical practice is still hampered by safety aspects. In order to get a complete safety profile, it is necessary to conduct clinical trials for the final products before being commercialized.

\subsection{Biosensors}


Biosensors are analytical devices that connect the biological sensing, such as monosaccharides, cells and nucleic acids, to a detector or transducer. Biomolecules response and then the detector/transducer convert the biochemical reaction as a biological response into a computable signal ${ }^{155}$. Biosensors possess three main components: a bio-recognition element, an immobilization surface such as NPs and conducting polymers, and a detector/transducer unit ${ }^{156}$.

Sensors and biosensors have found many clinical applications, such as glucose for diabetic patients, and environmental applications such as monitoring organophosphorus pesticides ${ }^{157}$.

The advent and advances in the conducting polymers heralded a novel generation of biosensors. Among all the electrically conducting polymers, PANI is of great interest because of its unique properties, such as easy and reversible doping/dedoping ability, adaptable electrical conductivity, and good stability ${ }^{158}$. Moreover, PANI displays two redox couples which ease the charge transfer between an enzyme and a polymer. Therefore, there is no need to add additional diffusional mediators to the biosensing system for the electron transfer because the PANI performs as a selfcontained electron transfer mediator. As a result, the high long-term stability for the biosensor can be achieved because the localization of the mediator to the surface of the sensor avoids the mediator leaching into the media (Fig. 12A) ${ }^{156}$. Due to great electrochemical properties and optical detection along with in vivo biocompatibility, the PANI based nanocomposites can be used to detect the negligible amount of biomolecules with high sensitivities and fast responses.

Synthesis of different nanoarchitectures of PANI including spherical particles ${ }^{159}$, rods ${ }^{160}$, wires ${ }^{161}$, tubes ${ }^{162}$, and fibers ${ }^{163}$ leads to performance improvement in sensing. For instance, the PANI nanofibers have higher sensitivity with a faster response as compared to their traditional bulk counterparts, since they contain a larger surface area and have a shorter penetration depths for the target (bio)molecule ${ }^{86}$. 


\subsubsection{Enzyme and cholesterol biosensors}

Polyaniline-based nanocomposites have been extensively used for enzymes detections, such as estimating the blood glucose level, which is important in homecare diagnostics ${ }^{8}$. For instance, conducting silica-PANI nanobeads showed a great sensitivity $\left(38.53 \mu \mathrm{A} \cdot \mathrm{mM}^{-1} \mathrm{~cm}^{2}\right)$ with an extensive linear range (from 1 to $16 \mathrm{mM}$ ) and a $96.4 \%$ glucose response current after 45 days ${ }^{164}$. The $\mathrm{TiO}_{2}$ NPs/PANI nanocomposites were also employed to achieve a good response with the detection limit of $18 \mu \mathrm{M}$ and shelf life of 30 days ${ }^{165}$. The NiO NPs/PANI nanowire/graphene oxide nanosheet composites have also been utilized for the glucose detection $\left(376.22 \mu \mathrm{A} \mathrm{mM}{ }^{-1}\right.$ $\left.\mathrm{cm}^{-2}\right)$ with a linearity range $(2-5.560 \mathrm{mM})$ in the presence of some interfering compounds, such as dopamine, uric acid and ascorbic acid ${ }^{166}$.

A 3D nanostructured hydrogels based on platinum NPs-PANI were also fabricated for the determination of glucose (Fig. 12B) ${ }^{167}$. Other types of nanostructures, such as gold NPs ${ }^{168}$, carbon nanotubes ${ }^{169}$, and copper NPs ${ }^{170}$ have been exploited for the detection of the glucose level. Apart from enzyme biosensors, PANI has been applied for the detection of other biomolecules. For instance, the electrodes based on chitosan-grafted polyaniline porous structured cryogel were utilized for the determination of sialic acid as presented in Fig. 12C ${ }^{171}$.

The development of lipids determinations, such as cholesterol biosensors, is clinically important because of hypertension, arteriosclerosis, and cardiovascular diseases. The detection of the free cholesterol is based on an oxidation reaction catalyzed by the cholesterol oxidase, a watersoluble enzyme ${ }^{172}$. Highly sensitive biosensors based on PANI, such as carbon nanotubes/PANI and PANI fibers, have been utilized for the detection of cholesterol ${ }^{173,174}$. Other biomolecules, such as triglyceride, have also been detected by using PANI-based biosensors ${ }^{156}$.

Ascorbic acid (Vitamin C) is an important analyte in the food and beverages industries and medical applications. For instance, it is a vital antioxidant in the brain. Also it is involved in some 
diseases such as diabetes mellitus ${ }^{175,176}$. Bartlett et al. used microelectrodes coated with PANIpoly(styrene sulfonate) copolymer to catalyze the ascorbate oxidation. They found that the current for the ascorbate oxidation is independent of the thickness of the coated copolymer indicating that the reaction carries out at the outer surface of the copolymer film ${ }^{177}$. However, in many studies, different conducting polymers have shown greater promises (e.g. polypyrrole family for the DNA sensors and poly(3,4-ethylenedioxythiophene) for the detection of small molecular oxidizable analytes such as dopamine, uric acid, and ascorbic acid) ${ }^{178,179}$. Nevertheless, PEDOT showed several restrictions for in-vivo applications owing to its low biocompatibility and unfunctionality required to be improved ${ }^{180}$. 

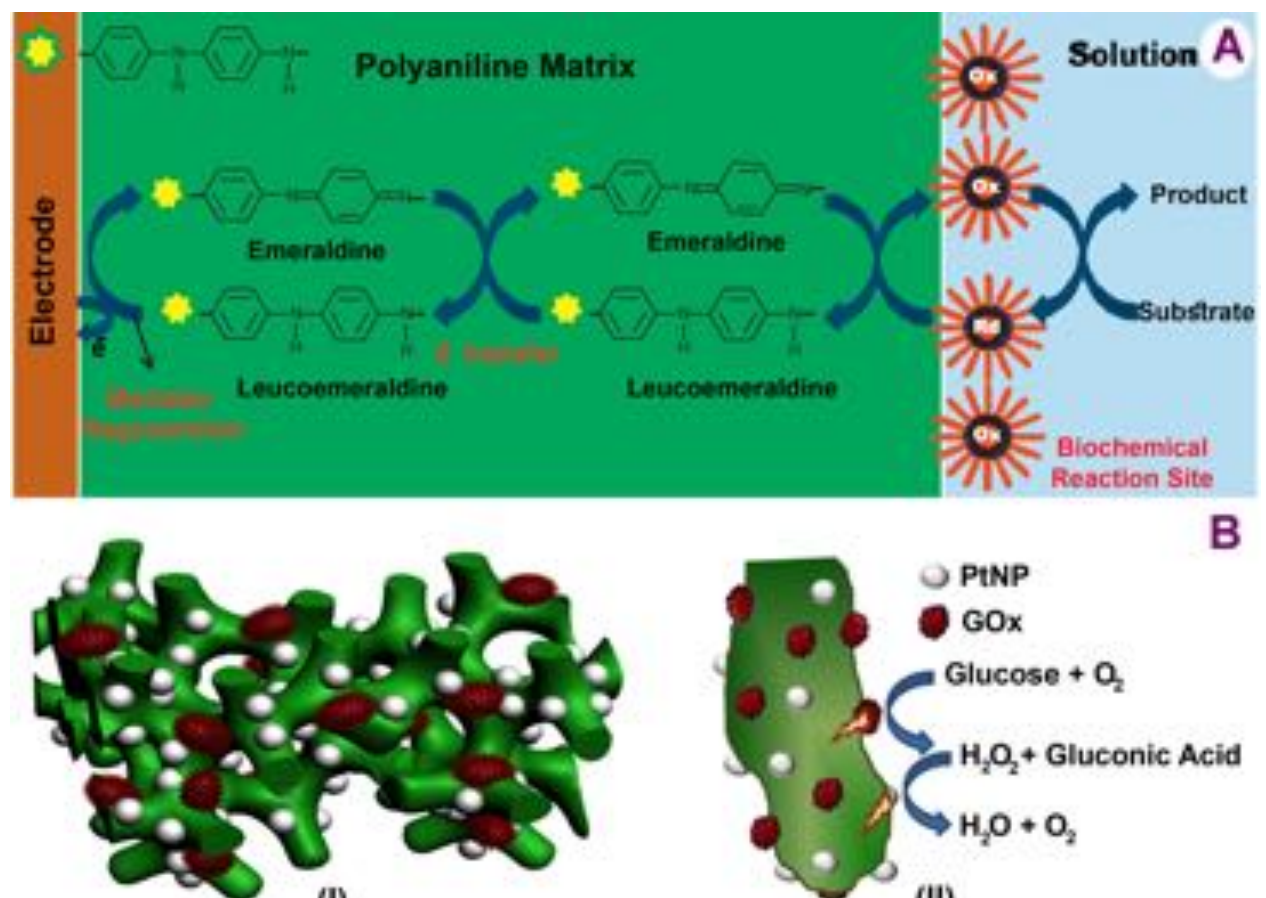

(I)
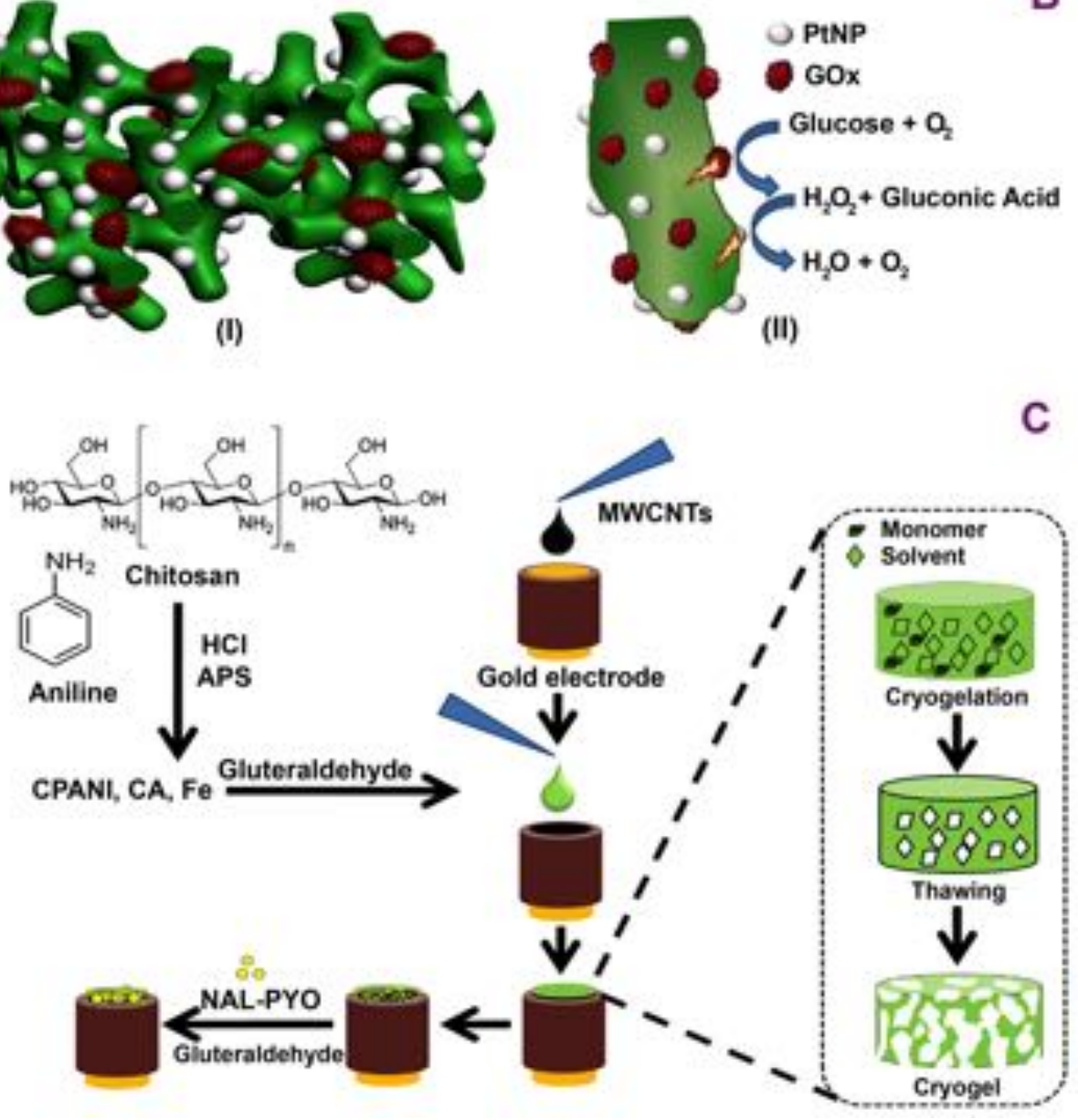

Fig. 12. (A) Schematic image of an amperometric biosensor based on polyaniline network showing electron transfer between the biochemical medium and electrode surface. Reprinted with permission from ref ${ }^{156}$. Copyright Elsevier. (B) Schematic 3D image of the Pt nanoparticles/polyaniline (PtNP/PANI) hydrogel, in which the glucose oxidase (GOx) enzyme and Pt NPs immobilized onto the PANI hydrogel matrix (I) and a 2D scheme of the PtNP/PANI-based glucose biosensor reaction mechanism (II). Reprinted from ref ${ }^{167}$. Copyright American Chemical Society. (C) Preparation of the modified electrode based on the chitosan grafted polyaniline 
(CPANI) cryogel for the immobilization of pyruvate oxidase (PYO) and $N$-acetylneuraminic acid aldolase (NAL) enzymes. Reprinted with permission from ref ${ }^{171}$. Copyright Elsevier.

\subsubsection{Hydrogen peroxide and phenolic compounds biosensors}

The determination of hydrogen peroxide is important in the food industry. PANI, due to its remarkable catalytic activity and selectivity for its substrates, is used to attain the peroxidasemodified electrodes for the preparation of the electrochemical biosensors ${ }^{8,181}$. For example, the glutaraldehyde functionalized-PANI, nanoCu-PANI-Ni foam, and silver-PANI nanotube nanocomposite with good sensitivities have been used for the $\mathrm{H}_{2} \mathrm{O}_{2}$ detection ${ }^{182,183}$.

Phenolic compounds, as toxic materials, are ubiquitous in nature and found in food, environmental and biological samples and, therefore, the detection of such compounds is vital to preserve the quality of the products ${ }^{8}$. Polyphenol oxidase, which contains copper atom(s) in its active center, have been employed for the phenol determination through the catalysis of phenol oxidation ${ }^{184}$. In regards to the types and mechanism of action, the polyphenol oxidases are of three types including tyrosinase, catechol oxidase and laccase ${ }^{184}$. In a study, polyphenol oxidase enzyme was immobilized on the PANI-activated carbon composite for the determination of phenol ${ }^{185}$.

\subsubsection{Geno- and Immuno-sensors}

Genetic material detection has found many applications in medical and forensic science. DNA determination has been used for the disease diagnosis, gene analysis, and fast detection of the biological weapons ${ }^{156,186}$. For instance, the PANI nanotubes-indium tin oxide electrode has been used as the electrochemical genosensor for the ultrasensitive detection of chronic myelogenous leukemia (detection level $\sim 1 \times 10^{-16} \mathrm{M}$ ) ${ }^{187}$. In another study, the flower-like carbon nanotubesPANI hybrid has been used for the amperometric detection of DNA with remarkable sensitivity and a wide linear detection in the range from $1 \mathrm{fM}$ to $10 \mathrm{nM}^{186}$. 
The immunosensors based on PANI are used for the interaction between antigen and antibody, i.e., the lock and key model. The development of nanotechnology has resulted in the precise immobilization of antibodies along with various types and concentration of antigen ${ }^{8,188}$. For instance, the potassium ferricyanide-doped PANI NPs have been used for the preparation of labelfree immunosensor to detect the carcinoembryonic antigen with a wide linear range $\left(1.0 \mathrm{pg} \mathrm{mL}^{-1}\right.$ to $500.0 \mathrm{ng} \mathrm{mL}^{-1}$ ) and a low detection limit of $0.1 \mathrm{pg} \mathrm{mL}^{-1} 189$. In a work conducted by $\mathrm{Li}$ et al. ${ }^{190}$, a film based on graphene nanosheets-PANI (GNS-PANI) was prepared for the synthesis of thionine/GNS-PANI/Au NPs. This immunosensor was applied for the detection of kanamycin with the detection limit of $8.6 \times 10^{-9} \mathrm{M}$. Other immunosensors based on graphene/PANI/Au nanocomposites were also used to detect tuberculosis ${ }^{191}$. Table 3 represents a summary of PANI and its nanocomposite based biosensors. 
Table 3. Summary of PANI and its nanocomposite-based biosensors.

\begin{tabular}{|c|c|c|c|c|c|}
\hline Nanostructure & Analyte & Detection Limit & $\begin{array}{c}\text { Sensitivity } \\
\left(\mu \mathrm{A} \mathrm{mM}^{-1} \mathrm{~cm}^{-2}\right)\end{array}$ & Linear range & $\begin{array}{c}\text { Reference } \\
\text { s }\end{array}$ \\
\hline PANI-poly(ethylene oxide) & Glucose & $0.82 \mathrm{mM}$ & 16.04 & 1 to $10 \mathrm{mM}$ & 192 \\
\hline $\begin{array}{l}\text { PANI/tinoxide/reduced graphene } \\
\text { oxide }\end{array}$ & Glucose & $0.047 \mathrm{ng} \mathrm{mL}^{-1}$ & N.R* & $0.1 \mathrm{ng} \mathrm{mL}^{-1}$ to $5 \mathrm{~g} \mathrm{~mL}^{-1}$ & 193 \\
\hline Ni-PANI-reduced graphene oxide & Glucose & $0.08 \mu \mathrm{M}$ & 6.050 & $0.1 \mu \mathrm{M}$ to $1.0 \mathrm{mM}$ & 194 \\
\hline Graphene-PANI & Glucose & $2.769 \mu \mathrm{M}$ & 22.1 & $10.0 \mu \mathrm{M}$ to $1.48 \mathrm{mM}$ & 195 \\
\hline $\mathrm{TiO}_{2} /$ PANI-graphene oxide & Glucose & $18 \mu \mathrm{M}$ & 6.31 & $0.02 \mathrm{mM}$ to $6.0 \mathrm{mM}$ & 165 \\
\hline Pt NPs/PANI & Glucose & $0.7 \mu \mathrm{M}$ & 96.1 & 0.01 to $8 \mathrm{mM}$ & 167 \\
\hline $\begin{array}{l}\text { Multi-walled carbon nanotubes- } \\
\text { PANI/Pt }\end{array}$ & Cholesterol & $0.8 \mu \mathrm{M}$ & 109.9 & $2.0-510.0 \mu \mathrm{M}$ & 172 \\
\hline $\begin{array}{l}\text { PANI/multi-walled carbon } \\
\text { nanotubes /starch }\end{array}$ & Cholesterol & $0.01 \mathrm{mM}$ & 800 & 0.032 to $5 \mathrm{mM}$ & 173 \\
\hline $\begin{array}{l}\text { Mesoporous PANI nanofiber } \\
\text { decorated graphene }\end{array}$ & Cholesterol & $1.93 \mathrm{mg} \mathrm{dl}^{-1}$ & $\begin{array}{l}0.101 \mu \mathrm{A} \mathrm{mg}{ }^{-1} \mathrm{dl} \\
\mathrm{cm}^{-2}\end{array}$ & 1.93 to $464.04 \mathrm{mg} \mathrm{dl}^{-1}$ & 174 \\
\hline $\begin{array}{l}\text { PANI/crystalline } \\
\text { nanocellulose/ionic liquid modified } \\
\text { Screen-Printed Electrode }\end{array}$ & Cholesterol & $0.48 \mu \mathrm{M}$ & 1 to $12 \mathrm{mM}$ & $35.19 \mu \mathrm{A} \mathrm{mM} / \mathrm{cm}^{-2}$ & 196 \\
\hline $\begin{array}{l}\text { PANI/single-walled carbon } \\
\text { nanotubes }\end{array}$ & Triglyceride & N.R. & $\begin{array}{r}4.28 \times 10^{-4} \\
\mathrm{~mA} \mathrm{mg}{ }^{-1} \mathrm{dL}\end{array}$ & 50 to $400 \mathrm{mg} \mathrm{dL}^{-1}$ & 197 \\
\hline PANI/catalase/glutaraldehyde & Hydrogen peroxide & $2.18 \times 10^{-6} \mathrm{M}$ & N.R. & $\begin{array}{l}5.0 \times 10^{-6} \text { to } \\
1.0 \times 10^{-4} \mathrm{M}\end{array}$ & 183 \\
\hline Silver/PANI nanotube & $\begin{array}{l}\text { Hydrogen } \\
\text { peroxide }\end{array}$ & $0.2 \mu \mathrm{M}$ & N.R. & 0.1 to $90 \mathrm{mM}$ & 182 \\
\hline
\end{tabular}




\begin{tabular}{|c|c|c|c|c|c|}
\hline PANI nanotubes & $\begin{array}{l}\text { Hydrogen } \\
\text { peroxide }\end{array}$ & $\begin{array}{c}3.56 \times 10^{-10} \mathrm{mg} / \mathrm{m} \\
\mathrm{L}\end{array}$ & N.R. & $\begin{array}{l}1.0 \times 10^{-9} \text { to } \\
0.10 \mathrm{mg} / \mathrm{mL}\end{array}$ & 198 \\
\hline $\begin{array}{l}\text { Gold NPs doped poly(8-anilino-1- } \\
\text { naphthalene sulphonic acid) }\end{array}$ & $\begin{array}{l}\text { Tyramine } \\
\text { (a phenolic } \\
\text { compound) }\end{array}$ & $0.71 \mu \mathrm{M}$ & N.R. & 10 to $120 \mu \mathrm{M}$ & 199 \\
\hline $\begin{array}{ll}\text { Carbon } & \text { nanotubes-PANI } \\
\text { nanohybrid } & \end{array}$ & DNA & $0.33 \mathrm{fM}$ & N.R. & $1 \mathrm{fM}$ to $10 \mathrm{nM}$ & 186 \\
\hline Gold NPs/PANI & DNA & $0.01 \mathrm{fM}$ & N.R. & 0.001 to $1000 \mathrm{pM}$ & 200 \\
\hline $\begin{array}{l}\text { Gold electrode modified with } \mathrm{Au} \\
\text { and PANI NPs }\end{array}$ & DNA & $2.5 \times 10^{-10} \mathrm{M}$ & N.R & $10^{-9}$ to $1 \times 10^{-6} \mathrm{M}$ & 201 \\
\hline PANI nanotubes & Nucleic acid & $10^{-16} \mathrm{M}$ & $1 \times 10^{-16} \mathrm{M}$ & $10^{-6}$ to $10^{-16} \mathrm{M}$ & 187 \\
\hline $\begin{array}{ll}\text { Potassium } & \text { ferricyanide-doped } \\
\text { PANI NPs } & \\
\end{array}$ & $\begin{array}{r}\text { Carcinoem- } \\
\text { bryonic antigen }\end{array}$ & $0.1 \mathrm{pg} \mathrm{mL}^{-1}$ & N.R. & $\begin{array}{l}1.0 \mathrm{pg} \mathrm{mL}^{-1} \text { to } 500.0 \mathrm{ng} \\
\mathrm{mL}^{-1}\end{array}$ & 189 \\
\hline $\begin{array}{l}\text { Graphene/PANI-Modified Screen- } \\
\text { Printed Au electrode }\end{array}$ & Tuberculosis & $15 \mathrm{ng} / \mathrm{mL}$ & N.R. & 20 to $100 \mathrm{ng} / \mathrm{mL}$ & 191 \\
\hline PANI/Au NPs & Acrylamide & $5.0 \times 10^{-11} \mathrm{M}$ & N.R. & $\begin{array}{c}5.0 \times 10-10 \mathrm{M} \text { to } 2.0 \times 10- \\
7 \mathrm{M}\end{array}$ & 202 \\
\hline $\begin{array}{l}\text { Polyamidoamine grafted } \\
\text { multiwalled carbon nanotube }\end{array}$ & Urea & $0.4 \mathrm{mM}$ & $6.6 \mathrm{nA} / \mathrm{mM}$ & 1 to $20 \mathrm{mM}$ & 203 \\
\hline PANI-cladding modified fiber & Urea & $100 \mathrm{nM}$ & N.R & $100 \mathrm{nM}$ to $100 \mathrm{mM}$ & 204 \\
\hline $\begin{array}{l}\text { PANI-encapsulated carbon } / \mathrm{Cu} \\
\text { composite nanofibers }\end{array}$ & Polyphenol & $0.24 \mu \mathrm{M}$ & $41.65 \mu \mathrm{A} \mathrm{mM}^{-1}$ & $500 \mathrm{nM}$ to $110 \mu \mathrm{M}$ & 205 \\
\hline $\begin{array}{l}\text { Poly(carboxybetaine) } \\
\text { functionalized PANI nanowires }\end{array}$ & $\begin{array}{l}\text { Carcinoembryo } \\
\text { nic antigen }\end{array}$ & $3.05 \mathrm{fg} \mathrm{mL}^{-1}$ & N.R. & $\begin{array}{c}1.0 \times 10^{-14} \text { to } \\
1.0 \times 10^{-10} \mathrm{~g} \mathrm{~mL}^{-1}\end{array}$ & 206 \\
\hline
\end{tabular}




\begin{tabular}{|c|c|c|c|c|c|}
\hline $\begin{array}{l}\text { Peptide } \\
\text { nanoparticles-PANI immobilized } \\
\text { pencil graphite electrode }\end{array}$ & $\begin{array}{l}\text { Prostate specific } \\
\text { antigen }\end{array}$ & $0.68 \mathrm{ng} / \mathrm{mL}$ & N.R. & 1 to $100 \mathrm{ng} / \mathrm{mL}$ & 207 \\
\hline $\begin{array}{l}\text { Glassy carbon electrode/PANI- } \\
\text { ZnO NPs }\end{array}$ & Dopamine & $0.153 \times 10^{-7} \mathrm{M}$ & $\begin{array}{c}0.089 \\
\mu \mathrm{A} / \mu \mathrm{M}\end{array}$ & 0.2 to $2.4 \mu \mathrm{M}$ & 208 \\
\hline $\begin{array}{l}\text { Glassy carbon electrode/PANI- } \\
\mathrm{Fe}_{3} \mathrm{O}_{4} \mathrm{NPs}\end{array}$ & Dopamine & $0.176 \times 10^{-7} \mathrm{M}$ & $0.058 \mu \mathrm{A} / \mu \mathrm{M}$ & 0.2 to $2.4 \mu \mathrm{M}$ & 208 \\
\hline $\begin{array}{l}\text { Glassy carbon electrode/PANI- } \\
\text { NiO NPs }\end{array}$ & Dopamine & $0.166 \times 10^{-7} \mathrm{M}$ & $0.078 \mu \mathrm{A} / \mu \mathrm{M}$ & 0.2 to $2.4 \mu \mathrm{M}$ & 208 \\
\hline $\begin{array}{l}\text { Molybdenum disulfide nanosheets- } \\
\text { PANI/Au NPs }\end{array}$ & Dopamine & $1 \times 10^{-6} \mathrm{M}$ & $0.0274 \mu \mathrm{A} / \mu \mathrm{M}$ & 1 to $500 \mu \mathrm{M}$ & 209 \\
\hline Graphene nanosheets/Pt/PANI & Dopamine & $3.33 \times 10^{-6} \mathrm{M}$ & 1.53 and $0.35 \mu \mathrm{A} / \mu \mathrm{M}$ & $\begin{array}{c}2.0 \text { to } 10 \text { and } \\
40 \text { to } 400\end{array}$ & 210 \\
\hline $\begin{array}{l}\text { Nitrogen-doped functionalized } \\
\text { graphene/Ag NPs/PANI }\end{array}$ & $\begin{array}{c}\text { Ascorbic acid } \\
\text { (vitamin C) }\end{array}$ & $8 \mu \mathrm{M}$ & N.R & 10 to $11.460 \mu \mathrm{M}$ & 211 \\
\hline $\begin{array}{l}\text { Indium tin oxide coated glass } \\
\text { substrate/manganese } \\
\text { phthalocyanine/PANI }\end{array}$ & $\begin{array}{l}\text { Fenitrothion } \\
\text { (a pesticide) }\end{array}$ & $0.049 \mu \mathrm{mol} \mathrm{dm}-3$ & $4.67 \mathrm{Acm}^{-2} \mathrm{M}^{-1}$ & 0.12 to $15.00 \mu \mathrm{mol} \mathrm{dm}{ }^{-3}$ & 212 \\
\hline
\end{tabular}




\section{Conclusion and perspectives}

This review presents a comprehensive overview of polyaniline and its nanocomposites, underlining advantages and properties, from structure, synthesis, physicochemical properties, to their potential in a wide spectrum of biomedical applications. Conductive polyaniline-based nanocomposites surely represent a new and promising, but not yet completely explored, area of biomaterial science where promising results and unresolved technology challenges both call for opportunities of deeper studies and developed researches. Polyanilines are, indeed, gaining a continuously increasing interest from the scientific community. However, it should be mentioned from an industrial perspective that some of these challenges have also important drawbacks on regulatory and quality assurance issues: this widely explains the relatively low amount of clinical data related to the use of PANI.

There are some major limitations such as cytotoxicity, processability, significant difference of in-vivo and in-vitro studies, and physicochemical properties on the applications of PANI and its nanocomposites into clinical practice. However, the low physical properties and biocompatibility of PANI is the main challenge in the tissue engineering applications, especially those that are aimed to be employed inside of the human body, e.g. for the bone regeneration. This issue has been moderately solved with the fabrication of PANI composites containing nanostructures, including $\mathrm{Ag}$ and $\mathrm{TiO}_{2}$, and/or biodegradable synthetic polymers, such as PCL, PLGA and PLA which improves their mechanical properties and integration into the biological tissues. Besides, non-biodegradability of the pure PANI scaffolds still restricts their applications in the tissue regeneration. Thus, a great consideration has been focused on the development of the degradable PANI blends and composites with biobased polymers. 


\section{Author information}

\section{Corresponding Authors}

Email: e.nazarzadeh@du.ac.ir \& ehsan.nazarzadehzare@gmail.com (E.N. Zare); pooyan.makvandi@ipcb.cnr.it (P. Makvandi)

\section{ORCID}

Ehsan Nazarzadeh Zare: 0000-0002-0446-4385

Pooyan Makvandi: 0000-0003-2456-0961

\section{Notes}

The authors declare no competing financial interest.

\section{Biographies}

Ehsan Nazarzadeh Zare received his $\mathrm{PhD}$ in polymer chemistry from University of Mazandaran, Iran, in 2015. He was a postdoctoral research fellow at the University of Mazandaran from May 2015 to May 2016. Currently, he is an assistant professor in polymer chemistry at Damghan University, Damghan, Iran. His current research interests include biomaterials, conductive polymers and nanocomposites, biological activities of nanocomposites, synthesis and characterization of nanomaterials.

Pooyan Makvandi received his $\mathrm{PhD}$ in polymer chemistry from University of Mazandaran, Iran, in 2017. Prior to completing $\mathrm{PhD}$, he was a visiting scholar at University of Salento, Italy, for 6 months. Currently, he is working at Institute for Polymers, Composites, and Biomaterials 
(IPCB), National Research Council (CNR) of Italy. His works focus on biomaterials for tissue regeneration, antimicrobial compounds, dental materials, nanostructures and nanocomposites.

Behnaz Ashtari received her $\mathrm{PhD}$ in nanobiotechnology from the University of Tarbiat Modaress, Tehran-Iran in 2012. She is currently working as an assistant professor at Iran University of Medical Sciences since December 2014. Her expertise is mainly focused on the design, synthesis, and evaluation of nanomaterials and microfluidic systems for various medical applications.

Filippo Rossi is Assistant Professor in Applied Physical Chemistry at Politecnico di Milano, Milano, Italy. He has worked in the field of innovative polymer materials for nanomedicine, drug delivery and tissue engineering with experimental and model studies.

Ahmad Motahari received his $\mathrm{PhD}$ in physical chemistry from the University of Mazandaran, Iran. He has worked on the structural studies of nanoporous materials and nanocomposites using small angle X-ray scattering (SAXS) as a visiting research scholar at the University of Cincinnati, USA. Also, he has worked as a postdoctoral researcher at Sharif University of Technology, Iran. His current research interests are polymer nanocomposites, nanoporous materials, and computational chemistry.

Giuseppe Perale is full professor in biomaterials at University of Applied Sciences and Arts of Southern Switzerland, Switzerland. He has worked in the field of materials and technologies for biomedical applications, particularly in the field of tissue engineering and controlled drug delivery. His research and experimental activities are devoted to theoretical investigations and development of feasible solutions for in vivo human applications, aiming both at achieving new knowledge and developing industrially-scaled processes for applicable medical devices. 


\section{Abbreviation used}

APS, Ammonium persulfate; CNTs, Carbon nano-tubes; CTE, Cardiac tissue engineering; CS-g-AT, Chitosan-graft-aniline tetramer; DMF, Dimethyl formamide; DMSO, Dimethyl sulfoxide; DPPH, 1,1-diphenyl-2-picrylhydrazyl; EC50, Half maximal effective concentration; EM, Emeraldine; EM-B, Emeraldine-base; EM-S, Emeraldine-salt; ER, Electrorheological; GNS, Graphene nanosheets; GS, Gentamicin sulfate; HaCaT, Human keratinocyte; HEK, Human embryonic kidney, HMSC, Human mesenchymal stem cells; ICPs, Inherently conducting polymers; KPS, Potassium persulfate; LE, Leucoemeraldine; MAA, Methacrylic acid; MAPLE, Matrix-assisted pulsed laser evaporation; MMP, Mitochondrial membrane potential; MPP, Modified polypropylene; MTT, 3-(4,5-dimethylthiazol-2-yl)-2,5diphenyltetrazolium bromide; NIH/3T3, Mouse embryonic fibroblast; NIR, Near-infrared; NMP, N-methyl-2-pyrrolidone; ND, Nanodiamond; NPs, Nanoparticles; PANI, Polyaniline; P3ABA, Poly(3-aminobenzoic acid); Pas, Polyacetylene; PC12, Pheochromocytoma cells; PCL, Polycaprolactone; PEGDA, Polyethyleneglycol diacrylate; PEG-DA, Dibenzaldehydeterminated poly(ethylene glycol); PEO, Poly (ethylene oxide); PHB, Poly-3-hydroxybutyrate; PFu, Polyfuran; PG, Pernigraniline; PLA, Poly(lactic acid); PLGA, Poly(lactic-co-glycolic acid); PNIPAm, Poly(N-isopropylacrylamide); PPy, Polypyrrole; PSiNPs, Porous silicon nanoparticles; PTh, Polythiophene; $p$ TSA, Para-toluene sulfonic acid; PUF, Polyurethane foam; PXT, Polyxanthonetriazole; rGO, Reduced graphene oxide; ROS, Reactive oxygen species; RRS, Reactive radical species; ROS, reactive oxygen species; SDDS, Smart drug delivery systems; STPU, Siloxane terminated polyurethane; THF, Tetrahydrofuran; UA, Usnic acid; 


\section{References}

(1) Su, W. Principles of Polymer Design and Synthesis, 1st ed.; Carpenter, B., Ceroni, P., Kirchner, B., Koskinen, A., Landfester, K., Leszczynski, J., Luh, T., Mahlke, C., N. C. Polfer, Gainesville FL, U., R. Salzer, Dresden, G., Eds.; Springer Heidelberg: New York, 2013.

(2) Huang, J.; B. Kaner, R. Conjugated Polymers: Theory, Synthesis, Properties, and Characterization, 3rd ed.; Skotheim, T. A., Reynolds, J., Eds.; CRC press: Boca Raton, 2006.

(3) Kiristi, M.; Uygun, A. Polyaniline. In Handbook of Engineering and Specialty Thermoplastics; Thomas, S., Visakh, P. M., Eds.; Wiley Online Library: Salem, Massachusetts., 2011; Vol. 4, pp 183-210.

(4) Zare, E. N.; Lakouraj, M. M.; Moghadam, P. N.; Azimi, R. Novel Polyfuran/Functionalized Multiwalled Carbon Nanotubes Composites With Improved Conductivity: Chemical Synthesis, Characterization, and Antioxidant Activity. Polym. Compos. 2013, 34, 732-739.

(5) Kaur, G.; Adhikari, R.; Cass, P.; Bown, M.; Gunatillake, P. Electrically Conductive Polymers and Composites for Biomedical Applications. RSC Adv. 2015, 5, 3755337567.

(6) Norouzian, R.-S.; Lakouraj, M. M.; Zare, E. N. Novel Conductive PANI/Hydrophilic Thiacalix[4]Arene Nanocomposites: Synthesis, Characterization and Investigation of Properties. Chinese J. Polym. Sci. 2014, 32 (2), 218-219.

(7) Moghadam, P. N.; Zareh, E. N. Synthesis of Conductive Nanocomposites Based on Polyaniline/Poly(Styrene- Alt-Maleic Anhydride)/Polystyrene. E-Polymers 2010, 054, $1-10$.

(8) Oves, M.; Shahadat, M.; Ansari, S. A.; Aslam, M. Polyaniline Nanocomposite Materials for Biosensor Designing. In Electrically Conductive Polymer and Polymer Composites: From Synthesis to Biomedical Applications; Khan, A., Jawaid, M., Khan, A. A. P., Asiri, A. M., Eds.; Wiley-VCH Verlag: Weinheim, 2018; pp 113-135.

(9) Nezakati, T.; Seifalian, A.; Tan, A.; Seifalian, A. M. Conductive Polymers : Opportunities and Challenges in Biomedical Applications. Chem. Rev. 2018, 118, 67666843.

(10) Bhandari, S. Polyaniline: Structure and Properties Relationship. In Polyaniline Blends, Composites, and Nanocomposites; P.M. Visakh, Pina, C. Della, Falletta, E., Eds.; Elsevier: Amsterdam, Netherlands, 2018; pp 23-60. 
(11) Itoi, H.; Hayashi, S.; Matsufusa, H.; Ohzawa, Y. Electrochemical Synthesis of Polyaniline in the Micropores of Activated Carbon for High-Performance Electrochemical Capacitors. Chem. Commun. 2017, 53 (22), 3201-3204.

(12) Menon, R.; Mukherjee, A. K. Polyaniline Fractal Nanocomposites. Encycl. Nanosci. Nanotechnol. 2004, 8, 715-729.

(13) Freitas, T. V; Sousa, E. A.; Jr, G. C. F.; Arlindo, E. P. S. Different Morphologies of Polyaniline Nanostructures Synthesized by Interfacial Polymerization. Mater. Lett. 2018, 224, 42-45.

(14) Tian, Z.; Yu, H.; Wang, L.; Saleem, M.; Ren, F.; Ren, P. Recent Progress in the Preparation of Polyaniline Nanostructures and Their Applications in Anticorrosive Coatings. RSC Adv. 2014, 4, 28195-28208.

(15) Peng, H.; Ma, G.; Sun, K.; Mu, J.; Lei, Z. A Novel Fabrication of Nitrogen-Containing Carbon Nanospheres with High Rate Capability as Electrode Materials for Supercapacitors. RSC Adv. 2015, 5, 12034-12042.

(16) Dong, Y.; Zhou, Y.; Ding, Y.; Wang, C. Sensitive Detection of Pb(II) at Gold Nanoparticle/ Polyaniline/Graphene Modified Electrode Using Differential Pulse Anodic Stripping Voltammetry. Anal. Methods 2014, 6, 9367-9374.

(17) Zujovic, Z. D.; Bowmaker, G. A.; Tran, H. D.; Kaner, R. B. Solid-State NMR of Polyaniline Nanofibers. Synth. Met. 2009, 159, 710-714.

(18) Sim, B.; Choi, H. J. Facile Synthesis of Polyaniline Nanotubes and Their Enhanced Stimuli-Response under Electric Field. RSC Adv. 2015, 5, 11905-11912.

(19) Yin, C.; Gao, L.; Zhou, F.; Duan, G. Facile Synthesis of Polyaniline Nanotubes Using Self-Assembly Method Based on the Hydrogen Bonding : Mechanism and Application in Gas Sensing. Polymers (Basel). 2017, 9 (544), 1-14.

(20) Moghadam, P. N.; Zare, E. N.; Amiri, H.; Lakouraj, M. M. Preparation of Conductive Nanocomposites Based on Poly (Aniline- Co- Butyl 3-Aminobenzoate) and Poly (Aniline-Co-Ethyl 3-Aminobenzoate) by Solution Blending Method. Compos. Interfaces 2012, 19 (8), 457-488.

(21) I. Kong, K. Y. Tshai, M. E. H. Manufacturing of Natural Fibre-Reinforced Polymer Composites by Solvent Casting Method. In Manufacturing of natural fibre reinforced polymer composites; Salit, M. S., Jawaid, M., Yusoff, N. Bin, Hoque, M. E., Eds.; Springer: Switzerland, 2015; pp 331-349.

(22) Zare, E. N.; Lakouraj, M. M. Biodegradable Polyaniline / Dextrin Conductive Nanocomposites: Synthesis, Characterization, and Study of Antioxidant Activity and 
Sorption of Heavy Metal Ions. Iran. Polym. J. 2014, 23, 257-266.

(23) Zhan, C.; Yu, G.; Lu, Y.; Wang, L.; Wujcik, E.; Wei, S. Conductive Polymer Nanocomposites: A Critical Review of Modern Advanced Devices. J. Mater. Chem. C 2017, 5 (7), 1569-1585.

(24) Pierini, F.; Lanzi, M.; Nakielski, P.; Kowalewski, T. A. Electrospun Polyaniline-Based Composite Nanofibers: Tuning the Electrical Conductivity by Tailoring the Structure of Thiol-Protected Metal Nanoparticles. J. Nanomater. 2017, 2017, 1-10.

(25) Kaur, M.; Malik, B.; Garg, T.; Rath, G.; Goyal, A. K. Development and Characterization of Guar Gum Nanoparticles for Oral Immunization against Tuberculosis. Drug Deliv. 2015, 22 (3), 328-334.

(26) Khalid, M.; Tumelero, M. A.; Brandt, I. S.; Zoldan, V. C.; Acuña, J. J. S.; Pasa, A. A. Electrical Conductivity Studies of Polyaniline Nanotubes Doped with Different Sulfonic Acids. Indian J. Mater. Sci. 2013, 2013, 1-7.

(27) Kakde, K. P. Synthesis and Characterization of Polyaniline Doped with HCl , H2SO4 and PVA as Secondary Dopant for Toxic Gas ( Ammonia ) Sensor. Indian J. Sci. Technol. 2017, 10, 1-4.

(28) Zare, E. N.; Abdollahi, T.; Motahari, A. Effect of Functionalization of Iron Oxide Nanoparticles on the Physical Properties of Poly (Aniline-Co-Pyrrole) Based Nanocomposites: Experimental and Theoretical Studies. Arab. J. Chem. 2018. https://doi.org/10.1016/j.arabjc.2018.04.016.

(29) Gholami, H.; Shakeri, A.; Saadattalab, V. Investigation of Physical and Mechanical Properties of Polyaniline/MMT Nanocomposites. Curr. Chem. Lett. 2017, 6, 151-158.

(30) Bilal, S.; Arif, M.; Khan, M. S.; Shah, A.-H. A. Characterization of Sodium and Potassium Nitrate Contaminated Polyaniline-Poly (Ethylene Oxide) Composites Synthesized via Facile Solution Casting Technique. Materials (Basel). 2019, 12 (13), $2168-2182$.

(31) Gangopadhyay, R. Exploring Rheological Properties of Aqueous Polyaniline-PVP Dispersion. J. Polym. Sci. Part B Polym. Phys. 2008, 46 (22), 2443-2455.

(32) Wang, H.; Wen, H.; Hu, B.; Fei, G.; Shen, Y.; Sun, L.; Yang, D. Facile Approach to Fabricate Waterborne Polyaniline Nanocomposites with Environmental Benignity and High Physical Properties. Sci. Rep. 2017, 7, 43694(1-12).

(33) Sirqueira, A. da S.; Teodoro Júnior, D.; Coutinho, M. da S.; Neto, S.; Silva, A. dos A.; Soares, B. G. Rheological Behavior of Acrylic Paint Blends Based on Polyaniline. Polímeros 2016, 26 (3), 215-220. 
(34) Makvandi, P.; Ali, G. W.; Della Sala, F.; Abdel-Fattah, W. I.; Borzacchiello, A. Biosynthesis and Characterization of Antibacterial Thermosensitive Hydrogels Based on Corn Silk Extract, Hyaluronic Acid and Nanosilver for Potential Wound Healing. Carbohydr. Polym. 2019, 223, 115023-115035.

(35) Zhao, X.; Li, P.; Guo, B.; Ma, P. X. Antibacterial and Conductive Injectable Hydrogels Based on Quaternized Chitosan-Graft-Polyaniline / Oxidized Dextran for Tissue Engineering. Acta Biomater. 2015, 26, 236-248.

(36) Zhao, X.; Wu, H.; Guo, B.; Dong, R.; Qiu, Y.; Ma, P. X. Antibacterial Anti-Oxidant Electroactive Injectable Hydrogel as Self-Healing Wound Dressing with Hemostasis and Adhesiveness for Cutaneous Wound Healing. Biomaterials 2017, 122, 34-47.

(37) Fang, F. F.; Lee, B. M.; Choi, H. J. Electrorheologically Intelligent Polyaniline and Its Composites. Macromol. Res. 2010, 18 (2), 99-112.

(38) Kaur, A.; Kaur, A.; Saini, D. A Review on Synthesis of Silica Nanocomposites With Conducting Polymers: Polyaniline. Res. Cell Int. J. Eng. Sci 2016, 6913, 40-53.

(39) Zareh, E. N.; Moghadam, P. N.; Azariyan, E.; Sharifian, I. Conductive and Biodegradable Polyaniline/Starch Blends and Their Composites With Polystyrene. Iran. Polym. J. 2011, 20 (4), 319-328.

(40) Guo, B.; Glavas, L.; Albertsson, A. Biodegradable and Electrically Conducting Polymers for Biomedical Applications. Prog. Polym. Sci. 2013, 38, 1263-1286.

(41) Guo, B.; Ma, P. X. Synthetic Biodegradable Functional Polymers for Tissue Engineering: A Brief Review. Sci. China Chem. 2014, 57 (4), 490-500.

(42) Xia, B.; Wang, B.; Shi, J.; Zhang, Y.; Zhang, Q.; Chen, Z.; Li, J. Photothermal and Biodegradable Polyaniline / Porous Silicon Hybrid Nanocomposites as Drug Carriers for Combined Chemo-Photothermal Therapy of Cancer. Acta Biomater. 2017, 51, 197208.

(43) Luo, Y.-L.; Nan, Y.-F.; Xu, F.; Chen, Y.-S.; Zhao, P. Degradation Behavior and Biocompatibility of PEG/PANI-Derived Polyurethane Co-Polymers. J. Biomater. Sci. Polym. Ed. 2010, 21 (8-9), 1143-1172.

(44) Sarvari, R.; Akbari-Alanjaraghi, M.; Massoumi, B.; Beygi-Khosrowshahi, Y.; Agbolaghi, S. Conductive and Biodegradable Scaffolds Based on a Five-Arm and Functionalized Star-like Polyaniline-polycaprolactone Copolymer with Ad-Glucose Core. New J. Chem. 2017, 41 (14), 6371-6384.

(45) Humpolicek, P.; Kasparkova, V.; Saha, P.; Stejskal, J. Biocompatibility of Polyaniline. Synth. Met. 2012, 162 (7-8), 722-727. 
(46) Humpolíček, P.; Kašpárková, V.; Pacherník, J.; Stejskal, J.; Bober, P.; Capáková, Z.; Radaszkiewicz, K. A.; Junkar, I.; Lehocký, M. The Biocompatibility of Polyaniline and Polypyrrole: A Comparative Study of Their Cytotoxicity, Embryotoxicity and Impurity Profile. Mater. Sci. Eng. C 2018, 91 (May), 303-310.

(47) Zhang, X.; Qi, H.; Wang, S.; Feng, L.; Ji, Y.; Tao, L.; Li, S.; Wei, Y. Cellular Responses of Aniline Oligomers: A Preliminary Study. Toxicol. Res. (Camb). 2012, 1 (3), 201-205.

(48) Bairi, V. G.; Bourdo, S. E.; Moore, J. A.; Schnackenberg, L. K.; Berry, B. C.; Biris, A. S.; Viswanathan, T. Separation and Spectroscopic/Molecular Weight Analysis of Crude and Purified Polyaniline (S). J. Polym. Res. 2013, 20 (7), 193-201.

(49) Stejskal, J.; Hajná, M.; Humpolí , P.; Zhigunov, A.; Trchová, M. Purification of a Conducting Polymer, Polyaniline, for Biomedical Applications. Synth. Met. 2014, 195, 286-293.

(50) Liu, S.; Wang, J.; Zhang, D.; Zhang, P.; Ou, J.; Liu, B.; Yang, S. Investigation on Cell Biocompatible Behaviors of Polyaniline Film Fabricated via Electroless Surface Polymerization. Appl. Surf. Sci. 2010, 256 (11), 3426-3430.

(51) Humpolíček, P.; Radaszkiewicz, K. A.; Capáková, Z.; Pacherník, J.; Bober, P.; Kašpárková, V.; Rejmontová, P.; Lehocký, M.; Ponížil, P.; Stejskal, J. Polyaniline Cryogels: Biocompatibility of Novel Conducting Macroporous Material. Sci. Rep. 2018, $8(1), 1-12$.

(52) Kucekova, Z.; Humpolicek, P.; Kasparkova, V.; Perecko, T. Colloidal Polyaniline Dispersions: Antibacterial Activity, Cytotoxicity and Neutrophil Oxidative Burst. Colloids surfaces B Biointerfaces 2014, 116, 411-417.

(53) Li, Y.; Chen, B.; Li, X.; Zhang, W. K.; Tang, H. Cytotoxicity of Polyaniline Nanomaterial on Rat Celiac Macrophages In Vitro. PLoS One 2014, 9 (9), 1-6.

(54) Ibarra, L. E.; Tarres, L.; Bongiovanni, S.; Barbero, C. A.; Kogan, M. J.; Rivarola, V. A.; Bertuzzi, M. L.; Yslas, E. I. Assessment of Polyaniline Nanoparticles Toxicity and Teratogenicity in Aquatic Environment Using Rhinella Arenarum Model. Ecotoxicol. Environ. Saf. 2015, 114, 84-92.

(55) Yslas, E. I.; Ibarra, L. E.; Peralta, D. O.; Barbero, C. A.; Rivarola, V. A.; Bertuzzi, M. L. Polyaniline Nanofibers: Acute Toxicity and Teratogenic Effect on Rhinella Arenarum Embryos. Chemosphere 2012, 87 (11), 1374-1380.

(56) Rossetto, A. L. de O. F.; Vicentini, D. S.; Costa, C. H.; Melegari, S. P.; Matias, W. G. Synthesis, Characterization and Toxicological Evaluation of a Core-Shell Copper Oxide/Polyaniline Nanocomposite. Chemosphere 2014, 108, 107-114. 
(57) Saikia, J. P.; Banerjee, S.; Konwar, B. K.; Kumar, A. Biocompatible Novel Starch/Polyaniline Composites: Characterization, Anti-Cytotoxicity and Antioxidant Activity. Colloids Surfaces B Biointerfaces 2010, 81 (1), 158-164.

(58) Maráková, N.; Humpolíček, P.; Kašpárková, V.; Capáková, Z.; Martinková, L.; Bober, P.; Trchová, M.; Stejskal, J. Antimicrobial Activity and Cytotoxicity of Cotton Fabric Coated with Conducting Polymers, Polyaniline or Polypyrrole, and with Deposited Silver Nanoparticles. Appl. Surf. Sci. 2017, 396, 169-176.

(59) Villalba, P.; Ram, M. K.; Gomez, H.; Bhethanabotla, V.; Helms, M. N.; Kumar, A.; Kumar, A. Cellular and in Vitro Toxicity of Nanodiamond-Polyaniline Composites in Mammalian and Bacterial Cell. Mater. Sci. Eng. C 2012, 32 (3), 594-598.

(60) Tiwari, A.; Sharma, Y.; Hattori, S.; Terada, D.; Sharma, A. K.; Turner, A. P. F.; Kobayashi, H. Influence of Poly(n-Isopropylacrylamide)-CNT-Polyaniline ThreeDimensional Electrospun Microfabric Scaffolds on Cell Growth and Viability. Biopolymers 2013, 99 (5), 334-341.

(61) Nam, H.; An, T.; Lim, G. Cell Behaviour on a Polyaniline Nanoprotrusion Structure Surface. Nanoscale Res. Lett. 2014, 9 (1), 566-572.

(62) Shahadat, M.; Khan, M. Z.; Rupani, P. F.; Embrandiri, A.; Sultana, S.; Ahammad, S. Z.; Ali, S. W.; Sreekrishnan, T. R. A Critical Review on the Prospect of Polyaniline-Grafted Biodegradable Nanocomposite. Adv. Colloid Interface Sci. 2017, 249, 2-16.

(63) Gizdavic-nikolaidis, M. R.; Bennett, J. R.; Swift, S.; Easteal, A. J.; Ambrose, M. Broad Spectrum Antimicrobial Activity of Functionalized Polyanilines. Acta Biomater. 2011, 7 (12), 4204-4209.

(64) Hou, Y.; Feng, J.; Wang, Y.; Li, L. Enhanced Antibacterial Activity of Ag-Doped ZnO / Polyaniline Nanocomposites. J. Mater. Sci. Mater. Electron. 2016, 27 (7), 6615-6622.

(65) Qi, K.; Cheng, B.; Yu, J.; Ho, W. Review on the Improvement of the Photocatalytic and Antibacterial Activities of ZnO. J. Alloys Compd. 2017, 727, 792-820.

(66) Tanushree Sen, Satyendra Mishra, N. G. S. Synthesis and Sensing Applications of Polyaniline Nanocomposites : A Review. RSC Adv. 2016, 6, 42196-42222.

(67) Youssef, A. M.; Moustafa, H. A.; Barhoum, A.; Hakim, A. E. A. A.; Dufresne, A. Evaluation of the Morphological, Electrical and Antibacterial Properties of Polyaniline Nanocomposite Based on Zn/Al-Layered Double Hydroxides. ChemistrySelect 2017, 2 (27), 8553-8566.

(68) Liang, X.; Govindaraju, S.; Yun, K. Dual Applicability of Polyaniline Coated Gold Nanorods: A Study of Antibacterial and Redox Activity. BioChip J. 2018, 12 (2), 137- 
145.

(69) Zhao, S.; Huang, L.; Tong, T.; Zhang, W.; Wang, Z.; Wang, J.; Wang, S. Antifouling and Antibacterial Behavior of Polyethersulfone Membrane Incorporating Polyaniline@ Silver Nanocomposites. Environ. Sci. Water Res. Technol. 2017, 3 (4), 710-719.

(70) Zahed, F. M.; Hatamluyi, B.; Lorestani, F.; Es'haghi, Z. Silver Nanoparticles Decorated Polyaniline Nanocomposite Based Electrochemical Sensor for the Determination of Anticancer Drug 5-Fluorouracil. J. Pharm. Biomed. Anal. 2018, 161, 12-19.

(71) Eren, O.; Ucar, N.; Onen, A.; Kizildag, N.; Karacan, I. Synergistic Effect of Polyaniline, Nanosilver, and Carbon Nanotube Mixtures on the Structure and Properties of Polyacrylonitrile Composite Nanofiber. J. Compos. Mater. 2016, 50 (15), 2073-2086.

(72) Masim, F. C. P.; Tsai, C.-H.; Lin, Y.-F.; Fu, M.-L.; Liu, M.; Kang, F.; Wang, Y.-F. Synergistic Effect of PANI-ZrO2 Composite as Antibacterial, Anti-Corrosion, and Phosphate Adsorbent Material: Synthesis, Characterization and Applications. Environ. Technol. 2019, 40 (2), 226-238.

(73) Monjezi, J.; Jamaledin, R.; Ghaemy, M.; Makvandi, P. Antimicrobial ModifiedTragacanth Gum / Acrylic Acid Hydrogels for the Controlled Release of Quercetin. $J$. Appl. Chem. Res. 2019, 131 (1), 57-71.

(74) Makvandi, P.; Corcione, C. E.; Paladini, F.; Gallo, A. L.; Montagna, F.; Maffezzoli, A. Antimicrobial Modified Hydroxyapatite Composite Dental Bite by Stereolithography. Polym Adv Technol 2018, 29, 364-371.

(75) Yan, L.; Wang, R.; Wang, H.; Sheng, K.; Liu, C.; Qu, H.; Ma, A.; Zheng, L. Formulation and Characterization of Chitosan Hydrochloride and Carboxymethyl Chitosan Encapsulated Quercetin Nanoparticles for Controlled Applications in Foods System and Simulated Gastrointestinal Condition. Food Hydrocoll. 2018, 84, 450-457.

(76) Lukman, S. K.; Saidin, S. Antibacterial Effect of Ginseng/Polyaniline Encapsulated in Poly (Lactic-Co-Glycolic Acid) Microcapsules Coating on Stainless Steel 316L. In MATEC Web of Conferences; EDP Sciences, 2019; Vol. 253, p 3001.

(77) Robertson, J.; Gizdavic-Nikolaidis, M.; Swift, S. Investigation of Polyaniline and a Functionalised Derivative as Antimicrobial Additives to Create Contamination Resistant Surfaces. Materials (Basel). 2018, 11 (3), 436-461.

(78) Robertson, J.; Gizdavic-Nikolaidis, M.; Nieuwoudt, M. K.; Swift, S. The Antimicrobial Action of Polyaniline Involves Production of Oxidative Stress While Functionalisation of Polyaniline Introduces Additional Mechanisms. PeerJ 2018, 6, e5135-e5171.

(79) Hasantabar, V.; Lakouraj, M. M.; Zare, E. N.; Mohseni, M. Synthesis, Characterization, 
and Biological Properties of Novel Bioactive Poly(Xanthoneamide-TriazoleEthersulfone) and Its Multifunctional Nanocomposite with Polyaniline. Adv. Polym. Technol. 2017, 36 (3), 309-319.

(80) Gizdavic-nikolaidis, M.; Travas-sejdic, J.; Bowmaker, G. A.; Cooney, R. P.; Thompson, C.; Kilmartin, P. A. The Antioxidant Activity of Conducting Polymers in Biomedical Applications. Curr. Appl. Phys. 2004, 4, 347-350.

(81) Prasad, J.; Banerjee, S.; Kumar, B.; Kumar, A. Biocompatible Novel Starch / Polyaniline Composites: Characterization, Anti-Cytotoxicity and Antioxidant Activity. Colloids Surfaces B Biointerfaces 2010, 81 (1), 158-164.

(82) Kumar, A.; Banerjee, S.; Saikia, J. P.; Konwar, B. K. Swift Heavy Ion Irradiation Induced Enhancement in the Antioxidant Activity and Biocompatibility of Polyaniline Nanofibers. Nanotechnology 2010, 21, 175102-175110.

(83) Parsa, A.; Salout, S. A. Investigation of the Antioxidant Activity of Electrosynthesized Polyaniline / Reduced Graphene Oxide Nanocomposite in a Binary Electrolyte System on ABTS and DPPH Free Radicals. J. Electroanal. Chem. 2016, 760, 113-118.

(84) Zare, E. N.; Motahari, A.; Sillanpää, M. Nanoadsorbents Based on Conducting Polymer Nanocomposites with Main Focus on Polyaniline and Its Derivatives for Removal of Heavy Metal Ions/Dyes: A Review. Environmental Research. 2018, pp 173-195.

(85) Bertuoli, P. T.; Baldissera, A. F.; Zattera, A. J.; Ferreira, C. A. Progress in Organic Coatings Polyaniline Coated Core-Shell Polyacrylates : Control of Fi Lm Formation and Coating Application for Corrosion Protection. Prog. Org. Coatings 2019, 128, 40-51.

(86) Yassin, M. A.; Shrestha, S.; Park, C. H.; Kim, C. S. Exfoliated Nanosheets of Co3O4 Webbed with Polyaniline Nanofibers: A Novel Composite Electrode Material for Enzymeless Glucose Sensing Application. J. Ind. Eng. Chem. 2019, 73, 106-117.

(87) Srisuk, P.; Berti, F. V; da Silva, L. P.; Marques, A. P.; Reis, R. L.; Correlo, V. M. Electroactive Gellan Gum/Polyaniline Spongy-like Hydrogels. ACS Biomater. Sci. Eng. 2018, 4 (5), 1779-1787.

(88) Ismayil, K. M. M.; Varghese, A.; Antony, R. Silver-Doped Polyaniline-polyvinyl Chloride Nanocomposite Films for Photocatalytic and Antibacterial Applications. $J$. Elastomers Plast. 2019. https://doi.org/10.1177/0095244318819238.

(89) Baker, C. O.; Huang, X.; Nelson, W.; Kaner, R. B. Polyaniline Nanofibers: Broadening Applications for Conducting Polymers. Chem. Soc. Rev. 2017, 46 (5), 1510-1525.

(90) Jotiram, K. P.; Prasad, R. G. S. V; Jakka, V. S.; Aparna, R. S. L.; Phani, A. R. Antibacterial Activity of Nanostructured Polyaniline Combined With Mupirocin. Nano 
Biomed Eng 2012, 4 (3), 144-149.

(91) Wu, J. C.-C.; Ray, S.; Gizdavic-Nikolaidis, M.; Uy, B.; Swift, S.; Jin, J.; Cooney, R. P. Nanostructured Bioactive Material Based on Polycaprolactone and Polyaniline FiberScaffolds. Synth. Met. 2014, 198, 41-50.

(92) Dong, R.; Zhao, X.; Guo, B.; Ma, P. X. Self-Healing Conductive Injectable Hydrogels with Antibacterial Activity as Cell Delivery Carrier for Cardiac Cell Therapy. ACS Appl. Mater. Interfaces 2016, 8 (27), 17138-17150.

(93) Deng, Z.; Guo, Y.; Zhao, X.; Ma, P. X.; Guo, B. Multifunctional Stimuli-Responsive Hydrogels with Self-Healing, High Conductivity, and Rapid Recovery through Hostguest Interactions. Chem. Mater. 2018, 30 (5), 1729-1742.

(94) Bhattarai, D. P.; Shrestha, S.; Shrestha, B. K.; Park, C. H.; Kim, C. S. A Controlled Surface Geometry of Polyaniline Doped Titania Nanotubes Biointerface for Accelerating MC3T3-E1 Cells Growth in Bone Tissue Engineering. Chem. Eng. J. 2018, $350,57-68$.

(95) dos Santos, M. R.; Alcaraz-Espinoza, J. J.; da Costa, M. M.; de Oliveira, H. P. Usnic Acid-Loaded Polyaniline/Polyurethane Foam Wound Dressing: Preparation and Bactericidal Activity. Mater. Sci. Eng. C 2018, 89, 33-40.

(96) Gharibi, R.; Yeganeh, H.; Gholami, H.; Hassan, Z. M. Aniline Tetramer Embedded Polyurethane/Siloxane Membranes and Their Corresponding Nanosilver Composites as Intelligent Wound Dressing Materials. RSC Adv. 2014, 4 (107), 62046-62060.

(97) Natarajan, T. S.; Tsai, C. H.; Huang, H. L.; Ho, K. S.; Lin, I.; Wang, Y. F. Fabrication of Polyaniline Coated Plasma Modified Polypropylene Filter for Antibioaerosol Application. Aerosol Air Qual. Res. 2016, 16 (8), 1911-1921.

(98) Zengin, H.; Aksin, G.; Zengin, G.; Kahraman, M.; Kilic, I. H. Preparation and Characterization of Conductive Polyaniline/Silver Nanocomposite Films and Their Antimicrobial Studies. Polym. Eng. Sci. 2019, 59 (S1), E182-E194.

(99) Suresh, A. K.; Pelletier, D. A.; Doktycz, M. J. Relating Nanomaterial Properties and Microbial Toxicity. Nanoscale 2013, 5 (2), 463-474.

(100) Liu, D.; Yang, F.; Xiong, F.; Gu, N. The Smart Drug Delivery System and Its Clinical Potential. Theranostics 2016, 6 (9), 1306.

(101) Ulbrich, K.; Hola, K.; Subr, V.; Bakandritsos, A.; Tucek, J.; Zboril, R. Targeted Drug Delivery with Polymers and Magnetic Nanoparticles: Covalent and Noncovalent Approaches, Release Control, and Clinical Studies. Chem. Rev. 2016, 116 (9), 53385431. 
(102) Tibbitt, M. W.; Dahlman, J. E.; Langer, R. Emerging Frontiers in Drug Delivery. J. Am. Chem. Soc. 2016, 138 (3), 704-717.

(103) Sugianto, T. D.; Chan, H.-K. Inhaled Antibiotics in the Treatment of Non-Cystic Fibrosis Bronchiectasis: Clinical and Drug Delivery Perspectives. Expert Opin. Drug Deliv. 2016, 13 (1), 7-22.

(104) Dai, T.; Jiang, X.; Hua, S.; Wang, X.; Lu, Y. Facile Fabrication of Conducting Polymer Hydrogels via Supramolecular Self-Assembly. Chem. Commun. 2008, No. 36, 42794281.

(105) Dai, T.; Jia, Y. Supramolecular Hydrogels of Polyaniline-Poly (Styrene Sulfonate) Prepared in Concentrated Solutions. Polymer (Guildf). 2011, 52 (12), 2550-2558.

(106) Li, W.; Zeng, X.; Wang, H.; Wang, Q.; Yang, Y. Polyaniline-Poly (Styrene Sulfonate) Conducting Hydrogels Reinforced by Supramolecular Nanofibers and Used as Drug Carriers with Electric-Driven Release. Eur. Polym. J. 2015, 66, 513-519.

(107) Chen, H.; Liu, Z.; Li, S.; Su, C.; Qiu, X.; Zhong, H.; Guo, Z. Fabrication of Graphene and AuNP Core Polyaniline Shell Nanocomposites as Multifunctional Theranostic Platforms for SERS Real-Time Monitoring and Chemo-Photothermal Therapy. Theranostics 2016, 6 (8), 1096.

(108) Nguyen, H. T.; Dai Phung, C.; Thapa, R. K.; Pham, T. T.; Tran, T. H.; Jeong, J.-H.; Ku, S. K.; Choi, H.-G.; Yong, C. S.; Kim, J. O. Multifunctional Nanoparticles as Somatostatin Receptor-Targeting Delivery System of Polyaniline and Methotrexate for Combined Chemo-photothermal Therapy. Acta Biomater. 2018, 68, 154-167.

(109) Silva, J. S. F.; Silva, J. Y. R.; de Sá, G. F.; Araújo, S. S.; Filho, M. A. G.; Ronconi, C. M.; Santos, T. C.; Júnior, S. A. Multifunctional System Polyaniline-Decorated ZIF-8 Nanoparticles as a New Chemo-Photothermal Platform for Cancer Therapy. ACS omega 2018, 3 (9), 12147-12157.

(110) Wang, J.; Guo, F.; Yu, M.; Liu, L.; Tan, F.; Yan, R.; Li, N. Rapamycin/DiR Loaded Lipid-Polyaniline Nanoparticles for Dual-Modal Imaging Guided Enhanced Photothermal and Antiangiogenic Combination Therapy. J. Control. Release 2016, 237, $23-34$.

(111) Neira-Carrillo, A.; Yslas, E.; Marini, Y. A.; Vásquez-Quitral, P.; Sánchez, M.; Riveros, A.; Yáñez, D.; Cavallo, P.; Kogan, M. J.; Acevedo, D. Hybrid Biomaterials Based on Calcium Carbonate and Polyaniline Nanoparticles for Application in Photothermal Therapy. Colloids Surfaces B Biointerfaces 2016, 145, 634-642.

(112) You, C.; Wu, H.; Wang, M.; Wang, S.; Shi, T.; Luo, Y.; Sun, B.; Zhang, X.; Zhu, J. A 
Strategy for Photothermal Conversion of Polymeric Nanoparticles by Polyaniline for Smart Control of Targeted Drug Delivery. Nanotechnology 2017, 28 (16), 165102.

(113) Rana, S.; Jadhav, N. V; Barick, K. C.; Pandey, B. N.; Hassan, P. A. Polyaniline Shell Cross-Linked Fe3O4 Magnetic Nanoparticles for Heat Activated Killing of Cancer Cells. Dalt. Trans. 2014, 43 (32), 12263-12271.

(114) Gao, Z.; You, C.; Wu, H.; Wang, M.; Zhang, X.; Sun, B. FA and CRGD Dual Modified Lipid-Polymer Nanoparticles Encapsulating Polyaniline and Cisplatin for Highly Effective Chemo-Photothermal Combination Therapy. J. Biomater. Sci. Polym. Ed. 2018, 29 (4), 397-411.

(115) Hou, H.; Chen, L.; He, H.; Chen, L.; Zhao, Z.; Jin, Y. Fine-Tuning the LSPR Response of Gold Nanorod-polyaniline Core-shell Nanoparticles with High Photothermal Efficiency for Cancer Cell Ablation. J. Mater. Chem. B 2015, 3 (26), 5189-5196.

(116) Zhu, X.; Zhao, J.; Wang, C. Acid and Base Dual-Controlled Cargo Molecule Release from Polyaniline Gated-Hollow Mesoporous Silica Nanoparticles. Polym. Chem. 2016, 7 (42), 6467-6474.

(117) Xing, Y.; Li, L.; Ai, X.; Fu, L. Polyaniline-Coated Upconversion Nanoparticles with Upconverting Luminescent and Photothermal Conversion Properties for Photothermal Cancer Therapy. Int. J. Nanomedicine 2016, 11, 4327.

(118) You, C.; Wu, H.; Wang, M.; Zhang, Y.; Wang, J.; Luo, Y.; Zhai, L.; Sun, B.; Zhang, X.; Zhu, J. Near-Infrared Light and PH Dual-Responsive Targeted Drug Carrier Based on Core-Crosslinked Polyaniline Nanoparticles for Intracellular Delivery of Cisplatin. Chem. Eur. J. 2017, 23 (22), 5352-5360.

(119) Xia, H.; Tao, X. In Situ Crystals as Templates to Fabricate Rectangular Shaped Hollow Polyaniline Tubes and Their Application in Drug Release. J. Mater. Chem. 2011, 21 (8), $2463-2465$.

(120) Mazrad, Z. A. I.; Choi, C. A.; Kim, S. H.; Lee, G.; Lee, S.; In, I.; Lee, K.-D.; Park, S. Y. Target-Specific Induced Hyaluronic Acid Decorated Silica Fluorescent Nanoparticles@polyaniline for Bio-Imaging Guided near-Infrared Photothermal Therapy. J. Mater. Chem. B 2017, 5 (34), 7099-7108.

(121) Wang, J.; Tan, X.; Pang, X.; Liu, L.; Tan, F.; Li, N. MoS2 Quantum Dot@ Polyaniline Inorganic-organic Nanohybrids for in Vivo Dual-Modal Imaging Guided Synergistic Photothermal/Radiation Therapy. ACS Appl. Mater. Interfaces 2016, 8 (37), 2433124338.

(122) Zhou, J.; Lu, Z.; Zhu, X.; Wang, X.; Liao, Y.; Ma, Z.; Li, F. NIR Photothermal Therapy 
Using Polyaniline Nanoparticles. Biomaterials 2013, 34 (37), 9584-9592.

(123) Zhou, Y.; Hu, Y.; Sun, W.; Zhou, B.; Zhu, J.; Peng, C.; Shen, M.; Shi, X. PolyanilineLoaded $\gamma$-Polyglutamic Acid Nanogels as a Platform for Photoacoustic Imaging-Guided Tumor Photothermal Therapy. Nanoscale 2017, 9 (34), 12746-12754.

(124) Xu, Y.; Shi, Y.; Ding, S. A Chemical Approach to Stem-Cell Biology and Regenerative Medicine. Nature 2008, 453 (7193), 338.

(125) Wan, A. C. A.; Ying, J. Y. Nanomaterials for in Situ Cell Delivery and Tissue Regeneration. Adv. Drug Deliv. Rev. 2010, 62 (7-8), 731-740.

(126) Langer, R. Perspectives and Challenges in Tissue Engineering and Regenerative Medicine. Adv. Mater. 2009, 21 (32-33), 3235-3236.

(127) Guo, B.; Ma, P. X. Conducting Polymers for Tissue Engineering. Biomacromolecules 2018, 19 (6), 1764-1782.

(128) Qazi, T. H.; Rai, R.; Boccaccini, A. R. Tissue Engineering of Electrically Responsive Tissues Using Polyaniline Based Polymers: A Review. Biomaterials 2014, 35 (33), 9068-9086.

(129) Li, W.; Laurencin, C. T.; Caterson, E. J.; Tuan, R. S.; Ko, F. K. Electrospun Nanofibrous Structure: A Novel Scaffold for Tissue Engineering. J. Biomed. Mater. Res. An Off. J. Soc. Biomater. Japanese Soc. Biomater. Aust. Soc. Biomater. Korean Soc. Biomater. 2002, 60 (4), 613-621.

(130) Sharma, Y.; Tiwari, A.; Hattori, S.; Terada, D.; Sharma, A. K.; Ramalingam, M.; Kobayashi, H. Fabrication of Conducting Electrospun Nanofibers Scaffold for ThreeDimensional Cells Culture. Int. J. Biol. Macromol. 2012, 51 (4), 627-631.

(131) Yan, X.; Chen, J.; Yang, J.; Xue, Q.; Miele, P. Fabrication of Free-Standing, Electrochemically Active, and Biocompatible Graphene Oxide- Polyaniline and Graphene- Polyaniline Hybrid Papers. ACS Appl. Mater. Interfaces 2010, 2 (9), 25212529.

(132) Shi, Z.; Zang, S.; Jiang, F.; Huang, L.; Lu, D.; Ma, Y.; Yang, G. In Situ Nano-Assembly of Bacterial Cellulose-polyaniline Composites. Rsc Adv. 2012, 2 (3), 1040-1046.

(133) Li, M.; Guo, Y.; Wei, Y.; MacDiarmid, A. G.; Lelkes, P. I. Electrospinning PolyanilineContained Gelatin Nanofibers for Tissue Engineering Applications. Biomaterials 2006, 27 (13), 2705-2715.

(134) Borriello, A.; Guarino, V.; Schiavo, L.; Alvarez-Perez, M. A.; Ambrosio, L. Optimizing PANi Doped Electroactive Substrates as Patches for the Regeneration of Cardiac Muscle. J. Mater. Sci. Mater. Med. 2011, 22 (4), 1053-1062. 
(135) Hsiao, C.-W.; Bai, M.-Y.; Chang, Y.; Chung, M.-F.; Lee, T.-Y.; Wu, C.-T.; Maiti, B.; Liao, Z.-X.; Li, R.-K.; Sung, H.-W. Electrical Coupling of Isolated Cardiomyocyte Clusters Grown on Aligned Conductive Nanofibrous Meshes for Their Synchronized Beating. Biomaterials 2013, 34 (4), 1063-1072.

(136) McKeon, K. D.; Lewis, A.; Freeman, J. W. Electrospun Poly (D, L-lactide) and Polyaniline Scaffold Characterization. J. Appl. Polym. Sci. 2010, 115 (3), 1566-1572.

(137) Ghasemi-mobarakeh, L.; Prabhakaran, M. P.; Morshed, M. Application of Conductive Polymers, Scaffolds and Electrical Stimulation for Nerve Tissue Engineering. J. Tissue Eng. Regen. Med. 2011, 5, e17-e35.

(138) Bhang, S. H.; Jeong, S. I.; Lee, T.; Jun, I.; Lee, Y. Bin; Kim, B.; Shin, H. Electroactive Electrospun Polyaniline/Poly [(L-lactide)-co-(E-caprolactone)] Fibers for Control of Neural Cell Function. Macromol. Biosci. 2012, 12 (3), 402-411.

(139) Moura, R. M.; de Queiroz, A. A. A. Dendronized Polyaniline Nanotubes for Cardiac Tissue Engineering. Artif. Organs 2011, 35 (5), 471-477.

(140) Senn, N. On the Healing of Aseptic Bone Cavities by Implantation of Antiseptic Decalcified Bone. Am. J. Med. Sci. 1889, 98 (3), 219.

(141) Winkler, T.; Sass, F. A.; Duda, G. N.; Schmidt-Bleek, K. A Review of Biomaterials in Bone Defect Healing, Remaining Shortcomings and Future Opportunities for Bone Tissue Engineering: The Unsolved Challenge. Bone Joint Res. 2018, 7 (3), 232-243.

(142) Fernandez de Grado, G.; Keller, L.; Idoux-Gillet, Y.; Wagner, Q.; Musset, A.-M.; Benkirane-Jessel, N.; Bornert, F.; Offner, D. Bone Substitutes: A Review of Their Characteristics, Clinical Use, and Perspectives for Large Bone Defects Management. $J$. Tissue Eng. 2018, 9, 1-18.

(143) Campana, V.; Milano, G.; Pagano, E.; Barba, M.; Cicione, C.; Salonna, G.; Lattanzi, W.; Logroscino, G. Bone Substitutes in Orthopaedic Surgery: From Basic Science to Clinical Practice. J. Mater. Sci. Mater. Med. 2014, 25 (10), 2445-2461.

(144) Haugen, H. J.; Lyngstadaas, S. P.; Rossi, F.; Perale, G. Bone Grafts: Which Is the Ideal Biomaterial? J. Clin. Periodontol. 2019, 46, 92-102.

(145) Chen, J.; Yu, M.; Guo, B.; Ma, P. X.; Yin, Z. Conductive Nanofibrous Composite Scaffolds Based on In-Situ Formed Polyaniline Nanoparticle and Polylactide for Bone Regeneration. J. Colloid Interface Sci. 2018, 514, 517-527.

(146) Pournaqi, F.; Ghiaee, A.; Vakilian, S.; Ardeshirylajimi, A. Improved Proliferation and Osteogenic Differentiation of Mesenchymal Stem Cells on Polyaniline Composited by Polyethersulfone Nanofibers. Biologicals 2017, 45, 78-84. 
(147) Timin, A. S.; Muslimov, A. R.; Zyuzin, M. V; Peltek, O. O.; Karpov, T. E.; Sergeev, I. S.; Dotsenko, A. I.; Goncharenko, A. A.; Yolshin, N. D.; Sinelnik, A. Multifunctional Scaffolds with Improved Antimicrobial Properties and Osteogenicity Based on Piezoelectric Electrospun Fibers Decorated with Bioactive Composite Microcapsules. ACS Appl. Mater. Interfaces 2018, 10 (41), 34849-34868.

(148) Visan, A. I.; Popescu-Pelin, G.; Gherasim, O.; Grumezescu, V.; Socol, M.; Zgura, I.; Florica, C.; Popescu, R. C.; Savu, D.; Holban, A. M. Laser Processed Antimicrobial Nanocomposite Based on Polyaniline Grafted Lignin Loaded with GentamicinFunctionalized Magnetite. Polymers (Basel). 2019, 11 (2), 283.

(149) Xu, D.; Fan, L.; Gao, L.; Xiong, Y.; Wang, Y. Micro-Nano-Structured Polyaniline Assembled in Cellulose Matrix Via Interfacial Polymerization for Applications in Nerve Regeneration Micro-Nano-Structured Polyaniline Assembled in Cellulose Matrix Via Interfacial Polymerization for Applications in Nerve. ACS Appl. Mater. Interfaces 2016, 8 (27), 17090-17097.

(150) Guarino, V.; Alvarez-Perez, M. A.; Borriello, A.; Napolitano, T.; Ambrosio, L. Conductive PANi/PEGDA Macroporous Hydrogels For Nerve Regeneration. $A d v$. Healthc. Mater. 2013, 2 (1), 218-227.

(151) Suradip Das, Manav Sharma, Dhiren Saharia, Kushal Konwar Sarma, Elizabeth M. Muir, U. B. Electrospun Silk-Polyaniline Conduits for Functional Nerve Regeneration in Rat Sciatic Nerve Injury Model. Biomed. Mater. 2017, 12 (4), 045025-045035.

(152) Baniasadi, H.; A, A. R. S.; Mashayekhan, S. Fabrication and Characterization of Conductive Chitosan / Gelatin-Based Scaffolds for Nerve Tissue Engineering. Int. J. Biol. Macromol. 2015, 74, 360-366.

(153) Ashtari, K.; Nazari, H.; Ko, H.; Tebon, P.; Akhshik, M.; Akbari, M.; Alhosseini, S. N.; Mozafari, M.; Mehravi, B.; Soleimani, M. Electrically Conductive Nanomaterials for Cardiac Tissue Engineering. Adv. Drug Deliv. Rev. 2019. https://doi.org/https://doi.org/10.1016/j.addr.2019.06.001.

(154) Baheiraei, N.; Yeganeh, H.; Ai, J.; Gharibi, R.; Azami, M.; Faghihi, F. Synthesis, Characterization and Antioxidant Activity of a Novel Electroactive and Biodegradable Polyurethane for Cardiac Tissue Engineering Application. Mater. Sci. Eng. C 2014, 44, 24-37.

(155) Sharma, A.; Kumar, B.; Singh, S. K.; Gulati, M.; Vaidya, Y.; Rathee, H.; Ghai, D.; Malik, A. H.; Yadav, A. K.; Maharshi, P. In-Vitro and In-Vivo Pharmacokinetic Evaluation of Guar Gum-Eudragit S100 Based Colon-Targeted Spheroids of 
Sulfasalazine Co-Administered with Probiotics. Curr. Drug Deliv. 2018, 15 (3), 367387.

(156) Dhand, C.; Das, M.; Datta, M.; Malhotra, B. D. Recent Advances in Polyaniline Based Biosensors. Biosens. Bioelectron. 2011, 26 (6), 2811-2821.

(157) Rassas, I.; Braiek, M.; Bonhomme, A.; Bessueille, F.; Raffin, G.; Majdoub, H.; Jaffrezic-Renault, N. Highly Sensitive Voltammetric Glucose Biosensor Based on Glucose Oxidase Encapsulated in a Chitosan/Kappa-Carrageenan/Gold Nanoparticle Bionanocomposite. Sensors 2019, 19 (1), 154-165.

(158) Lai, J.; Yi, Y.; Zhu, P.; Shen, J.; Wu, K.; Zhang, L.; Liu, J. Polyaniline-Based Glucose Biosensor: A Review. J. Electroanal. Chem. 2016, 782, 138-153.

(159) Ren, Y.; Zhu, J.; Wang, L.; Liu, H.; Liu, Y.; Wu, W.; Wang, F. Synthesis of Polyaniline Nanoparticles Deposited on Two-Dimensional Titanium Carbide for High-Performance Supercapacitors. Mater. Lett. 2018, 214, 84-87.

(160) DiTullio, B. T.; Wright, C. J.; Hayes, P.; Molino, P. J.; Hanks, T. W. Surface Modification of Polyaniline Nanorods with Thiol-Terminated Poly (Ethylene Oxide). Colloid Polym. Sci. 2018, 296 (4), 637-645.

(161) Zeng, R.; Luo, Z.; Zhang, L.; Tang, D. Platinum Nanozyme-Catalyzed Gas Generation for Pressure-Based Bioassay Using Polyaniline Nanowires-Functionalized Graphene Oxide Framework. Anal. Chem. 2018, 90 (20), 12299-12306.

(162) Kapralova, V. M.; Sapurina, I. Y. Variation in the Conductivity of Polyaniline Nanotubes During Their Formation. Semiconductors 2018, 52 (6), 816-819.

(163) Zhou, K.; He, Y.; Xu, Q.; Zhang, Q.; Zhou, A.; Lu, Z.; Yang, L.-K.; Jiang, Y.; Ge, D.; Liu, X. Y. A Hydrogel of Ultrathin Pure Polyaniline Nanofibers: Oxidant-Templating Preparation and Supercapacitor Application. ACS Nano 2018, 12 (6), 5888-5894.

(164) Al-Sagur, H.; Komathi, S.; Karakaş, H.; Atilla, D.; Gürek, A. G.; Basova, T.; Farmilo, N.; Hassan, A. K. A Glucose Biosensor Based on Novel Lutetium Bis-Phthalocyanine Incorporated Silica-Polyaniline Conducting Nanobeads. Biosens. Bioelectron. 2018, $102,637-645$.

(165) Tang, W.; Li, L.; Zeng, X. A Glucose Biosensor Based on the Synergistic Action of Nanometer-Sized TiO2 and Polyaniline. Talanta 2015, 131, 417-423.

(166) Zhuang, X.; Tian, C.; Luan, F.; Wu, X.; Chen, L. One-Step Electrochemical Fabrication of a Nickel Oxide Nanoparticle/Polyaniline Nanowire/Graphene Oxide Hybrid on a Glassy Carbon Electrode for Use as a Non-Enzymatic Glucose Biosensor. RSC $A d v$. 2016, 6 (95), 92541-92546. 
(167) Zhai, D.; Liu, B.; Shi, Y.; Pan, L.; Wang, Y.; Li, W.; Zhang, R.; Yu, G. Highly Sensitive Glucose Sensor Based on Pt Nanoparticle/Polyaniline Hydrogel Heterostructures. ACS Nano 2013, 7 (4), 3540-3546.

(168) Ahammad, A. J. S.; Al Mamun, A.; Akter, T.; Mamun, M. A.; Faraezi, S.; Monira, F. Z. Enzyme-Free Impedimetric Glucose Sensor Based on Gold Nanoparticles/Polyaniline Composite Film. J. Solid State Electrochem. 2016, 20 (7), 1933-1939.

(169) Zeng, X.; Zhang, Y.; Du, X.; Li, Y.; Tang, W. A Highly Sensitive Glucose Sensor Based on a Gold Nanoparticles/Polyaniline/Multi-Walled Carbon Nanotubes Composite Modified Glassy Carbon Electrode. New J. Chem. 2018, 42 (14), 11944-11953.

(170) Shukla, S. K.; Demir, M. M.; Govender, P. P.; Tiwari, A.; Shukla, S. K. Optical Fibre Based Non-Enzymatic Glucose Sensing over Cu2+-Doped Polyaniline Hybrid Matrix. Sensors Actuators B Chem. 2017, 242, 522-528.

(171) Fatoni, A.; Numnuam, A.; Kanatharana, P. Conductive Porous Structured ChitosanGrafted Polyaniline Cryogel for Use as a Sialic Acid Biosensor. Electrochim. Acta 2014, 130, 296-304.

(172) Xu, Z.; Cheng, X.; Tan, J.; Gan, X. Fabrication of Multiwalled Carbon Nanotubepolyaniline/Platinum Nanocomposite Films toward Improved Performance for a Cholesterol Amperometric Biosensor. Biotechnol. Appl. Biochem. 2016, 63 (6), 757764.

(173) Gautam, V.; Singh, K. P.; Yadav, V. L. Polyaniline/MWCNTs/Starch Modified Carbon Paste Electrode for Non-Enzymatic Detection of Cholesterol: Application to Real Sample (Cow Milk). Anal. Bioanal. Chem. 2018, 410 (8), 2173-2181.

(174) Lakshmi, G.; Sharma, A.; Solanki, P. R.; Avasthi, D. K. Mesoporous Polyaniline Nanofiber Decorated Graphene Micro-Flowers for Enzyme-Less Cholesterol Biosensors. Nanotechnology 2016, 27 (34), 345101-345111.

(175) Sanchis, C.; Ghanem, M. A.; Salavagione, H. J.; Morallon, E.; Bartlett, P. N. The Oxidation of Ascorbate at Copolymeric Sulfonated Poly (Aniline) Coated on Glassy Carbon Electrodes. Bioelectrochemistry 2011, 80 (2), 105-113.

(176) Harrison, F. E.; May, J. M. Vitamin C Function in the Brain: Vital Role of the Ascorbate Transporter SVCT2. Free Radic. Biol. Med. 2009, 46 (6), 719-730.

(177) Bonastre, A. M.; Sosna, M.; Bartlett, P. N. An Analysis of the Kinetics of Oxidation of Ascorbate at Poly (Aniline)-Poly (Styrene Sulfonate) Modified Microelectrodes. Phys. Chem. Chem. Phys. 2011, 13 (12), 5365-5372.

(178) Wang, M.; Cui, M.; Liu, W.; Liu, X. Highly Dispersed Conductive Polypyrrole 
Hydrogels as Sensitive Sensor for Simultaneous Determination of Ascorbic Acid, Dopamine and Uric Acid. J. Electroanal. Chem. 2019, 832, 174-181.

(179) Tukimin, N.; Abdullah, J.; Sulaiman, Y. Electrodeposition of Poly (3, 4Ethylenedioxythiophene)/Reduced Graphene Oxide/Manganese Dioxide for Simultaneous Detection of Uric Acid, Dopamine and Ascorbic Acid. J. Electroanal. Chem. 2018, 820, 74-81.

(180) Zamani, F. G.; Moulahoum, H.; Ak, M.; Demirkol, D. O.; Timur, S. Current Trends in the Development of Conducting Polymers-Based Biosensors. TrAC Trends Anal. Chem. 2019, 118, 264-276.

(181) Rotariu, L.; Lagarde, F.; Jaffrezic-Renault, N.; Bala, C. Electrochemical Biosensors for Fast Detection of Food Contaminants-trends and Perspective. TrAC Trends Anal. Chem. 2016, 79, 80-87.

(182) Lorestani, F.; Shahnavaz, Z.; Nia, P. M.; Alias, Y.; Manan, N. S. A. One-Step Preparation of Silver-polyaniline Nanotube Composite for Non-Enzymatic Hydrogen Peroxide Detection. Appl. Surf. Sci. 2015, 347, 816-823.

(183) Akyilmaz, E.; Oyman, G.; Cinar, E.; Odabas, G. A New Polyaniline-catalaseglutaraldehyde-Modified Biosensor for Hydrogen Peroxide Detection. Prep. Biochem. Biotechnol. 2017, 47 (1), 86-93.

(184) Gul, I.; Ahmad, M. S.; Naqvi, S. M. S.; Hussain, A.; Wali, R.; Farooqi, A. A.; Ahmed, I. Polyphenol Oxidase (PPO) Based Biosensors for Detection of Phenolic Compounds: A Review. J Appl Biol Biotechnol 2017, 5, 72-85.

(185) Arslan, H.; Şenarslan, D.; Çevrimli, B. S.; Zengin, H.; Uzun, D.; Arslan, F. Preparation of Carbon Paste Electrode Containing Polyaniline-Activated Carbon Composite for Amperometric Detection of Phenol. Bulg. Chem. Commun. 2018, 50 (1), 16-20.

(186) Chen, Y.; Guo, S.; Zhao, M.; Zhang, P.; Xin, Z.; Tao, J.; Bai, L. Amperometric DNA Biosensor for Mycobacterium Tuberculosis Detection Using Flower-like Carbon Nanotubes-Polyaniline Nanohybrid and Enzyme-Assisted Signal Amplification Strategy. Biosens. Bioelectron. 2018, 119, 215-220.

(187) Soni, A.; Pandey, C. M.; Solanki, S.; Kotnala, R. K.; Sumana, G. Electrochemical Genosensor Based on Template Assisted Synthesized Polyaniline Nanotubes for Chronic Myelogenous Leukemia Detection. Talanta 2018, 187, 379-389.

(188) Mistry, K. K.; Layek, K.; Mahapatra, A.; RoyChaudhuri, C.; Saha, H. A Review on Amperometric-Type Immunosensors Based on Screen-Printed Electrodes. Analyst 2014, 139 (10), 2289-2311. 
(189) He, S.; Wang, Q.; Yu, Y.; Shi, Q.; Zhang, L.; Chen, Z. One-Step Synthesis of Potassium Ferricyanide-Doped Polyaniline Nanoparticles for Label-Free Immunosensor. Biosens. Bioelectron. 2015, 68, 462-467.

(190) Li, F.; Guo, Y.; Sun, X.; Wang, X. Aptasensor Based on Thionine, Graphenepolyaniline Composite Film, and Gold Nanoparticles for Kanamycin Detection. Eur. Food Res. Technol. 2014, 239 (2), 227-236.

(191) Mohd Azmi, U.; Yusof, N.; Kusnin, N.; Abdullah, J.; Suraiya, S.; Ong, P.; Ahmad Raston, N.; Abd Rahman, S.; Mohamad Fathil, M. Sandwich Electrochemical Immunosensor for Early Detection of Tuberculosis Based on Graphene/PolyanilineModified Screen-Printed Gold Electrode. Sensors 2018, 18 (11), 3926-3940.

(192) Hansen, B.; Hocevar, M. A.; Ferreira, C. A. A Facile and Simple Polyaniline-Poly (Ethylene Oxide) Based Glucose Biosensor. Synth. Met. 2016, 222, 224-231.

(193) Wu, S.; Su, F.; Dong, X.; Ma, C.; Pang, L.; Peng, D. Development of Glucose Biosensors Based on Plasma Polymerization-Assisted Nanocomposites of Polyaniline, Tin Oxide, and Three-Dimensional Reduced Graphene Oxide. Appl. Surf. Sci. 2017, $401,262-270$.

(194) Zhang, B.; He, Y.; Liu, B.; Tang, D. Nickel-Functionalized Reduced Graphene Oxide with Polyaniline for Non-Enzymatic Glucose Sensing. Microchim. Acta 2015, 182 (34), 625-631.

(195) Feng, X.; Cheng, H.; Pan, Y.; Zheng, H. Development of Glucose Biosensors Based on Nanostructured Graphene-Conducting Polyaniline Composite. Biosens. Bioelectron. 2015, 70, 411-417.

(196) Abdi, M. M.; Razalli, R. L.; Tahir, P. M.; Chaibakhsh, N.; Hassani, M.; Mir, M. Optimized Fabrication of Newly Cholesterol Biosensor Based on Nanocellulose. Int. J. Biol. Macromol. 2019, 126, 1213-1222.

(197) Dhand, C.; Solanki, P. R.; Datta, M.; Malhotra, B. D. Polyaniline/Single-walled Carbon Nanotubes Composite Based Triglyceride Biosensor. Electroanalysis 2010, 22 (22), $2683-2693$.

(198) Wang, Q.; Xue, R.; Guo, H.; Wei, Y.; Yang, W. A Facile Horseradish Peroxidase Electrochemical Biosensor with Surface Molecular Imprinting Based on Polyaniline Nanotubes. J. Electroanal. Chem. 2018, 817, 184-194.

(199) da Silva, W.; Ghica, M. E.; Ajayi, R. F.; Iwuoha, E. I.; Brett, C. M. A. Tyrosinase Based Amperometric Biosensor for Determination of Tyramine in Fermented Food and Beverages with Gold Nanoparticle Doped Poly (8-Anilino-1-Naphthalene Sulphonic 
Acid) Modified Electrode. Food Chem. 2019, 282, 18-26.

(200) Shoaie, N.; Forouzandeh, M.; Omidfar, K. Highly Sensitive Electrochemical Biosensor Based on Polyaniline and Gold Nanoparticles for DNA Detection. IEEE Sens. J. 2018, $18(5), 1835-1843$.

(201) Norouzi, P.; Eshraghi, M. A.; Ebrahimi, M. DNA Biosensor for Determination of 5Fluorouracil Based on Gold Electrode Modified with Au and Polyaniline Nanoparticles and FFT Square Wave Voltammetry. J. Appl. Chem. Res. 2019, 13 (1), 24-35.

(202) Norouzi, P.; Larijani, B.; Bidhendi, M. E.; Eshraghi, M.; Ebrahimi, M. A Sensitive Biosensor for Acrylamide Detection Based on Polyaniline and Au Nanoparticles Using FFT Admittance Voltammetry. Anal. Bioanal. Electrochem. 2018, 10 (1), 18-32.

(203) Dervisevic, M.; Dervisevic, E.; Şenel, M. Design of Amperometric Urea Biosensor Based on Self-Assembled Monolayer of Cystamine/PAMAM-Grafted MWCNT/Urease. Sensors Actuators B Chem. 2018, 254, 93-101.

(204) Botewad, S. N.; Pahurkar, V. G.; Muley, G. G. Fabrication and Evaluation of Evanescent Wave Absorption Based Polyaniline-Cladding Modified Fiber Optic Urea Biosensor. Opt. Fiber Technol. 2018, 40, 8-12.

(205) Fu, Y.; An, Q.; Ni, R.; Zhang, Y.; Li, Y.; Ke, H. Preparation of Polyaniline-Encapsulated Carbon/Copper Composite Nanofibers for Detection of Polyphenol Pollutant. Colloids Surfaces A Physicochem. Eng. Asp. 2018, 559, 289-296.

(206) Wang, J.; Hui, N. Zwitterionic Poly (Carboxybetaine) Functionalized Conducting Polymer Polyaniline Nanowires for the Electrochemical Detection of Carcinoembryonic Antigen in Undiluted Blood Serum. Bioelectrochemistry 2019, 125, 90-96.

(207) Vural, T.; Yaman, Y. T.; Ozturk, S.; Abaci, S.; Denkbas, E. B. Electrochemical Immunoassay for Detection of Prostate Specific Antigen Based on Peptide NanotubeGold Nanoparticle-Polyaniline Immobilized Pencil Graphite Electrode. J. Colloid Interface Sci. 2018, 510, 318-326.

(208) Fayemi, O. E.; Adekunle, A. S.; Swamy, B. E. K.; Ebenso, E. E. Electrochemical Sensor for the Detection of Dopamine in Real Samples Using Polyaniline / NiO , $\mathrm{ZnO}$, and Fe3O4 Nanocomposites on Glassy Carbon Electrode. J. Electroanal. Chem. 2018, 818, 236-249.

(209) Huang, K.-J.; Zhang, J.-Z.; Liu, Y.-J.; Wang, L.-L. Novel Electrochemical Sensing Platform Based on Molybdenum Disulfide Nanosheets-Polyaniline Composites and Au Nanoparticles. Sensors Actuators B Chem. 2014, 194, 303-310.

(210) Bagherzadeh, M.; Mozaffari, S. A.; Momeni, M. Fabrication and Electrochemical 
Characterization of Dopamine-Sensing Electrode Based on Modified Graphene Nanosheets. Anal. Methods 2015, 7 (21), 9317-9323.

(211) Salahandish, R.; Ghaffarinejad, A.; Naghib, S. M.; Niyazi, A.; Majidzadeh-A, K.; Janmaleki, M.; Sanati-Nezhad, A. Sandwich-Structured Nanoparticles-Grafted Functionalized Graphene Based 3D Nanocomposites for High-Performance Biosensors to Detect Ascorbic Acid Biomolecule. Sci. Rep. 2019, 9 (1), 1226-1237.

(212) Akyüz, D.; Koca, A. An Electrochemical Sensor for the Detection of Pesticides Based on the Hybrid of Manganese Phthalocyanine and Polyaniline. Sensors Actuators B Chem. 2019, 283, 848-856. 
Table of Contents

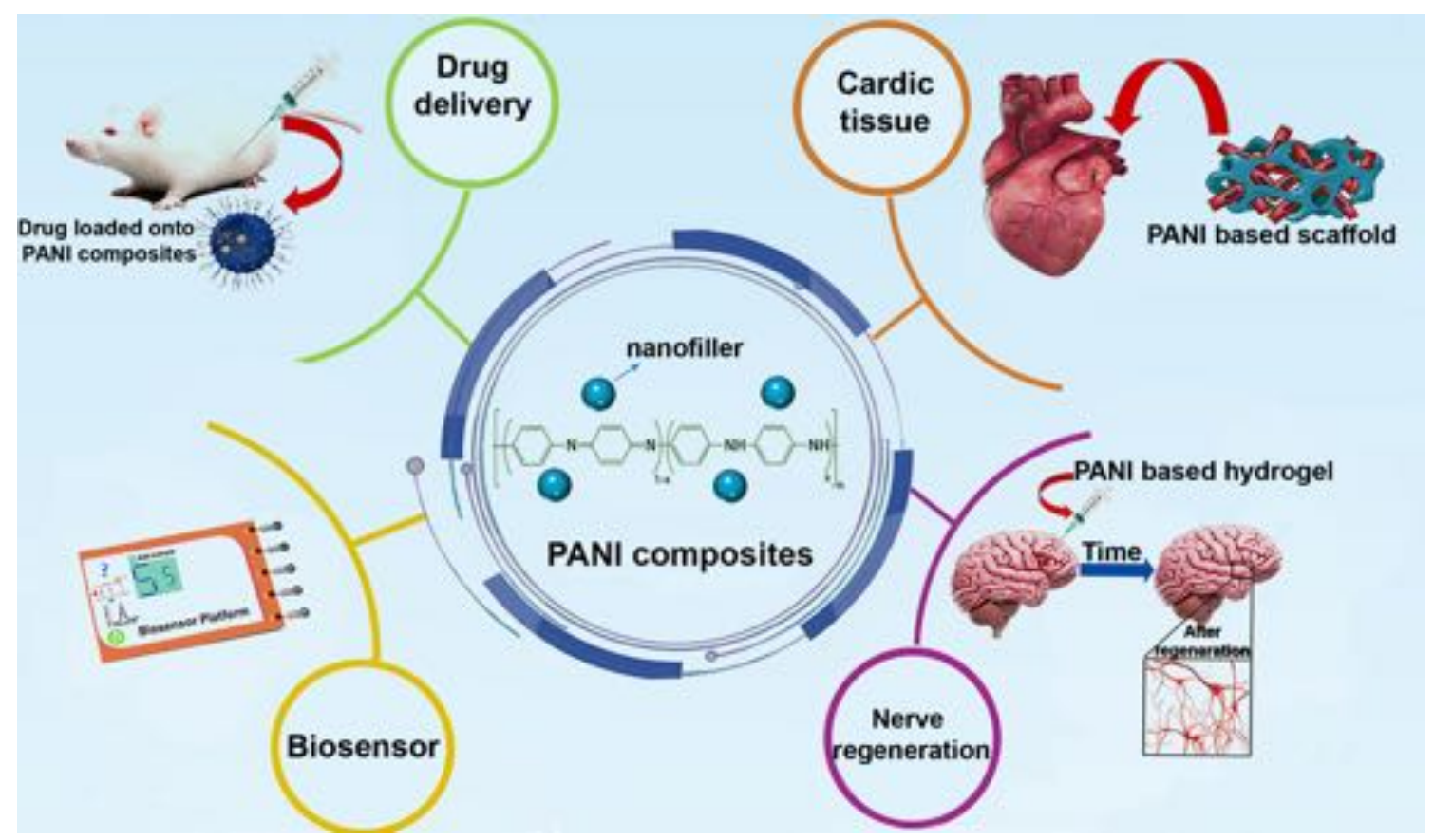

